\title{
INVESTIGATION OF THE POTENTIAL FOR CAUSTIC STRESS CORROSION CRACKING OF A537 CARBON STEEL NUCLEAR WASTE TANKS
}

\author{
P. S. Lam \\ Savannah River National Laboratory \\ Materials Science \& Technology Directorate
}

Publication Date: September 2009

\section{Savannah River Nuclear Solutions Savannah River Site Aiken, SC 29808}

This document was prepared in conjunction with work accomplished under Contract No. DE-AC0908SR22470 with the U.S. Department of Energy. Distribution authorized to the Department of Energy only; other requests shall be approved by the cognizant DOE Departmental Element. 


\section{DISCLAIMER}

This work was prepared under an agreement with and funded by the U.S. Government. Neither the U. S. Government or its employees, nor any of its contractors, subcontractors or their employees, makes any express or implied:

1. warranty or assumes any legal liability for the accuracy, completeness, or for the use or results of such use of any information, product, or process disclosed; or 2. representation that such use or results of such use would not infringe privately owned rights; or 3 . endorsement or recommendation of any specifically identified commercial product, process, or service. Any views and opinions of authors expressed in this work do not necessarily state or reflect those of the United States Government, or its contractors, or subcontractors. 
DOCUMENT: SRNS-STI-2009-00564 Rev.0

TITLE:

Investigation of the Potential for Caustic Stress Corrosion

Cracking of A537 Carbon Steel High Level Nuclear Waste

Tanks

\section{APPROVALS}

Poh-Sang Lam, Author

Date:

Materials Compatibility \& Welding Technology Group

SRNL-MATERIALS SCIENCE \& TECHNOLOGY

Bruce J. Wiersma, Technical Reviewer

Date:

Materials Performance \& Corrosion Technology Group

SRNL-MATERIALS SCIENCE \& TECHNOLOGY

Matthew E. Maryak, Structural Integrity Lead

Date:

Engineering Programs

SAVANNAH RIVER REMEDIATION, LLC

Kristine E. Zeigler, Manager

Date:

Materials Performance \& Corrosion Technology Group

SRNL-MATERIALS SCIENCE \& TECHNOLOGY

Thad M. Adams, Manager

Materials Compatibility \& Welding Technology Group

SRNL-MATERIALS SCIENCE \& TECHNOLOGY

Natraj C. Iyer, Director

Date:

SRNL-MATERIALS SCIENCE \& TECHNOLOGY

Date: 
SRNS-STI-2009-00564 Rev.0

\section{Table of Contents}

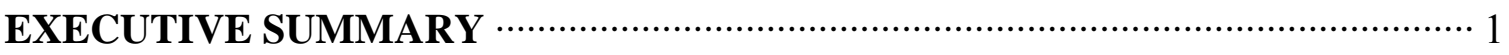

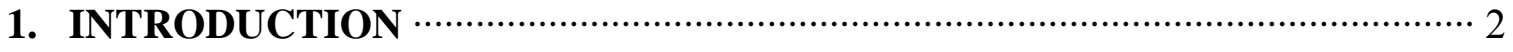

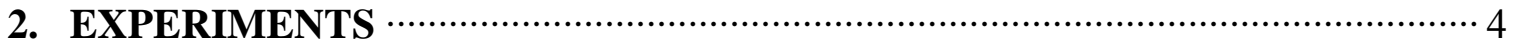

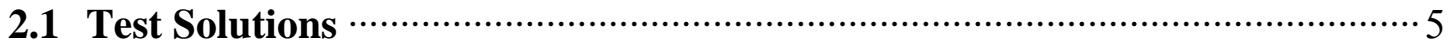

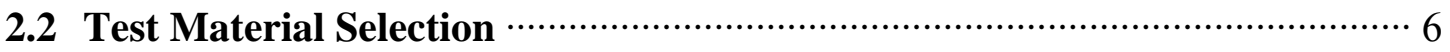

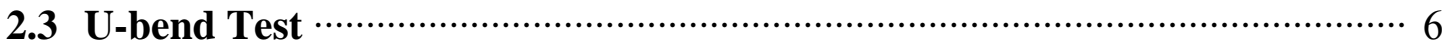

2.3.1 Stress Relief Heat Treatment for U-bend Specimens ………………....

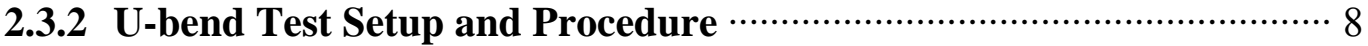

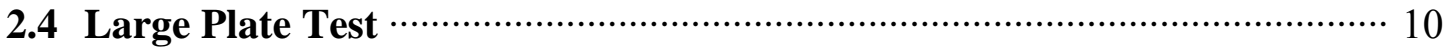

2.4.1 Large Plate Specimen Fabrication and Welding Procedure ………... 11

2.4.2 Stress Relief Heat Treatment for the Large Plate Specimen ………...12

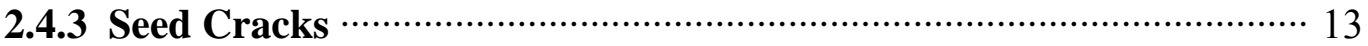

2.4.4 Large Plate Test Tank and Experimental Station …………………. 16

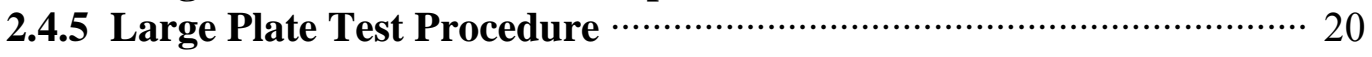

3. TEST RESULTS ……………………………………………………… 21

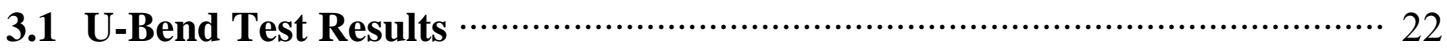

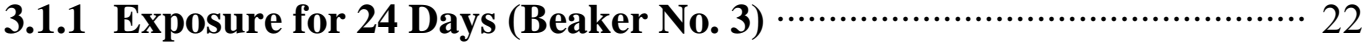

3.1.2 Exposure for 44 Days (Beaker No. 1) …………………………….... 24

3.1.3 Exposure for 95 Days (Beaker No. 2) ……………………………. 26

3.2 Large Plate Interim Test Results …………………………………… 28

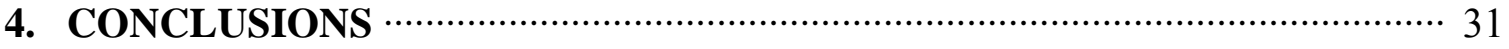

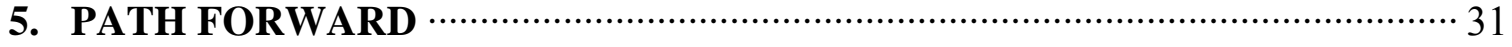

ACKNOWLEDGMENTS ……………………………………………………. 31

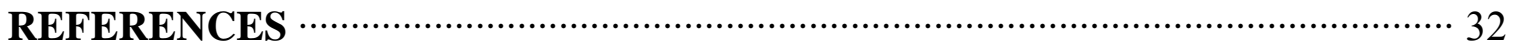

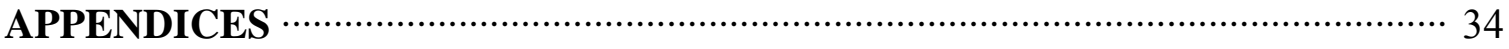

APPENDIX 1 Material Certificate of A537 for U-bend Specimens ………….... 35

APPENDIX 2 Material Certificate of A537 for Large Plate Specimens ……....3 37

APPENDIX 3 Certificate of Welding Electrodes for U-bend Specimens …… 38

APPENDIX 4 Welding Procedure for SRS Type III High Level Nuclear Waste Storage Tanks ……........................................................ 39

APPENDIX 5 Certificate of Welding Electrodes EM 70S-2 for Large Plate Specimens …….......................................................... 43

APPENDIX 6 Certificate of Welding Electrodes E-7018 for Large Plate

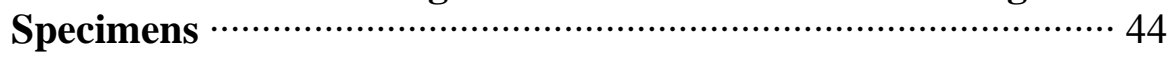

APPENDIX 7 Welding Parameters for the As-welded Plate …………………. 46

APPENDIX 8 Welding Parameters for the Heat-Treated Plate …………….... 49 


\section{List of Tables}

Table 1 Nominal Composition of A537 Class I carbon steel (wt.\%)[11] ……………..... 6

Table 2 Composition of A516-70 carbon steel (wt.\%) [9] (Steels procured by Nooter

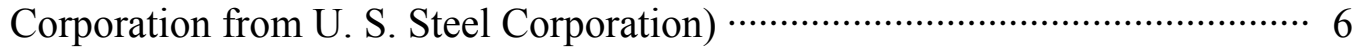

Table 3 U-bend specimens and exposure times 21

\section{List of Figures}

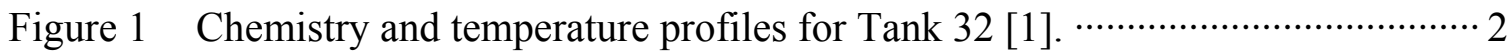

Figure 2 Chemistry and temperature profiles for Tank 30 [1]. ……............................. 3

Figure 3 Nitrate stress corrosion cracking of the as-welded A285 plate for Types I and II high level waste tanks (reported in 2002) [5]. …………........................ 3

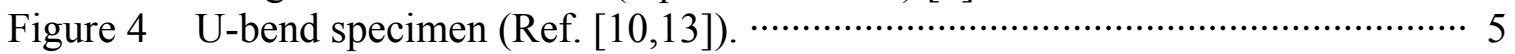

Figure 5 Large-plate specimen (Ref. [4]). ………………………………………… 5

Figure 6 (a) Schematic of the two welded plates from mill sheet, (b) schematic of the weld and the orientation for the U-bend specimen, (c) side view of the final Ubend specimen after bent around a mandrel $[11,15]$.

Figure 7 U-bend specimens are suspended from the hooks inside the glass cap to the beaker.

Figure $8 \quad$ The assembly of the test beaker ……………………………………………. 9

Figure 9 Graham Condensers on top of the test beakers. ………………………….... 9

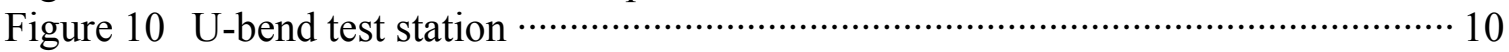

Figure 11 The 6 in. $\times 12$ in. plate is cut from an A537 mill sheet - the 6-inch side is parallel to the rolling direction of the mill sheet.

Figure 12 Vertical seam weld No. 26 in the bottom knuckle area (thickness: 1 inch). $\cdots 12$

Figure 13 Heat treatment temperature history. …………........................................ 13

Figure 14 Welded large plate specimen with machined cracks. …………………….... 14

Figure 15 Through-the-plate cracks across the weld (V1, V2, and V3). ……………... 15

Figure 16 Semi-circular surface cracks perpendicular to the weld (V4, V5, and V6). $\cdots 15$

Figure 17 Semi-circular surface cracks parallel to the weld (P1, P2, and P3). ……..... 16

Figure 18 Construction drawing for the Hastelloy (Alloy C-276) immersion tank. …. 17

Figure 19 Positioning of the test plate on the rack (hanger). …………………………... 18

Figure 20 Thermocouples for monitoring the solution temperature and the level float

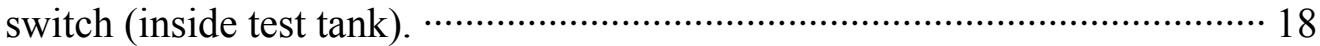

Figure 21 Insulating of rack with Teflon tapes. ……………………………………. 18

Figure 22 Winch assembly for lifting and lowering the plate specimens. …………….. 18

Figure 23 Large plate experimental station. …………………………………………. 19

Figure 24 Periodic inspection for cracking by lifting plate above the test solution. …... 21

Figure 25 As-welded Specimen No. 246 exposed to caustic solution for 24 days. $\cdots 22-23$

Figure 26 Heat-treated Specimen No. 241 exposed to caustic solution for 24 days. $\cdots \cdots \cdot 23$

Figure 27 As-welded Specimen No. 248 exposed to caustic solution for 44 days. ……24 
Figure 28 Heat-treated Specimen No. 242 exposed to caustic solution for 44 days. $\cdots \cdots \cdot 25$

Figure 29 Heat-treated Specimen No. 244 exposed to caustic solution for 44 days. $\cdot 25-26$

Figure 30 As-welded Specimen No. 245 exposed to caustic solution for 95 days. $\cdots 26-27$

Figure 31 As-welded Specimen No. 247 exposed to caustic solution for 95 days. $\cdots \cdots \cdot 27$

Figure 32 Heat-treated Specimen No. 243 exposed to caustic solution for 95 days. $\cdots \cdots 28$

Figure 33 As-welded plate before and after exposure for 6 weeks. ……......................29

Figure 34 Heat-treated plate before and after exposure for 6 weeks …….......................3 


\section{EXECUTIVE SUMMARY}

The evaporator recycle streams contain waste in a chemistry and temperature regime that may be outside of the current waste tank corrosion control program, which imposes temperature limits to mitigate caustic stress corrosion cracking (CSCC) ${ }^{1}$. A review of the recent service history (1998-2008) of Tanks 30 and 32 showed that these tanks were operated in highly concentrated hydroxide solution at high temperature. Visual inspections, experimental testing, and a review of the tank service history have shown that CSCC has occurred in uncooled/un-stress relieved F-Area tanks ${ }^{2}$. Therefore, for the Type III/IIIA waste tanks the efficacy of the stress relief of welding residual stress is the only corrosion-limiting mechanism. The objective of this experimental program is to test carbon steel small scale welded U-bend specimens and large welded plates $(12 \times 12 \times 1 \mathrm{in}$. $)$ in a caustic solution with upper bound chemistry $(12 \mathrm{M}$ hydroxide and $1 \mathrm{M}$ each of nitrate, nitrite, and aluminate) and temperature $\left(125^{\circ} \mathrm{C}\right)$. These conditions simulate worst-case situations in Tanks 30 and 32. Both as-welded and stress-relieved specimens have been tested. No evidence of stress corrosion cracking was found in the U-bend specimens after 21 days of testing. The large plate test is currently in progress, but no cracking has been observed after 9 weeks of immersion. Based on the preliminary results, it appears that the environmental conditions of the tests are unable to develop stress corrosion cracking within the duration of these tests.

1 “CSTF Corrosion Control Program," WSRC-TR-2002-00327, Rev. 4, December 2007.

2 "An Assessment of the Service History and Corrosion Susceptibility of Type IV Waste Tanks," B. J. Wiersma, SRNS-STI-2008-00096, September 2008. 


\section{INTRODUCTION}

The service history of Tank 30 (3H evaporator drop tank) and Tank 32 (3H evaporator feed tank) from 1998 to 2008 showed that the nitrate concentration $\left[\mathrm{NO}_{3}^{-}\right]$decreased to less than $1 \mathrm{M}$ while the hydroxide concentration $\left[\mathrm{OH}^{-}\right]$remained as high as $12 \mathrm{M}$ [1]. The temperatures in these tanks were also approaching 80 to $100{ }^{\circ} \mathrm{C}$. This condition exceeded the current waste tank corrosion control program, which imposes temperature limits $\left(60{ }^{\circ} \mathrm{C}\right)$ to mitigate caustic stress corrosion cracking (CSCC) [1,2]. It was concluded by an electrochemical experiment [3,4] with solutions consisting of $10 \mathrm{M}$ $\left[\mathrm{OH}^{-}\right]$and up to $2 \mathrm{M}\left[\mathrm{NO}_{3}^{-}\right]$and at temperatures from 60 to $95{ }^{\circ} \mathrm{C}$, that low-carbon steels may be susceptible to caustic stress corrosion cracking (CSCC). That set of experimental data suggested that, at a reduced $\left[\mathrm{NO}_{3}^{-}\right]$level, the corresponding corrosion potential $\left(\mathrm{E}_{\text {corr }}\right)$ was unable to suppress the initial active-passive transition peak. Therefore, it led to a conclusion that Tanks 30 and 32 might rely solely on the relief of welding residual stress to provide protection against CSCC by diminishing the internal driving force to cause cracking in the heat affected zone (HAZ). The heat treatment for stress relief also resulted in the formation of an oxide film which would further delay the stress corrosion cracking (SCC) in the waste tanks.

The chemistry and temperature histories of Tanks 30 and 32 in the past ten years can be seen in Figures 1 and 2 (reproduced from Ref. [1]). The most critical location can be identified at Tank 32 Bottom Plate (see Fig. 1, curve in cyan), where a high temperature above $120^{\circ} \mathrm{C}$ occurred for an extended period of time. Note that Tank 30 experienced a much higher temperature surge (Fig.2, yellow curve), but that temperature dissipated quickly because there is no sludge in Tank 30 to provide latent heat as in the case of Tank 30.
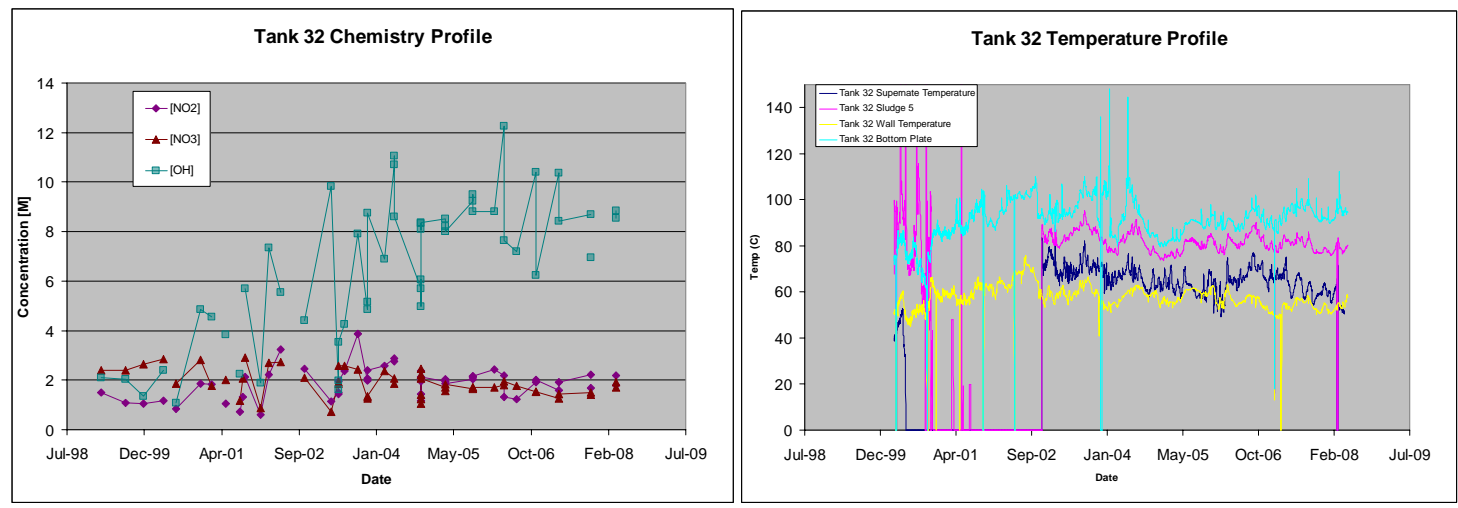

Figure 1 Chemistry and temperature profiles for Tank 32 [1]. 

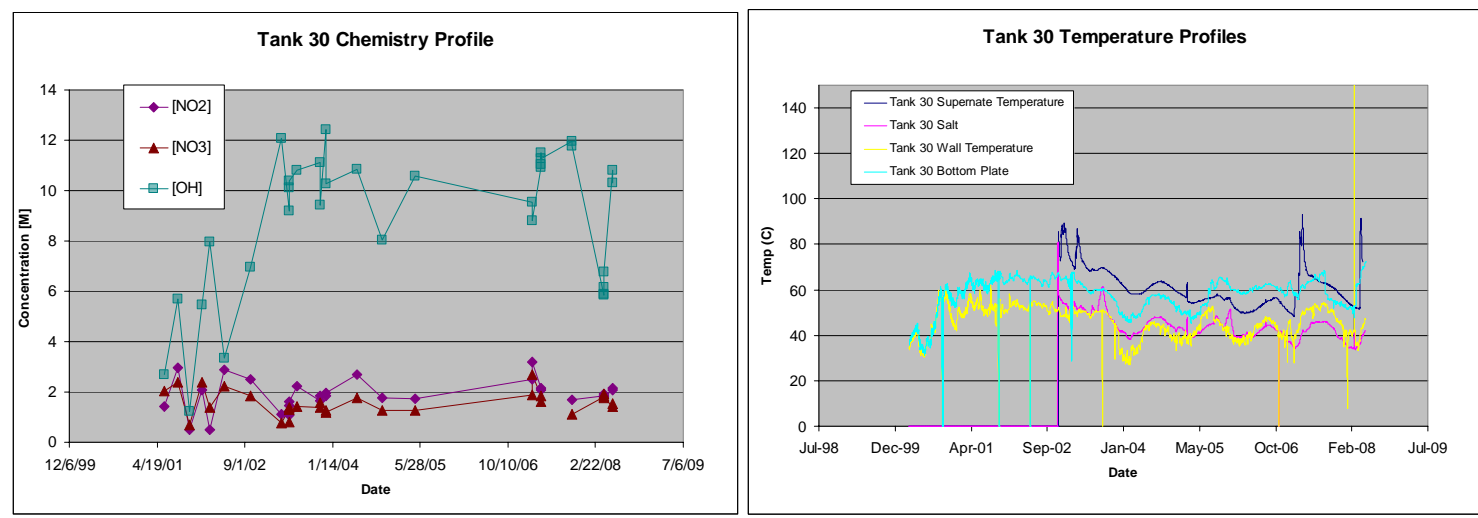

Figure 2 Chemistry and temperature profiles for Tank 30 [1].

In an earlier study ${ }^{\dagger}[5]$ sponsored by Westinghouse Savannah River Company High Level Waste Division [6] and by the U. S. Department of Energy Office of Science [7], the nitrate stress corrosion cracking in A285 carbon steel for Types I and II waste tanks was shown to be effectively eliminated by relieving the welding residual stress through heat treatment. Figure 3 shows the stress corrosion cracks growing from the initial, machined seed cracks in an as-welded, non-heat treated A285 plate, which was submerged in a $5 \mathrm{M}$ sodium nitrate solution at $90{ }^{\circ} \mathrm{C}$. Meanwhile, no cracking could be found even by ultrasonic testing in the companion test plate which had been heat treated. The stress corrosion cracking was initiated from the seed cracks as early as two weeks following immersion in the aggressive solution (no inhibitors were present).

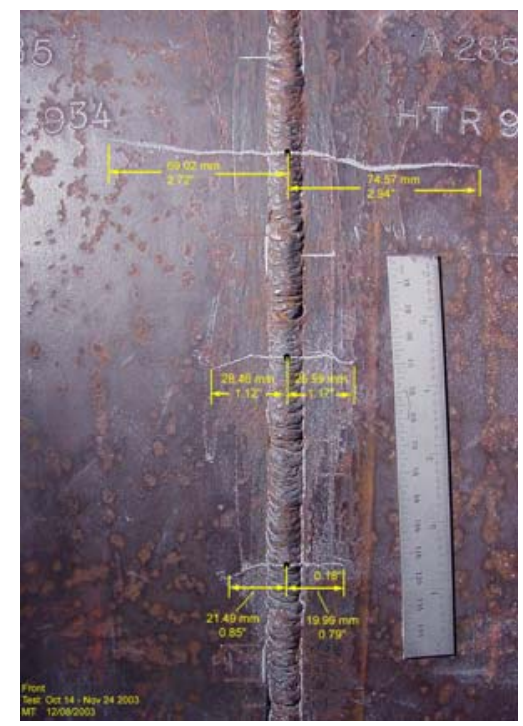

Front Side

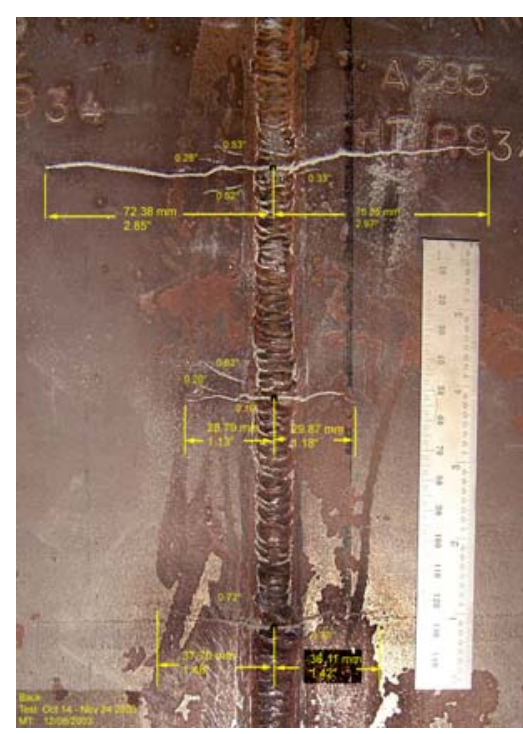

Back Side

Figure 3 Nitrate stress corrosion cracking of the as-welded A285 plate for Types I and II waste tanks (reported in 2002) [5].

\footnotetext{
$\dagger$ The work was also sponsored by the U. S. National Science Foundation Grant CMS0116238 to the University of South Carolina (PI: Professor Y. J. Chao) in welding simulation, residual stress calculation, and fracture mechanics analysis to quantify the extent of stress corrosion cracking.
} 
Following a similar approach, a representative material of construction for Type III waste tanks, A537 carbon steel, was used to fabricate the test specimens (small scale welded Ubends and the large welded plates). These were tested in a highly caustic solution defined by the bounding chemistry conditions of Tanks 30 and 32 (i.e., $12 \mathrm{M}$ hydroxide and $1 \mathrm{M}$ each of nitrate, nitrite, and aluminate) and a temperature of $125^{\circ} \mathrm{C}$, which may be close to the boiling temperature of the solution. The objective of the current investigation is two-fold: 1) to determine if CSCC can indeed occur under the test environment; and 2) if CSCC takes place in the as-welded specimens, it is necessary to confirm the efficacy of residual stress relief so the current state of Tanks 30 and 32 are temporarily protected from CSCC.

No cracking was found in the U-bend specimens within the scheduled 21-day test. Some U-bend specimens were left in the test station for up to 95 days and yet no SCC was observed. It should be noted that during the extended test, the concentrations of the test solution was changed to unknown states (more concentrated) and became sludge-like resulting from evaporation. Condensers were installed, but were not intended for very long testing beyond 21 days. The temperature was maintained at or slightly above 125 ${ }^{\circ} \mathrm{C}$.

The large plate test is in progress. The testing time is 12 weeks under the same exposure condition as the U-bend specimens, except the aluminate concentration was reduced to $0.3 \mathrm{M}$. The visual inspection at the end of the sixth week did not reveal any initiation of CSCC from the tips of the machined seed cracks.

A preliminary conclusion can be drawn from the current test results. It appears that the caustic solution at or slightly above $125{ }^{\circ} \mathrm{C}$ (below boiling point) provides a favorable condition for A537 to inhibit the initiation of CSCC. The cracking might have been inhibited by the oxygen solubility which may be sufficient enough to allow the continuous formation of protective oxide film on the test specimen surfaces.

Should CSCC eventually occur in the large plate test when it is completed, a Phase II test program must be developed to establish the long-term chemistry and temperature requirements and ranges to alleviate SCC susceptibility and to provide input to the technical justification of the waste tank corrosion control program. The need for $\mathrm{K}_{\mathrm{ISCC}}$ (fracture toughness for stress corrosion cracking) under the cracking condition may become essential for the structural integrity evaluation of the waste tanks.

\section{EXPERIMENTS}

Two types of specimens were used: 1) small scale U-bends (Fig. 4) with a before-bent dimensions of 5 -in. long, 1 in. wide, and $1 / 8$ in. thick; and 2$)$ large plate $(12 \times 12 \times 1$ in., formed by welding two $6 \times 12 \times 1$ in. sections together) with machined seed cracks (Fig. 5). Each specimen contained a weld. Heat treatment to relieve the welding residual stress 
was applied to half of the specimens. Both sets of the specimens (as-welded and heattreated) were submerged side by side in the same caustic solution at $125^{\circ} \mathrm{C}$.

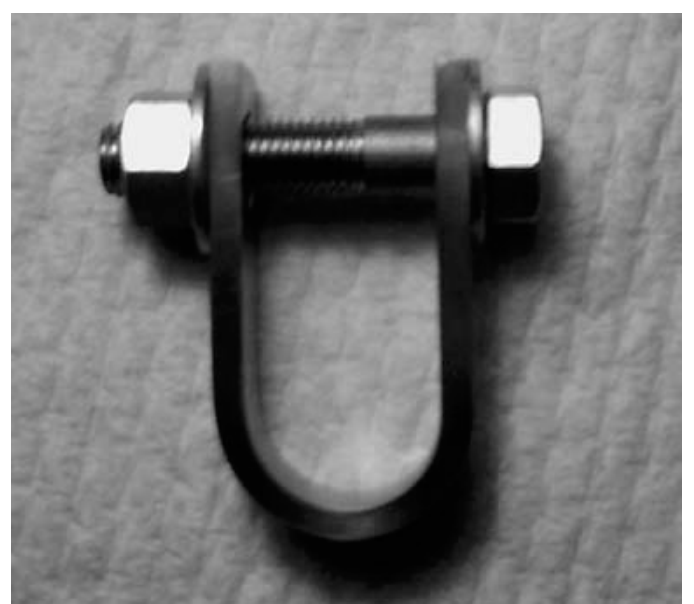

Figure 4 U-bend specimen (Ref. [10,13]).

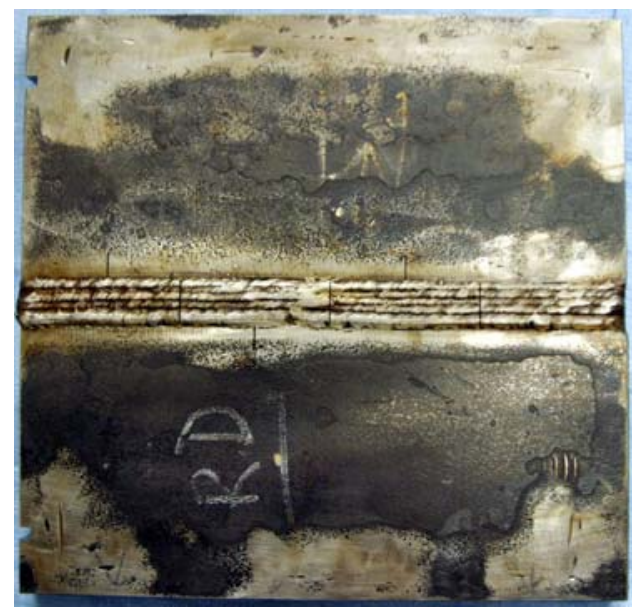

Figure 5 Large-plate specimen (Ref. [4]).

\subsection{Test Solutions}

The test condition was chosen to bound the chemistry and temperature histories since 2002 for Tanks 32 and 30, respectively, as shown in Figures 1 and 2. The test solution was made from $12 \mathrm{M}$ hydroxide $\left[\mathrm{OH}^{-}\right], 1 \mathrm{M}$ nitrate $\left[\mathrm{NO}_{3}^{-}\right], 1 \mathrm{M}$ nitrite $\left[\mathrm{NO}_{2}^{-}\right]$, and $1 \mathrm{M}$ (for the U-bend test) or $0.3 \mathrm{M}$ (for the large plate test) aluminate $\left[\mathrm{AlO}_{2}^{-}\right]$by dissolving salts of $\mathrm{NaOH}, \mathrm{NaNO}_{3}, \mathrm{NaNO}_{2}$, and $2\left(\mathrm{NaAlO}_{2}\right) \cdot 3 \mathrm{H}_{2} \mathrm{O}$ at above-room temperature. After the solution was transferred to the immersion test vessels, the temperature was raised to the target $125{ }^{\circ} \mathrm{C}$ in three 1.6-liter Teflon beakers for the U-bend test and a 6-gallon Hastelloy (C-276) test tank for the large plate test.

An adequate ratio of solution volume to specimen surface area was maintained. The ASTM G 123-00 (Reapproved 2005), "Standard Test Method for Evaluating Stress Corrosion Cracking of Stainless Alloys with Different Nickel Content in Boiling Acidified Sodium Chloride Solution," suggests that the ratio be $5 \mathrm{ml} / \mathrm{cm}^{2}$ or $33 \mathrm{ml} / \mathrm{in}^{2}$ (G 123 Paragraph 10.6). The corrosion product build-up due to general corrosion during this CSCC experiment was not expected to affect the test environment (solution) as much as that under the conditions specified in ASTM G 123. Therefore, using the ratio recommended in ASTM G 123 was considered appropriate. 


\subsection{Test Material Selection}

The SRS Type III and Type IIIA Tanks were constructed with carbon steels ASTM A516-70 or A537 [8-12]. These two carbon steels have similar carbon contents and yield strength ranges [11]. In addition, they have been shown to exhibit comparable SCC resistance [13]. Therefore, welded A537 was chosen as the test material for investigating CSCC behavior in the evaporator recycle streams in Tanks 30 and 32, which were made of A516-70. This material selection was in parallel with a previous study for the determination of corrosion inhibitor criteria for Type III/IIIA tanks during salt dissolution [14]. The nominal composition of A537 carbon steel is provided in Ref. [11] and is reproduced in Table 1. The carbon content of A537 used in Type IIIA tanks ranged from 0.14 to 0.23 wt. $\%[10,11]$.

Table 1 Nominal Composition of A537 Class I carbon steel (wt.\%)[11]

\begin{tabular}{|c|c|c|c|c|c|c|c|c|}
\hline $\mathrm{C}$ & $\mathrm{Cr}$ & $\mathrm{Cu}$ & $\mathrm{Mn}$ & $\mathrm{Mo}$ & $\mathrm{Ni}$ & $\mathrm{P}$ & $\mathrm{S}$ & $\mathrm{Si}$ \\
\hline 0.24 & 0.25 & 0.35 & $0.65-1.4$ & $\begin{array}{c}0.08 \\
(\max .)\end{array}$ & $\begin{array}{c}0.25 \\
(\max )\end{array}$ & $\begin{array}{c}0.035 \\
(\max .)\end{array}$ & $\begin{array}{c}0.04 \\
(\max .)\end{array}$ & $0.13-0.55$ \\
$(\max )$. & $(\max )$. & $(\max )$. & & & \\
\hline
\end{tabular}

For comparison, the composition of the original material of construction for Tanks 30 and 32 (A516-70 carbon steel) is listed in Table 2 [9]. The actual Material Certificates for the A537 carbon steels used for fabricating the U-bend specimens and for the two large plates (as-welded and stress-relieved) are in Appendices 1 and 2, respectively.

Table 2 Composition of A516-70 carbon steel (wt.\%) [9]

(Steels procured by Nooter Corporation from U. S. Steel Corporation)

\begin{tabular}{|c|c|c|c|c|}
\hline $\mathrm{C}$ & $\mathrm{Mn}$ & $\mathrm{P}$ & $\mathrm{S}$ & $\mathrm{Si}$ \\
\hline $0.20-0.27$ & $0.96-1.09$ & $0.008-0.016$ & $0.014-0.024$ & $0.21-0.24$ \\
\hline
\end{tabular}

Yield strength: 43,100 - 60,900 psi

Ultimate strength: 70,100 - 79,300 psi

Elongation (gage $=8$ in.): $19-29 \%$

\subsection{U-bend Test}

The U-bend specimens were first cut from A537 mill sheet, ground from the original $3 / 8$ in. to the desired $1 / 8$ in., then welded perpendicular to the rolling direction. Shielded Metal Arc Welding (SMAW) was applied with single pass on each side of the specimen [15]. The welding electrode certificate is shown in Appendix 3. This welded plate was then machined into a strip with dimensions of 5 in. long, 1 in. wide, and $1 / 8$ in. thick $[11,14,15]$ with the weld in the center of the strip in the longitudinal direction. The strip was bent around a mandrel with a radius of 0.505 in. [14] to form a U-bend specimen. Figure 6 (from Refs. [11,15]) shows the schematic of fabricating the U-bend specimen that contains a weld in the mid-section lengthwise. The specimen fabrication and assembly 
are consistent with ASTM G 30 - 97 (Reapproved 2003) entitled "Standard Practice for Making and Using U-Bend Stress-Corrosion Test Specimens."

Prior to submerging in the test solution, each pair of the specimen legs was bent approximately parallel. To maintain the shape without relaxing the elastic tensile strain, the legs were tightened by nuts and a screw which are properly insulated with Teflon washers and sleeve to avoid the galvanic effects between two different materials (Fig. 4).

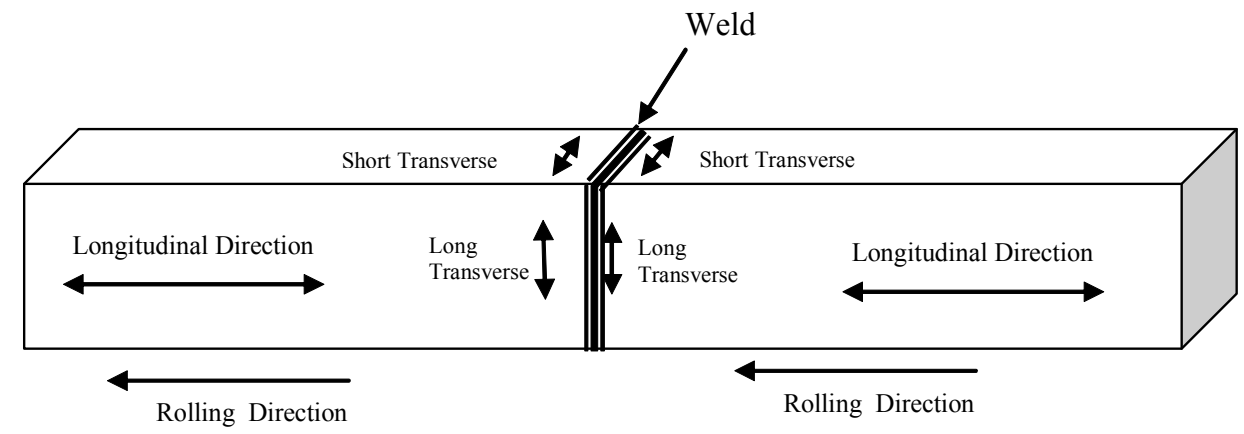

(a)

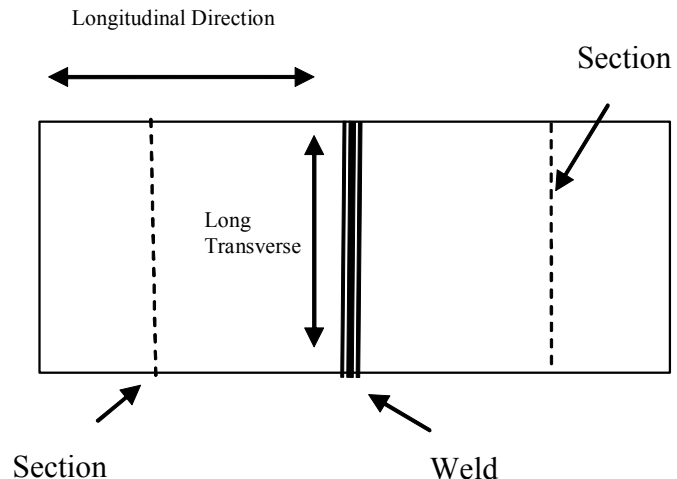

(b)

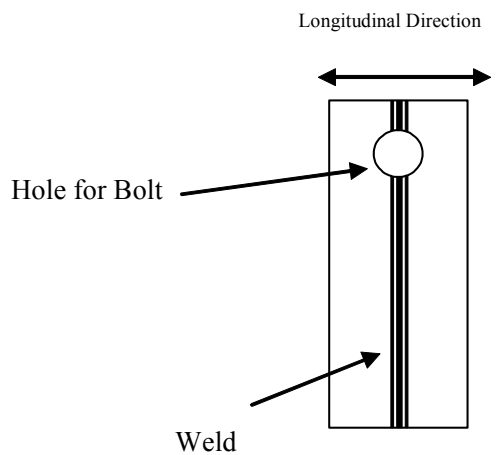

(c)

Figure 6 (a) Schematic of the two welded plates from mill sheet, (b) schematic of the weld and the orientation for the U-bend specimen, (c) side view of the final U-bend specimen after bent around a mandrel $[11,15]$.

\subsubsection{Stress Relief Heat Treatment for U-bend Specimens}

Two sets of U-bend specimens were tested simultaneously: (1) as-welded and (2) heattreated for welding residual stress relief. The heat treatment was guided by 1968 ASME Boiler and Pressure Vessel Code Section VIII, Paragraph UCS-56, which was used in the construction of SRS nuclear waste storage tanks in 1960s. Based on the recommendation of Ref. [16], the heat treatment procedure is summarized as follows: 
(1) The heat treatment is conducted in air.

(2) Heating from ambient to $1100^{\circ} \mathrm{F}$ at a rate of $90^{\circ} \mathrm{F} /$ hour.

(3) Holding at $1100^{\circ} \mathrm{F}$ for 60 minutes.

(4) Cooling to ambient at a rate of $115^{\circ} \mathrm{F} /$ hour.

\subsubsection{U-bend Test Setup and Procedure}

The testing used a total of eight U-bend specimens (Figs. 4 and 6), four of which were aswelded (fabricated and assembled per ASTM G 30) and the other four were heat treated (Section 2.3.1) prior to assembling. These eight specimens were submerged in three commercially available Teflon beakers filled with the pre-mixed caustic solution (Section 2. 1). These specimens were deployed in three beakers in the following manner to reduce the potential of experimental errors caused by any changes of solution concentrations and the fluctuation of the heater temperatures:

Beaker 1: one as-welded and two heat treated U-bend specimens Beaker 2: two as-welded and one heat treated U-bend specimens Beaker 3: one as-welded and one heat treated U-bend specimens

Figure 7 shows these specimens suspended with Teflon wires from the hooks that were built as part of the glass cap of the Teflon beaker. The glass cap has opening ports to accommodate the condenser and two thermocouples (Fig. 8). In addition, an extra port is available as needed, so a thermometer, for example, can be inserted to directly measure the solution temperature independent of the digital temperature controller readings. Each Teflon beaker was heated with an electric mantle to maintain the test temperature at 125 ${ }^{\circ} \mathrm{C}$. A glass condenser (Graham type, see Fig. 9) was fabricated for each of the beakers to recover the water vapor and to maintain constant salt concentrations in the test solution. 


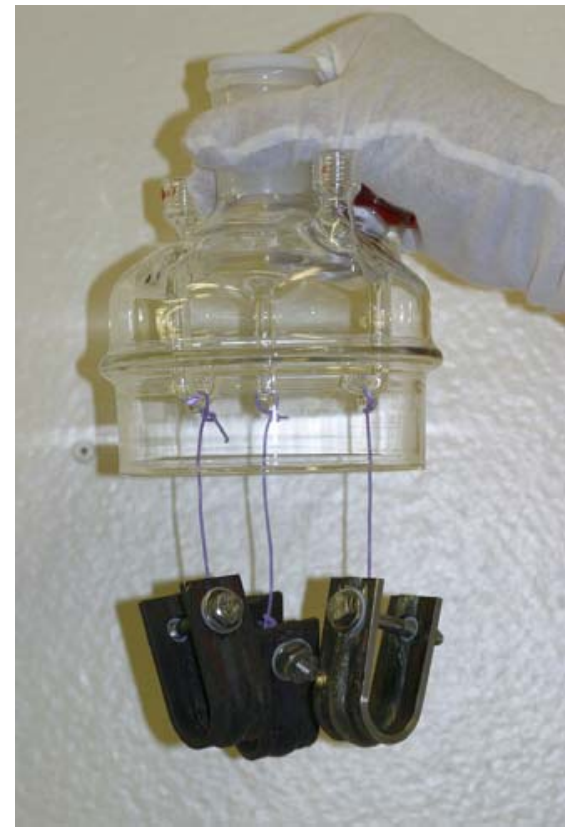

Figure 7 U-bend specimens are suspended from the hooks inside the glass cap to the beaker.

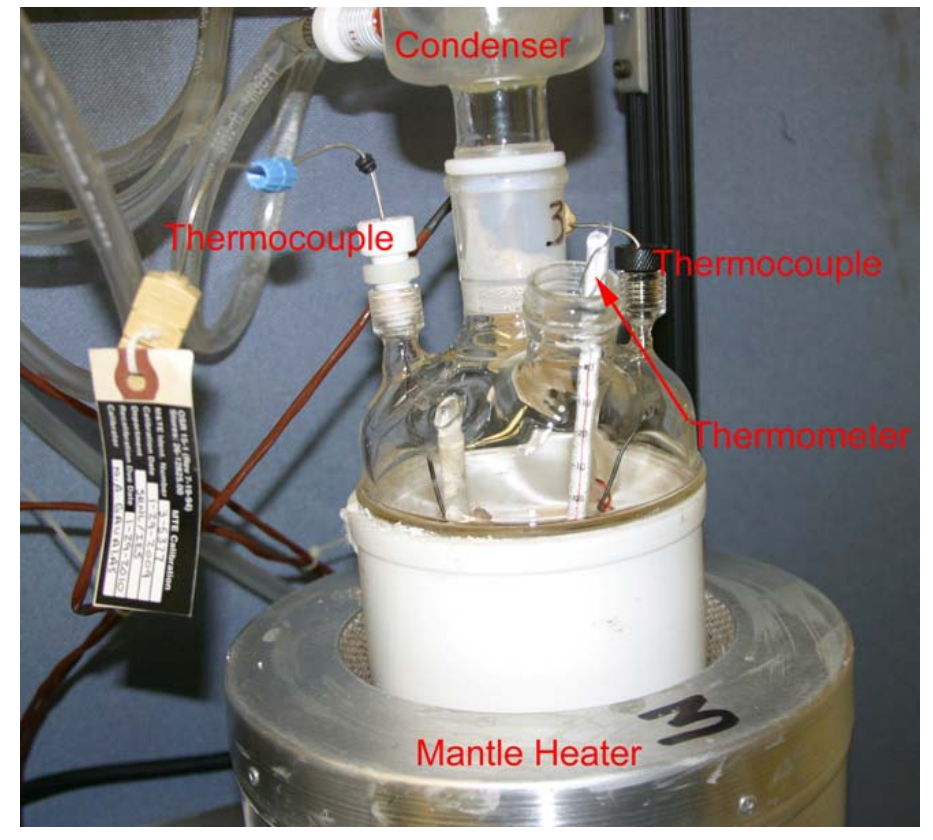

Figure 8 The assembly of the test beaker.

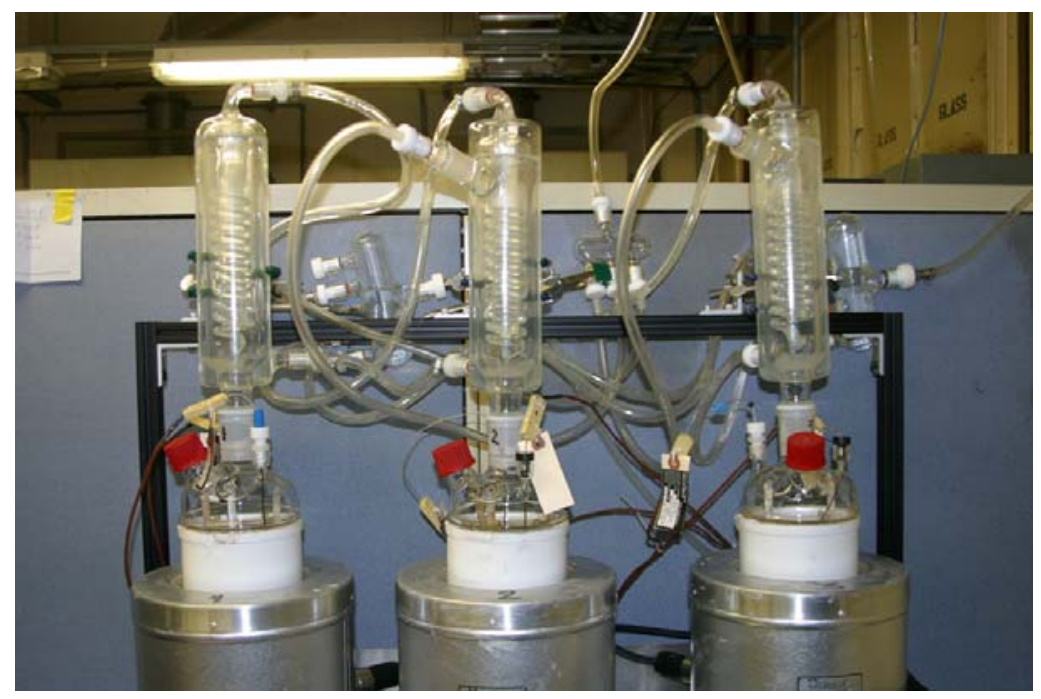

Figure 9 Graham Condensers on top of the test beakers. 
The overall laboratory setup can be seen in Figure 10. The duration of the testing was 21 days. The U-bend specimens were examined periodically for cracking during the test period.

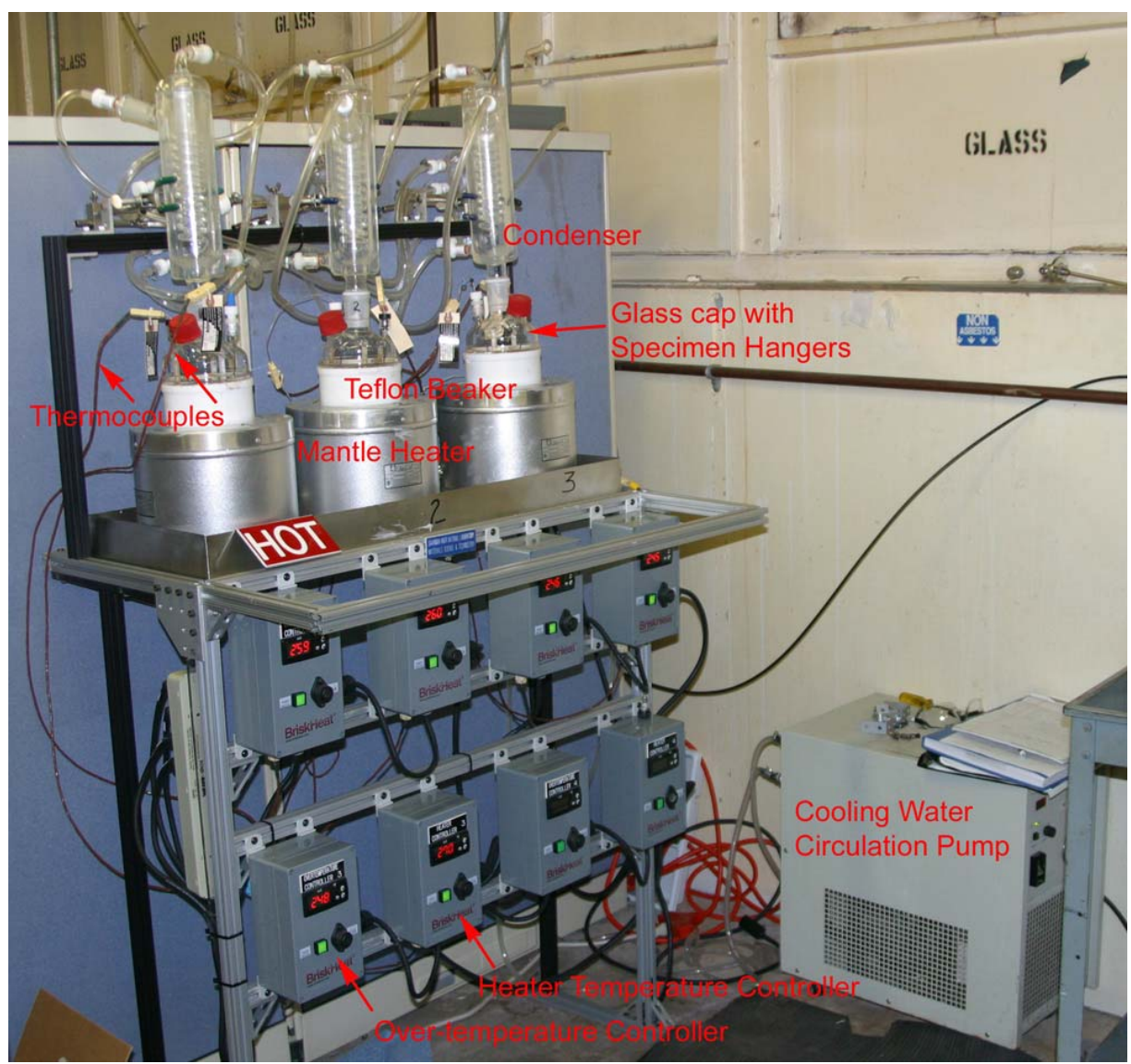

Figure 10 U-bend test station

\subsection{Large Plate Test}

The large plate test was designed to simulate the corrosion response of welded waste tanks (in particular, Tanks 30 and 32) with highly caustic waste form at very high temperature. The size of the plate specimen allows the use of the actual waste tank wall thickness and the actual welding practice as specified in the original engineering drawings [17]. The welding of the large plate also provides a constraint which is inherent to a large structure when welding is performed in-situ during construction. This constraint may affect the severity of welding residual stress that is developed in the heat affected zone. Similar to the U-bend test, an as-welded and a stress-relieved specimen were used. Identical heat treatment was used to relieve welding residual stress, as in the case of U-bends (see Section 2.3.1 and Ref. [16]). However, in the large plates, seed cracks (both through-the-plate and part-through cracks) were introduced across the weld and in the HAZ to create favorable SCC initiation sites [5]. The composition of the test 
solution was adjusted for the large plate test, that is, the aluminate concentration was changed to $0.3 \mathrm{M}$ from the $1 \mathrm{M}$ solution used in the U-bend test.

The test period for the large plate test is 12 weeks and is currently in progress. The stress corrosion cracking, if it occurs, can be observed visually by periodic inspection during the test period. The magnetic particle test (MT) will be applied to identify the very fine surface cracks after the test is complete. The non-destructive ultrasonic testing (UT) is used to detect the cracking inside the plates. Therefore, UT is performed once prior to the testing for establishing the baseline. At the conclusion of testing, these plates will be scanned by UT again. By comparison the pre- and post-test UT data, the internal cracking can be detected and may be quantified.

\subsubsection{Large Plate Specimen Fabrication and Welding Procedure}

The plate specimens were fabricated in a manner similar to those used in the previous nitrate SCC testing for Type I and II waste tanks (welded A285 carbon steel plates in 5 M sodium nitrate solution at $90{ }^{\circ} \mathrm{C}$ [5-7]). To be consistent with the U-bend specimens, the weld orientation was chosen to be perpendicular to the rolling direction of the steel mill sheet. Therefore, two 6 in. $\times 12$ in. plates were cut from an one-inch thick A537 sheet as schematically shown in Figure 11 and then butt-welded to form a 12 in. $\times 12$ in. specimen plate. Such an arrangement ensures that the weld is in the desired orientation.

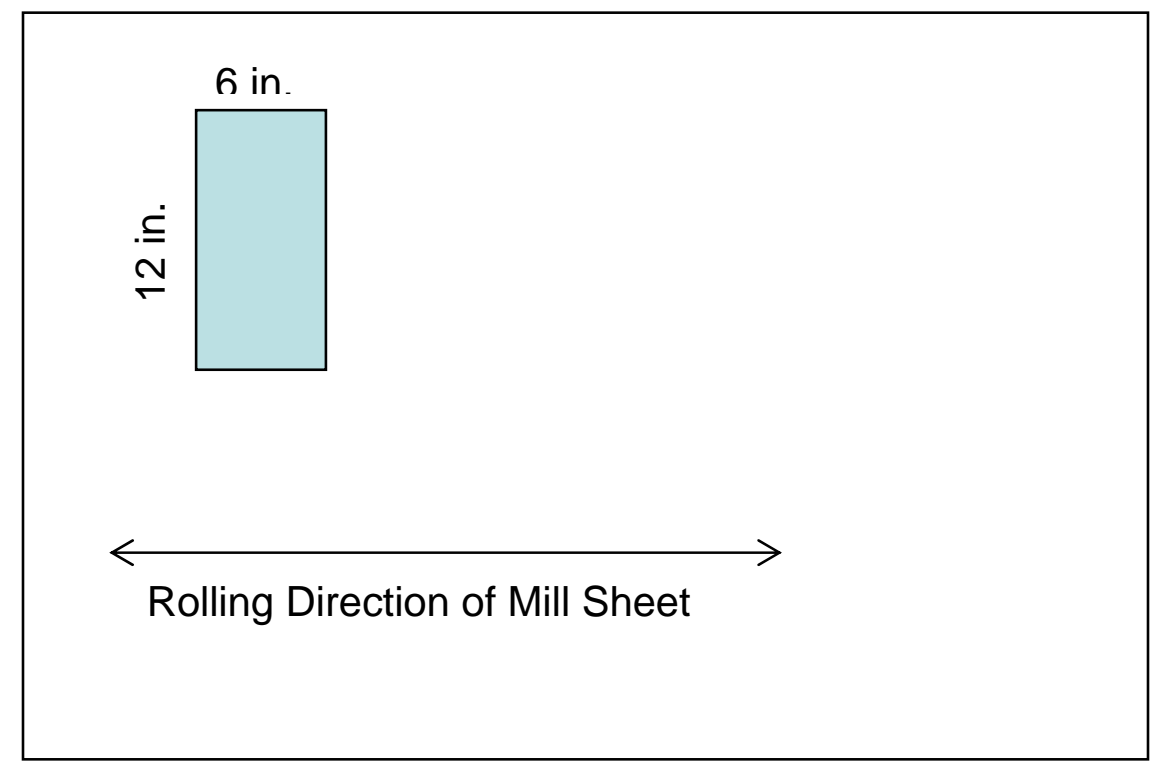

Figure 11 The 6 in. $\times 12$ in. plate is cut from an A537 mill sheet - the 6 -inch side is parallel to the rolling direction of the mill sheet. 
The thickness of the large plate specimen is one (1) inch, which was chosen based on the thickness of the plate at the location where the highest service temperature was found in Tank 32, near the bottom knuckle [1]. Within that bottom plate, the most susceptible area for CSCC to occur is the vertical seam, Weld No. 26, which is marked in red in Figure 12 (as part of the Blue Print File 211620 [17]). The original welding document from Nooter Corporation (in 1964, see Appendix 4) specified that the SMAW was used in butt-joining the tank wall with a double K-notch. The Oxweld 65 (brand name for ER70S-2 wire, see Appendix 5) was used for the initial weld between the closest point along the double-K notch; and the filler metal, coated E-7018 (Appendix 6), was used to complete the weld on one side of the tank wall (as many passes as necessary). This process was repeated for the other side of the tank wall. The same welding procedure and parameters were adopted to fabricate the plate specimens for the CSCC experiment. However, there were slight differences in the actual welding of the two plates, for example, the length of each pass and the number of passes. Appendices 7 and 8 document the actual welding processes and parameters for the as-welded plate and for the heat-treated plate, respectively.

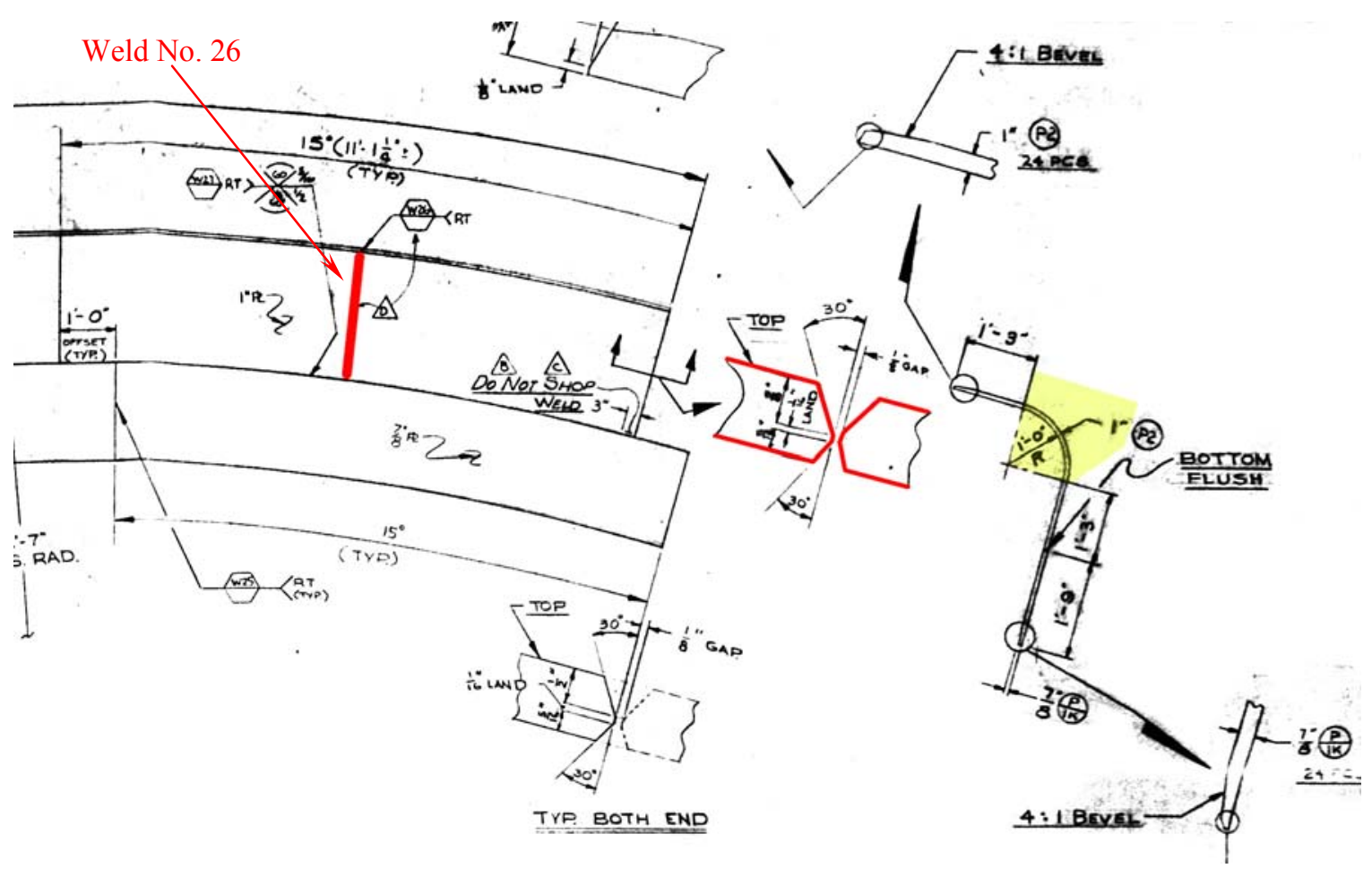

Figure 12 Vertical seam weld No. 26 in the bottom knuckle area (thickness: 1 inch).

\subsubsection{Stress Relief Heat Treatment for the Large Plate Specimen}

The same heat treatment was applied to the large plate specimen as described in Section 2.3.1 for the U-bend specimens. This information is repeated below: 
(1) The heat treatment is conducted in air.

(2) Heating from ambient to $1100^{\circ} \mathrm{F}$ at a rate of $90{ }^{\circ} \mathrm{F}$ /hour

(3) Holding at $1100^{\circ} \mathrm{F}$ for 60 minutes.

(4) Cooling to ambient at a rate of $115^{\circ} \mathrm{F} /$ hour.

However, during the heat treatment at the vendor site, the oven was found to have lost power at about $950{ }^{\circ} \mathrm{F}$ during the ramp-up stage (from ambient to $1100{ }^{\circ} \mathrm{F}$ ). It is estimated from the heat treatment chart (Fig. 13) that it took about 105 minutes to reheat to $950{ }^{\circ} \mathrm{F}$ (when the power failure occurred) and finally reached the maximum temperature, $1100{ }^{\circ} \mathrm{F}$, in the next 150 minutes. Because the temperature excursion occurred in the heating stage, it is considered as non-detrimental and this plate specimen was not re-fabricated.

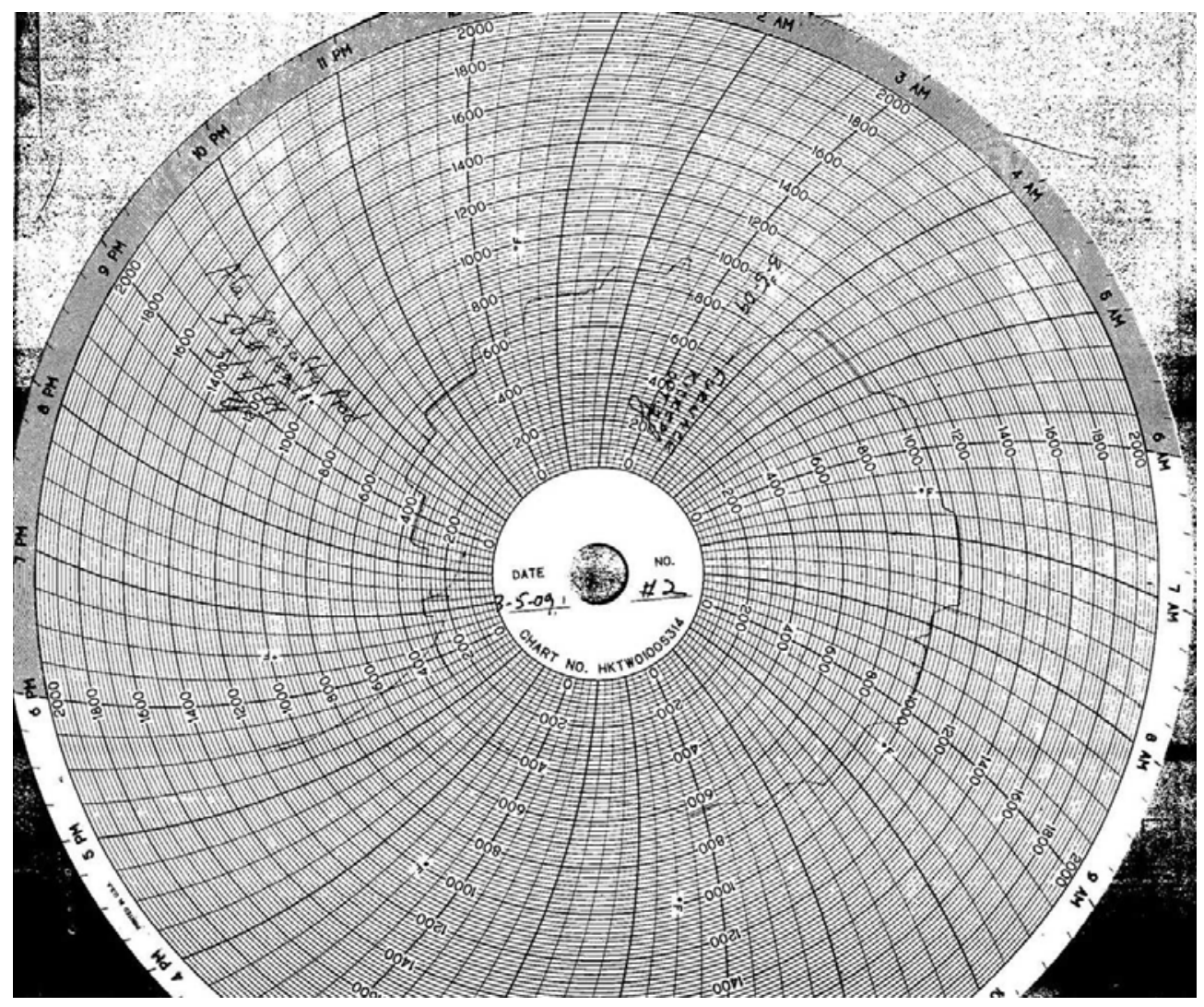

Figure 13 Heat treatment temperature history.

\section{$\underline{\text { 2.4.3 Seed Cracks }}$}

Unlike the U-bend specimens, seed cracks were machined into the large plate specimens and serve as the initiation sites for stress corrosion cracking. Note that for the stressrelieved plate specimen, the heat treatment must be performed prior to machining the seed cracks. 
The schematic seed crack placement and crack types can be seen in Figure 14. The actual seed cracks are shown in the insets of the figure. The electric discharge machining (EDM) was used to fabricate these cracks so the crack tips can be as sharp as possible. Due to the EDM wire or electrode size, the crack tip maintains a small but finite radius (e.g., 0.015 in.).

The three types of machined cracks are (see Figure 14):

1) V1, V2, and V3: vertical cracks through the thickness of the plate and across the weld (Fig. 15);

2) V4, V5, and V6: vertical cracks partly through plate in the heat affected zone (HAZ) perpendicular to the weld (Fig. 16); and

3) P1, P2, and P3: cracks parallel to the weld and partly through plate in the HAZ along the edge of the weld (Fig. 17).

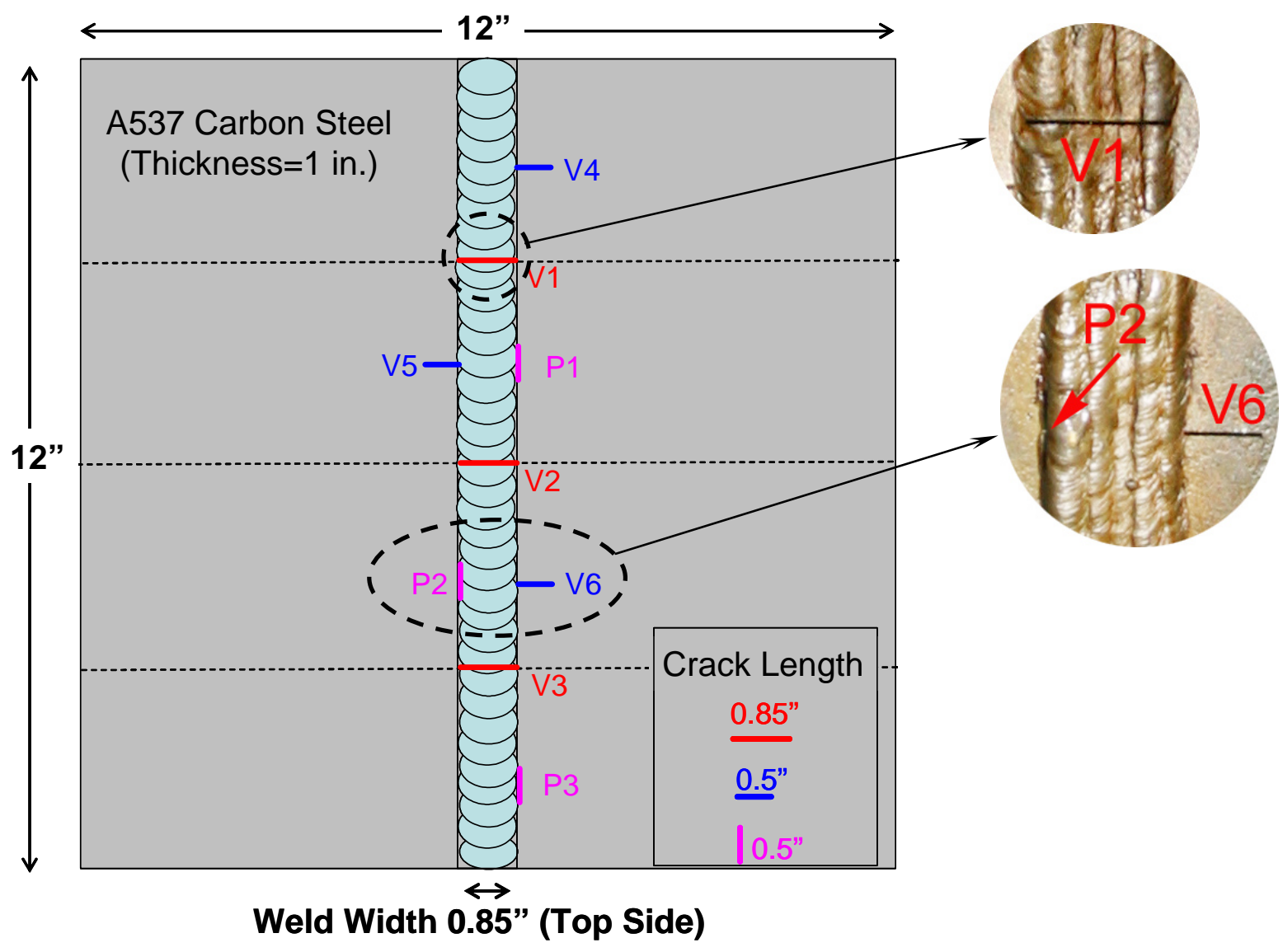

Figure 14 Welded large plate specimen with machined cracks. 


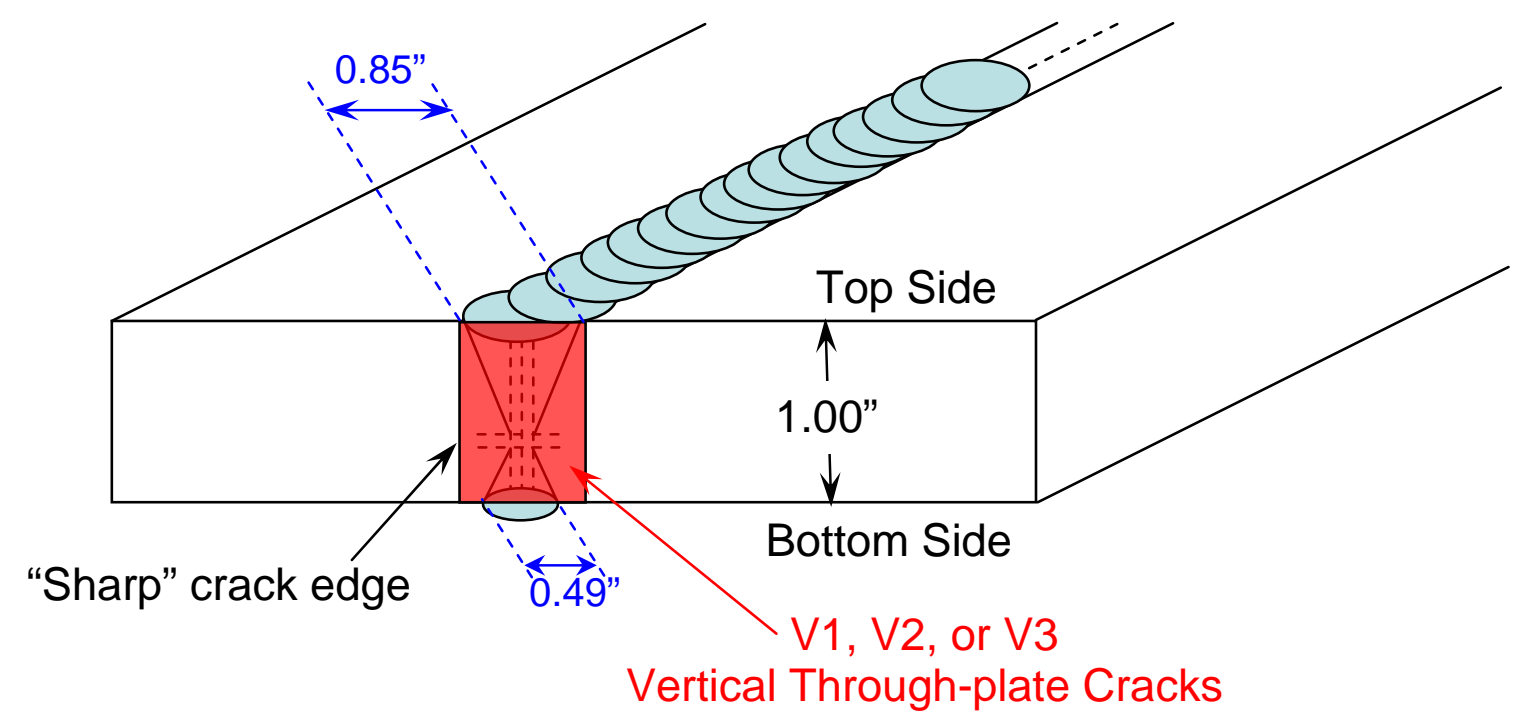

Figure 15 Through-the-plate cracks across the weld (V1, V2, and V3).

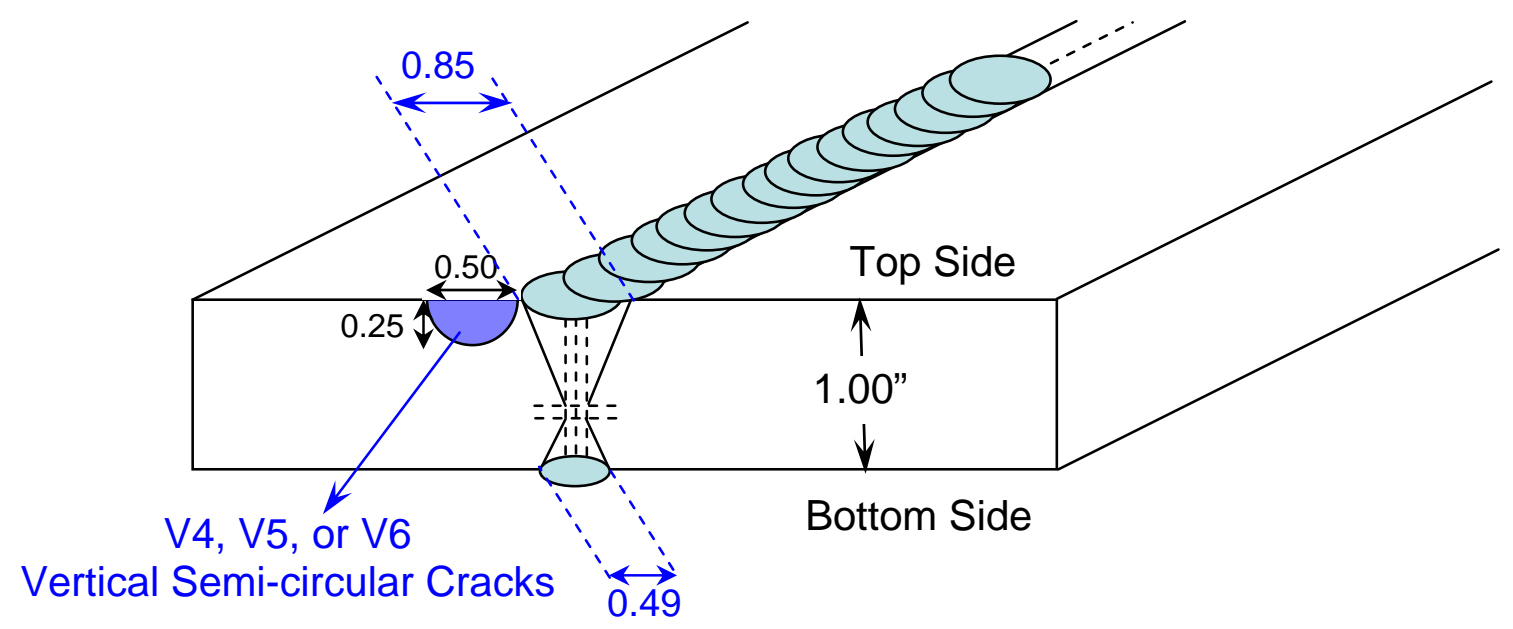

Figure 16 Semi-circular surface cracks perpendicular to the weld (V4, V5, and V6). 


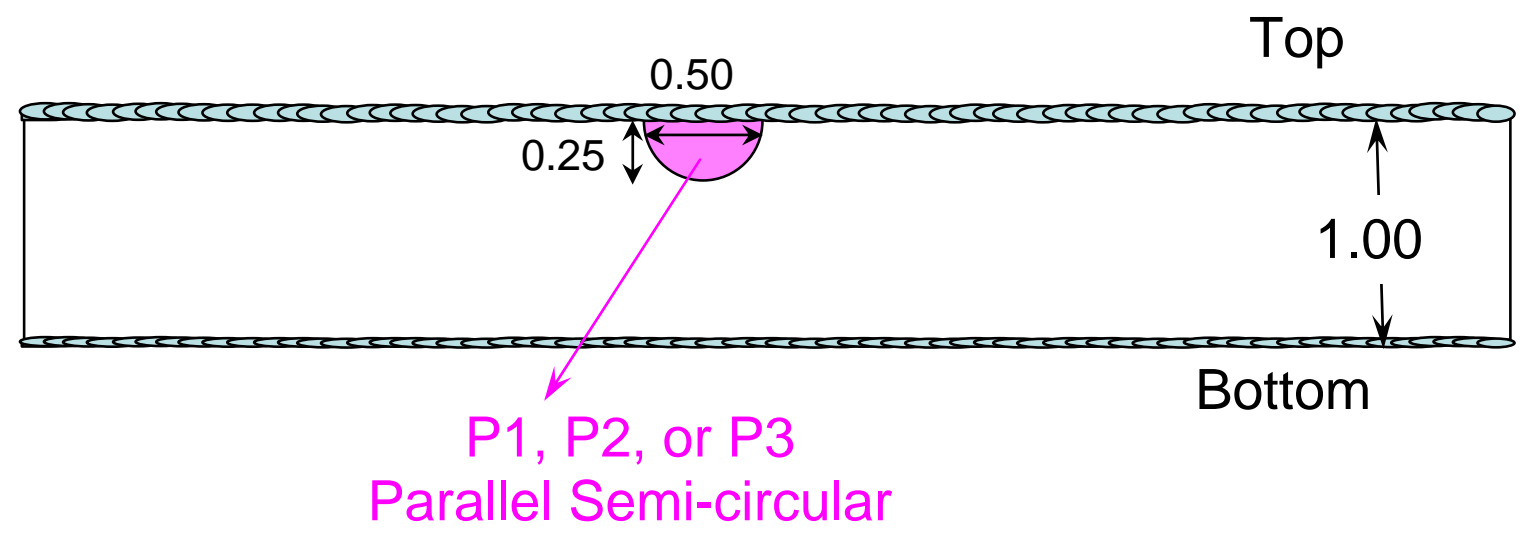

Figure 17 Semi-circular surface cracks parallel to the weld (P1, P2, and P3).

\subsubsection{Large Plate Test Tank and Experimental Station}

Typical stainless steels, especially their weldment, may corrode significantly during long exposure to highly caustic solutions at temperature as high as $125{ }^{\circ} \mathrm{C}$ (or slightly above, because the temperature control is of oscillatory nature). As a result, the nickelmolybdenum-chromium alloy, Hastelloy (i.e., C-276), was selected for constructing the immersion tank. This material, along with its welds, is known to be corrosion-resistant in highly caustic solutions at high temperatures. The design of the immersion tank was based on the specimen dimension (12 in. $\times 12$ in. $\times 1$ in.) and the ratio of solution volume to specimen surface area (i.e., $5 \mathrm{ml} / \mathrm{cm}^{2}$ or $33 \mathrm{ml} / \mathrm{in}^{2}$, suggested by ASTM G 123, see Section 2. 1). The tank is 18 -in. high with a cross-section of 18 in. $\times 6.5$ in. with a total volume of 34.5 liters (9.1 gallons) which could accommodate 6 gallons of the test solution required by ASTM G 123. The thickness of the tank wall is $3 / 8$ inches. The test tank was designed in such a manner that none of the C-276 plate edges (i.e., end-grains) would be exposed to the solution, which makes the test tank even more corrosionresistant. An engineering drawing of the tank construction along with the welding requirements can be seen in Figure 18. The test solution is not filled to the top of the tank. A $2 \frac{1}{2}$ inch headspace is left when the test plates and hangers (racks) (Figure 19) are in position with a liquid volume of 25 liters (6.6 gallons).

A heating unit with controller was designed to maintain the test temperature at $125{ }^{\circ} \mathrm{C}$ for an extended period of time. The heaters are housed in flexible silicone which adheres to the sides of the test tank. They are rated to function up to $232{ }^{\circ} \mathrm{C}\left(450{ }^{\circ} \mathrm{F}\right)$ but the adhesive is only rated at $149^{\circ} \mathrm{C}\left(300^{\circ} \mathrm{F}\right)$. Two (2) adhesive-backed thermocouples have been placed on the tank surface at the heater location to make sure the adhesive does not exceed this temperature during the startup process. When the temperature reaches the setpoint and stabilizes, thermocouple plugs may be disconnected from the heater thermocouples and connected to the thermocouples monitoring the liquid. This arrangement verifies liquid temperature after keeping the heater's adhesive within its desired temperature range. 


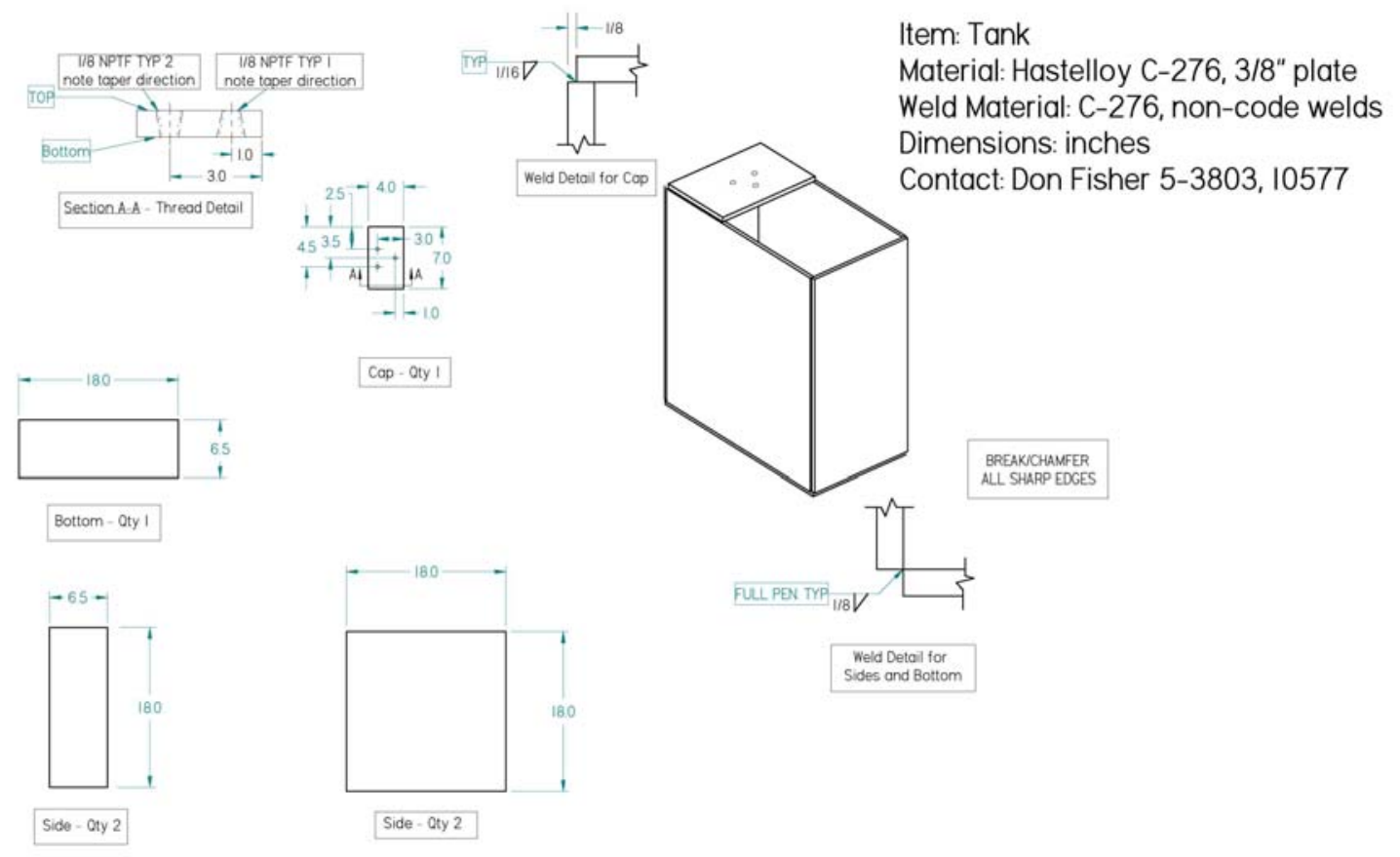

Figure 18 Construction drawing for the Hastelloy (Alloy C-276) immersion tank.

The heaters operate simultaneously and are controlled by a simple temperature controller backed up by a programmable digital over-temperature controller. Each has an independent thermocouple input. A high temperature, corrosion resistant level sensor (float) will cut off the power supply to the heaters if the liquid level drops below 14 inches measured from the bottom. Figure 20 is the inside view of the tank where the thermocouples are used to monitor the solution temperature and the level switch (float) is visible.

The controller (the assembly of all the electronic equipment) and heaters are protected by a ground fault circuit interrupter (GFCI) which switches power off within 5 milliseconds of any current fault. A fast-blow fuse protects the solid state relay and all heater power wiring.

Because the weight of each large plate specimen is about $40 \mathrm{lbs}$ and the specimens are lifted periodically above the heated caustic solution for visual inspection for cracking, a small manual rigging device is included in the design for safe operation during the test. Each carbon steel plate is suspended in a cradle (i.e., hanger or rack, see Fig. 19). The rack is made of stainless steel. Therefore, it is insulated from the A537 carbon steel plate by wrapping Teflon tapes throughout the rack/holder (Fig. 21). Furthermore, two notches were machined on the bottom edge of each test plate so the rack will catch the test plate securely. Because of the presence of the notches, the holder may get caught inside the notches and therefore is unable to provide an insulated barrier between the bottom edge 
of the test plate (A537) and the bottom of the test tank (Alloy C-276). A Teflon plate was placed on the bottom of the tank to avoid direct contact of A537 and C-276.

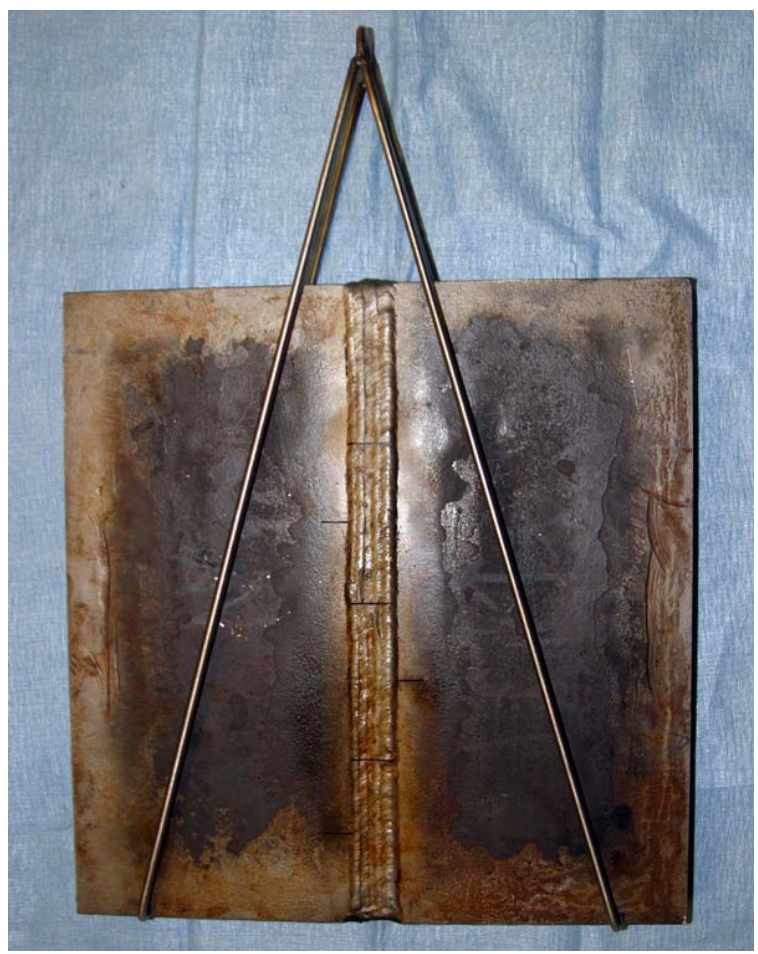

Figure 19 Positioning of the test plate on the rack (hanger).

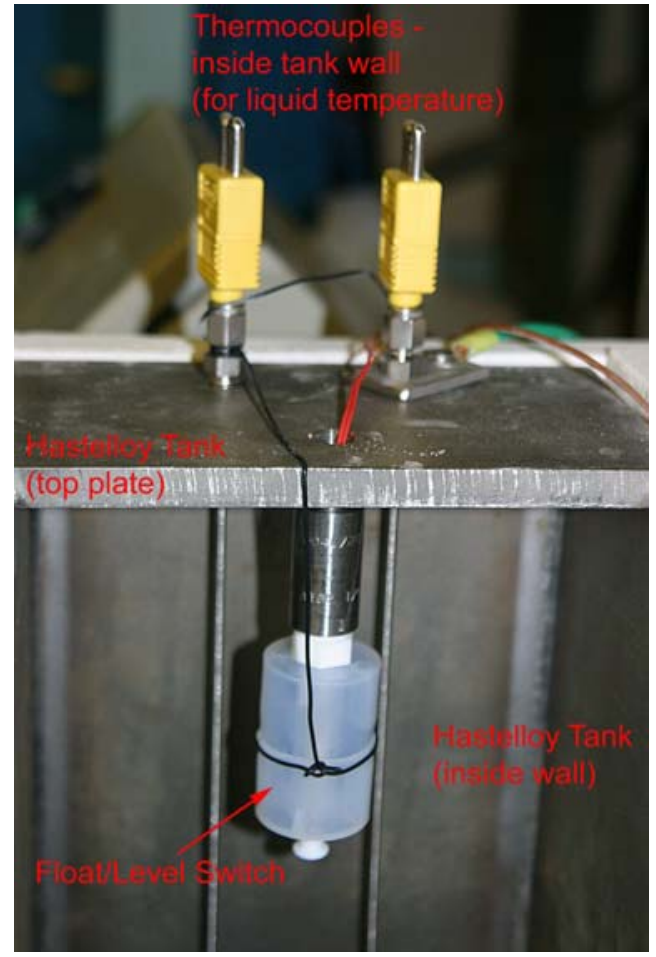

Figure 20 Thermocouples for monitoring the solution temperature and the level float switch (inside test tank).

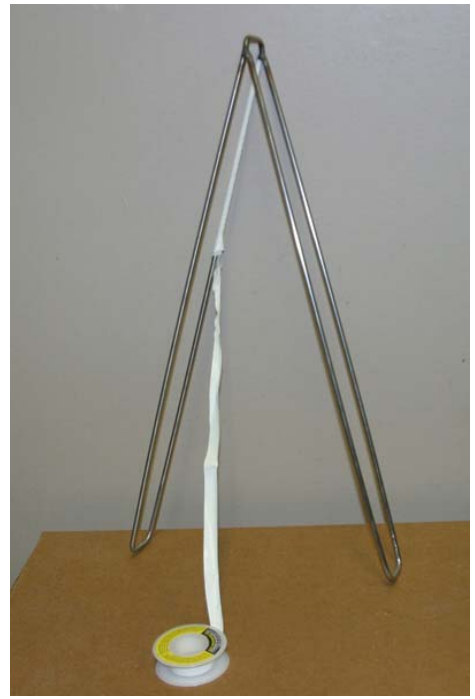

Figure 21 Insulating of rack with Teflon tapes.

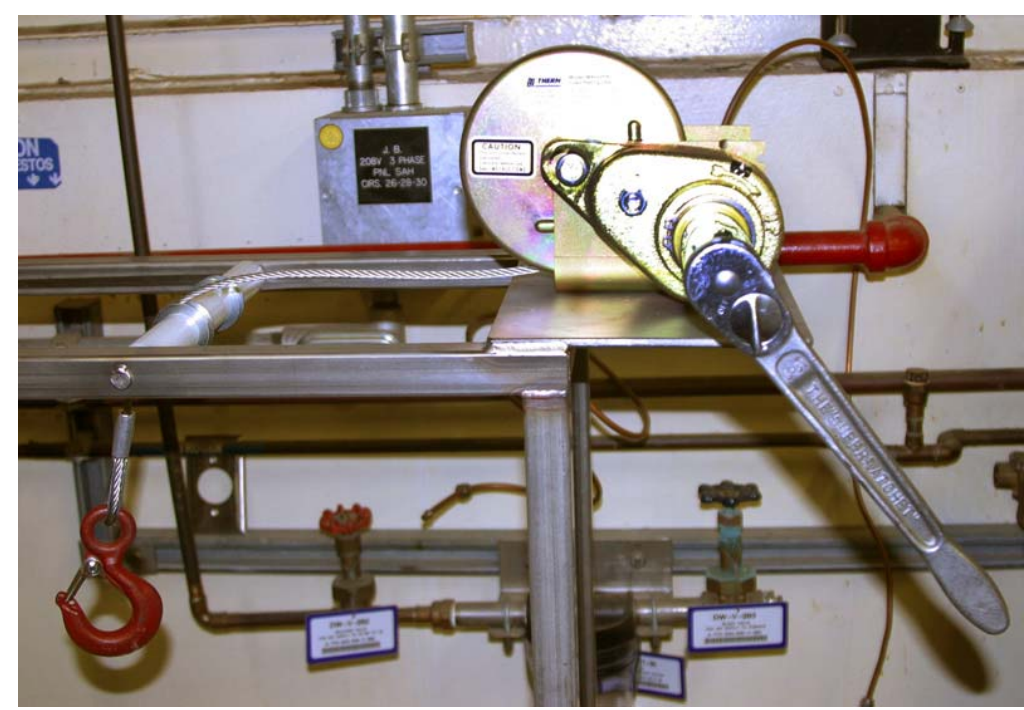

Figure 22 Winch assembly for lifting and lowering the plate specimens. 
The test plate and the rack (holder) were designed to be lifted with a winch (Fig. 22) from or lowered into the solution in the test tank which has been filled with highly caustic solution and at high temperature. The winch is equipped with a brake and clutch and must be manually powered up and down. The test tank is supplied with a lid which may be replaced once one plate is brought above the top of the test tank. This eliminates the possibility of corrosive material splashing out if objects are accidentally dropped into the test solution.

Secondary containment is required for any testing involving aggressive solutions. Secondary containment for these tests was constructed of stainless steel with a volume of 44.3 liters (11.7 gallons), which is sufficient to contain all the liquid should the test solution release from the test tank. The rapidly dropping temperature of the released liquid as it becomes exposed to ambient conditions allows the use of stainless steel for this application (i.e., the material of the test tank, Hastelloy C-276, is not needed for the temporary storage of low temperature caustic solution).

All the components of the large plate experimental station and the laboratory layout are shown in Figure 23.

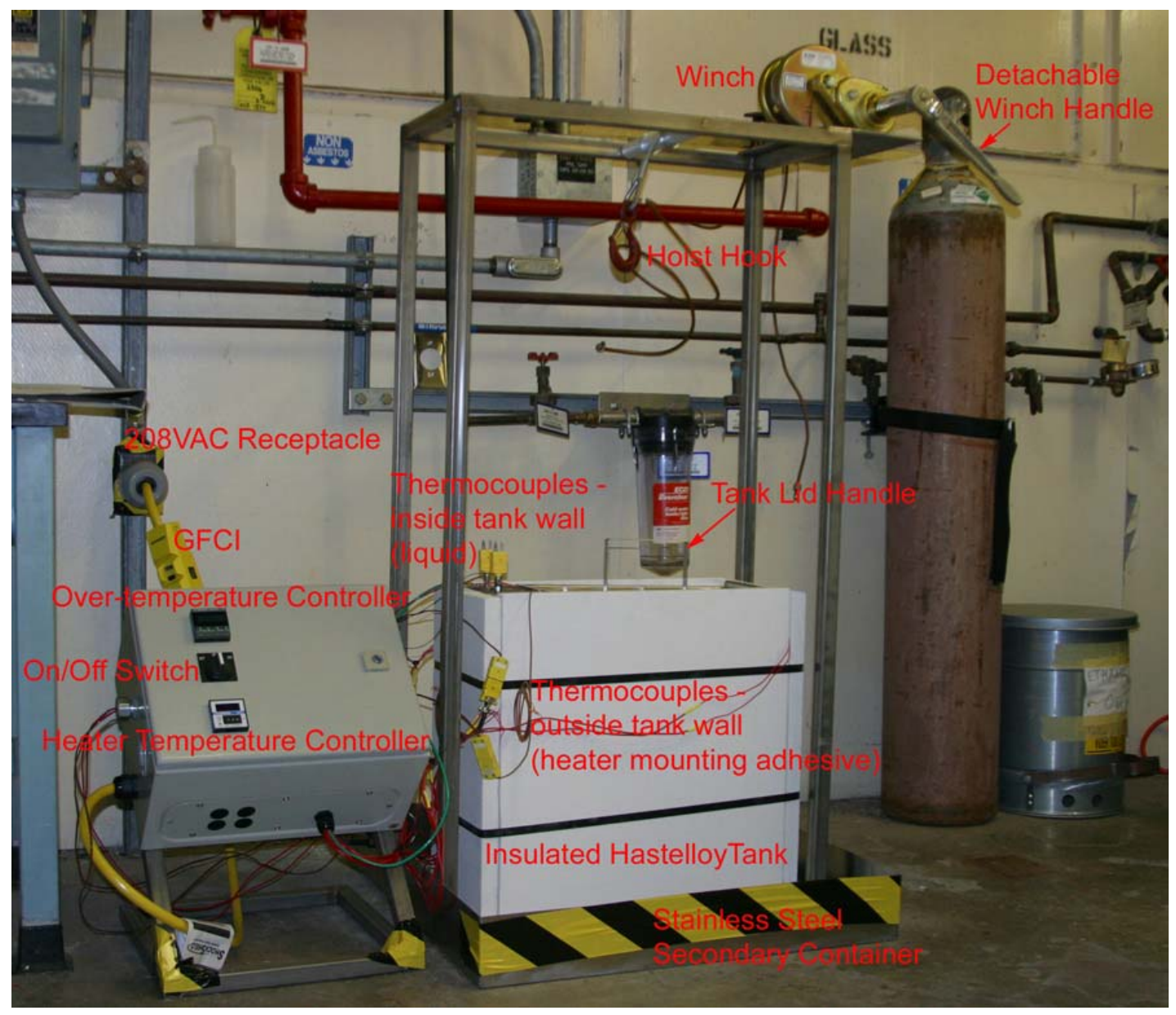

Figure 23 Large plate experimental station. 


\subsubsection{Large Plate Test Procedure}

Pre-test ultrasonic testing (UT) has been performed to characterize the initial flaw sizes of the machined cracks. After the test is complete, a second UT scan will be performed and data are compared with the baseline so any interior cracking can be detected.

Prior to submerging the large plate specimens into the caustic solution, the machined cracks were cleaned with Clarke's solution to remove the corrosion products (oxide) on the crack surfaces that would have formed naturally in the atmosphere. This treatment ensured that the caustic test solution will directly attack the fresh metal surface of the cracks, and the obstructing oxides will not interfere, especially at the crack tip where the welding residual stress is operating and tends to open the crack.

The Clarke's solution can be prepared by dissolving 20 grams of $\mathrm{Sb}_{2} \mathrm{O}_{3}$ and 50 grams of $\mathrm{SnCl}_{2}$ in $1000 \mathrm{ml}$ of concentrated $\mathrm{HCl}$ (see ASTM G 1-03 "Standard Practice for Preparing, Cleaning, and Evaluating Corrosion Test Specimens," Annex A1, Designation C.3.1 for iron and steel). A small amount of Clarke's solution was applied to the cracks on the specimen plate surface with a slurry (eyedropper). The treated area was rinsed with distilled water and then with ethanol to remove the residual chlorides trapped in the cracks. Like the test tank which contains highly caustic solution, this treatment of applying the Clarke's solution also required a secondary container to catch the spills.

After the plate specimen was submerged in the test solution, periodic inspections were performed by lifting the plate above the test solution with the winch and hoist hook (Fig. 24). The total exposure time of the large plate specimen was set to 12 weeks. No evaporation control was attempted (e.g., such as the condensers in the U-bend test). However, a small amount of insulation material was used to cover the seam around the lid of the test tank after the lid was closed. This practice has proven to be very effective in minimizing evaporation. To maintain the test temperature at $125{ }^{\circ} \mathrm{C}$, distilled water must be replenished periodically because the electrical power to the heaters will be cut off when the liquid drops below the preset level (14 in. above the tank bottom).

Non-destructive UT and magnetic particle test (MT) will be conducted at the end of the large plate test. The MT will reveal the fine details of the cracking pattern on the plate surface and the UT will detect the subsurface crack propagation. 


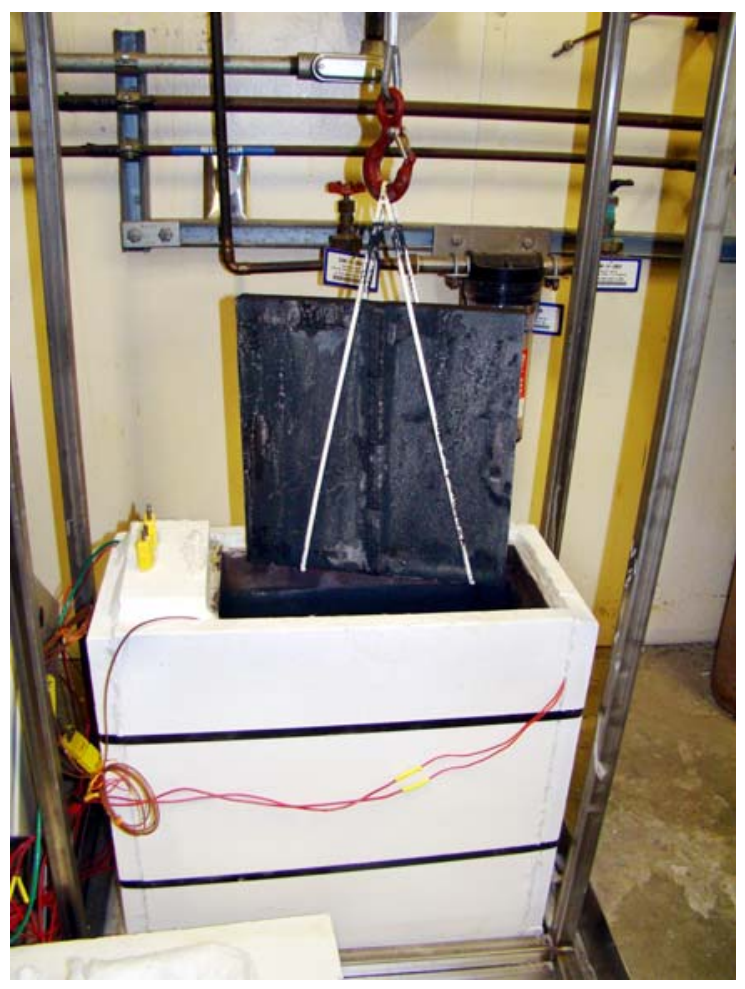

Figure 24 Periodic inspection for cracking by lifting plate above the test solution.

\section{TEST RESULTS}

The U-bend test has been completed. The test was planned for 21 days, but some specimens were actually left under the test conditions for an extended period of time. No cracking was found throughout the entire time of exposure. Table 1 lists the specimen numbers in each test beaker and the actual duration of the testing. The photographs of welds in the pre- and post-test specimens are shown in Section 3.1.

Table 3 U-bend specimens and exposure times

\begin{tabular}{|c|c|c|c|c|c|c|}
\hline $\begin{array}{l}\text { Beaker } \\
\text { Number }\end{array}$ & $\begin{array}{l}\text { Specimen } \\
\text { Number }\end{array}$ & $\begin{array}{l}\text { Specimen } \\
\text { Type }\end{array}$ & $\begin{array}{l}\text { Starting } \\
\text { Day }\end{array}$ & End Date & $\begin{array}{l}\text { Actual }^{*} \\
\text { Exposure } \\
\text { Days }\end{array}$ & $\begin{array}{l}\text { Actual }^{*} \\
\text { Exposure } \\
\text { Hours }\end{array}$ \\
\hline \multirow{3}{*}{1} & 242 & heat-treated & \multirow{3}{*}{$\begin{array}{l}\text { May 26, } \\
2009\end{array}$} & \multirow{3}{*}{$\begin{array}{l}\text { July 8, } \\
2009\end{array}$} & \multirow{3}{*}{44} & \multirow{3}{*}{1039} \\
\hline & 244 & heat-treated & & & & \\
\hline & 248 & as-welded & & & & \\
\hline \multirow{3}{*}{2} & 243 & heat-treated & \multirow{3}{*}{$\begin{array}{l}\text { May 26, } \\
2009\end{array}$} & \multirow{3}{*}{$\begin{array}{l}\text { August } \\
31,2009\end{array}$} & \multirow{3}{*}{95} & \multirow{3}{*}{2255} \\
\hline & 245 & as-welded & & & & \\
\hline & 247 & as-welded & & & & \\
\hline \multirow{2}{*}{3} & 241 & heat-treated & \multirow{2}{*}{$\begin{array}{l}\text { May 26, } \\
2009\end{array}$} & \multirow{2}{*}{$\begin{array}{l}\text { June 18, } \\
2009\end{array}$} & \multirow[b]{2}{*}{24} & \multirow[b]{2}{*}{558.5} \\
\hline & 246 & as-welded & & & & \\
\hline
\end{tabular}

* Actual exposure time: The system downtime has been taken into consideration. 
The large plate test is in progress. None of the plates (the as-welded and the heat-treated) had exhibited any indication of stress corrosion cracking. The photographs that were taken at the end of the sixth week are shown in Section 3.2.

\subsection{U-Bend Test Results}

The photographs of the specimens are grouped according to the Beaker Number, or the exposure time. The test time for Beaker No. 3 (24 days) is close to the planned 21 days (Section 3.1.1). Since there was no cracking at the end of the scheduled test duration, the testing in Beaker No. 1 (Section 3.1.2) and No. 2 (Section 3.1.3) was extended beyond the originally scheduled 21 days. However, it should be noted that the salt concentrations might have been altered due to the loss of water. In fact, when the test was finally terminated (44 days for Beaker No. 1 and 95 days for Beaker No. 2), the solution had become sludge-like and salt cakes had formed thickly around the test specimens. In all cases, no stress corrosion cracking could be found in the U-bend specimens. During the first 21 days of testing, all specimens were inspected once a week for evidence of cracking.

\subsubsection{Exposure for 24 Days (Beaker No. 3)}

The actual exposure time for these specimens in the caustic solution (12 M hydroxide) was 24 days, or more precisely, 558.5 hours. The test temperature was at least $125^{\circ} \mathrm{C}$. The pre- and post-exposure photographs of these specimens are placed side-by-side for comparison (Figs. 25-26). Both the outer side of the U-bend (tensile side) and the inner side (compressive) are documented. Although the SCC on the compressive side is highly improbable, it is reported here for completeness.

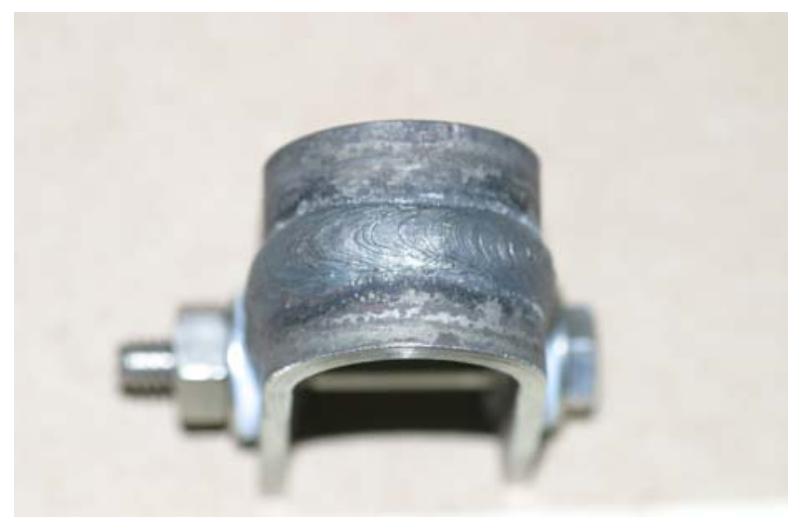

(a) Tensile side of U-bend before exposure

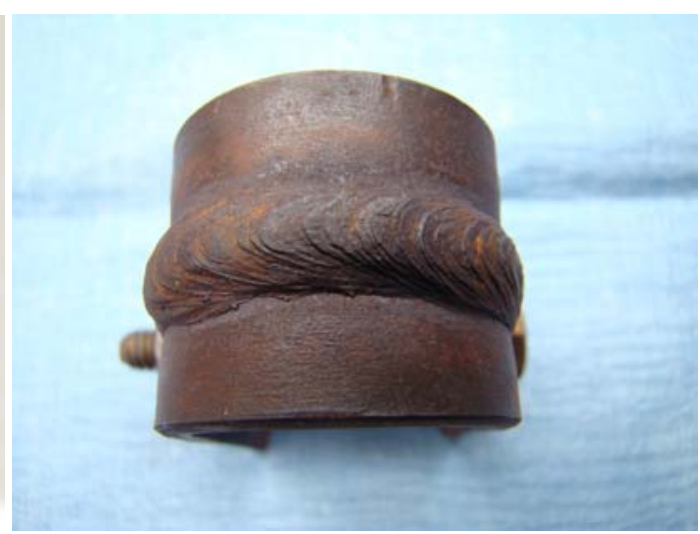

(b) Tensile side of U-bend after exposure 


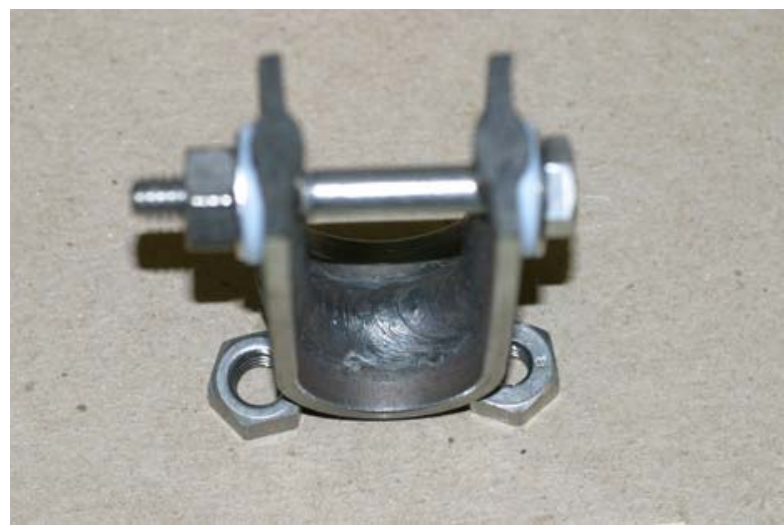

(c) Compressive side of U-bend before exposure

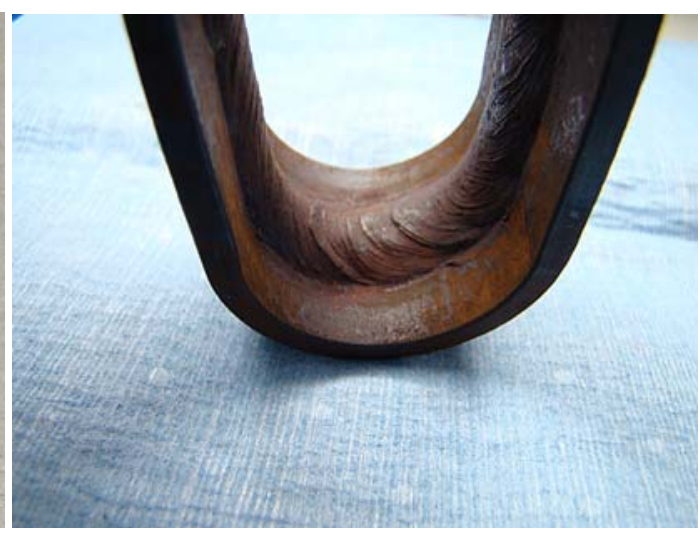

(d) Compressive side of U-bend after exposure

Figure 25 As-welded Specimen No. 246 exposed to caustic solution for 24 days.

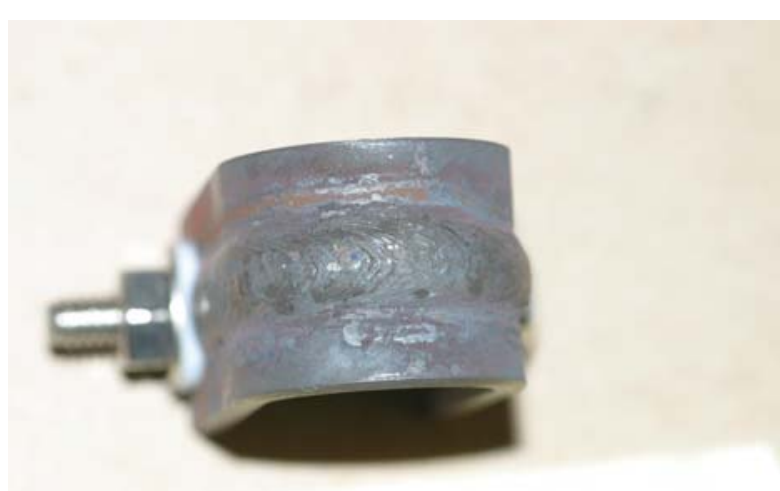

(a) Tensile side of U-bend before exposure

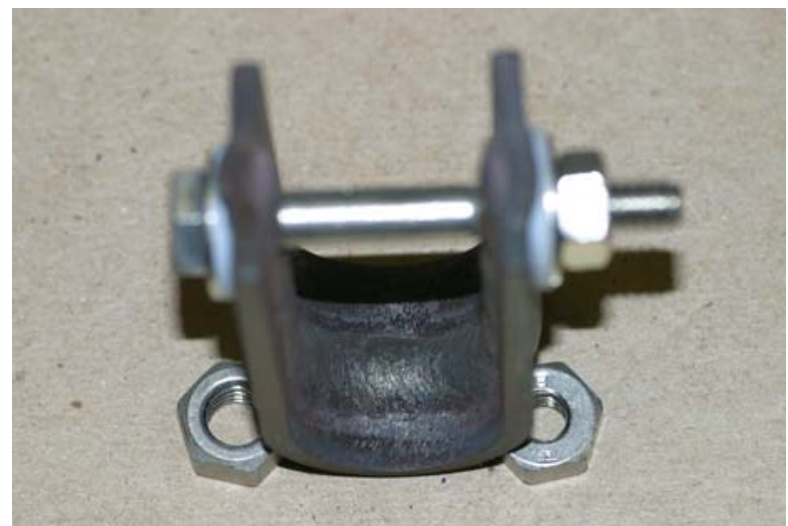

(c) Compressive side of U-bend before exposure

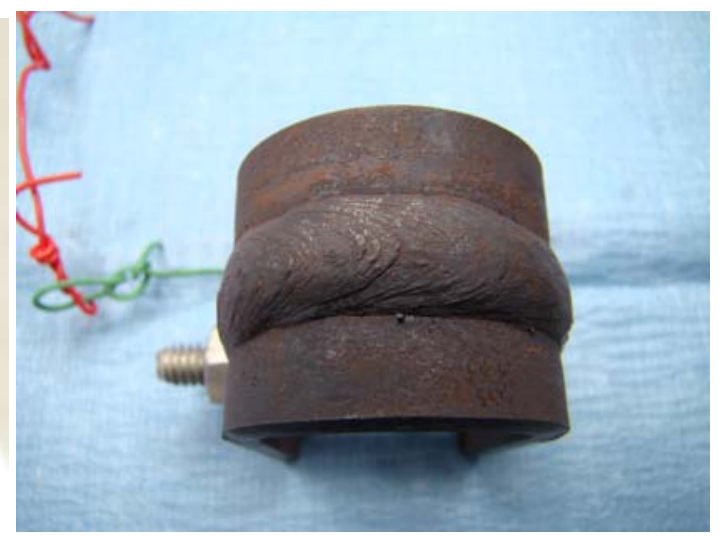

(b) Tensile side of U-bend after exposure

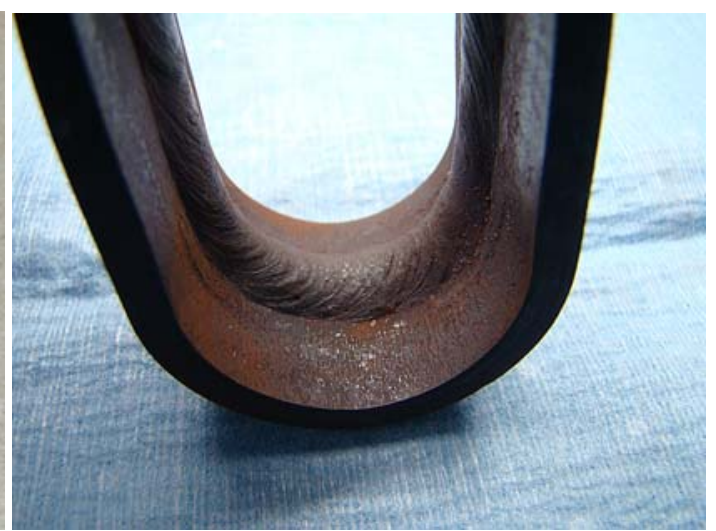

(d) Compressive side of U-bend after exposure

Figure 26 Heat-treated Specimen No. 241 exposed to caustic solution for 24 days. 


\subsubsection{Exposure for 44 Days (Beaker No. 1)}

The actual exposure time for specimens in the caustic solution was 44 days, or more precisely, 1039 hours. The test temperature was at least $125{ }^{\circ} \mathrm{C}$. The pre- and postexposure photographs of the specimens are placed side-by-side for comparison (Figs. 2729). The outer side of the U-bend (tensile side) is shown below along with the inner side (compressive), although SCC is unlikely under compressive stress.

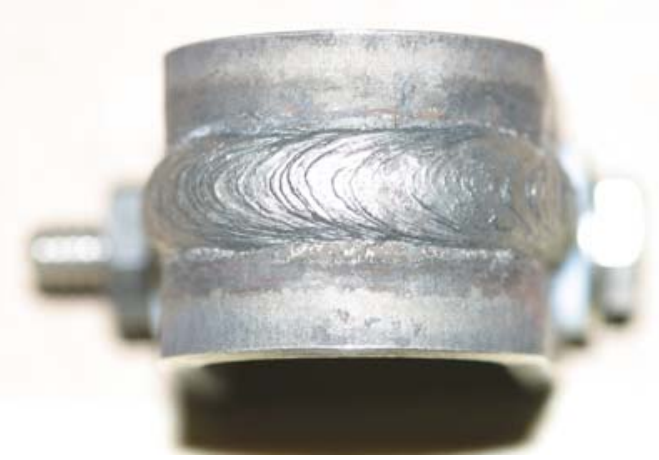

(a) Tensile side of U-bend before exposure

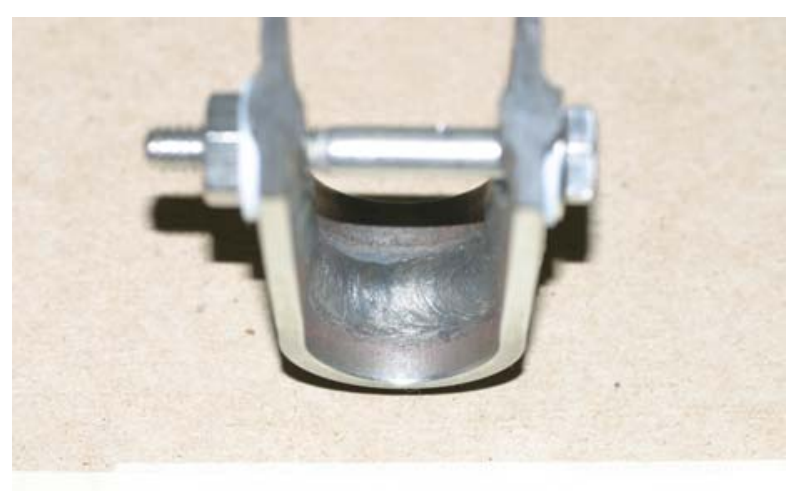

(c) Compressive side of U-bend before exposure

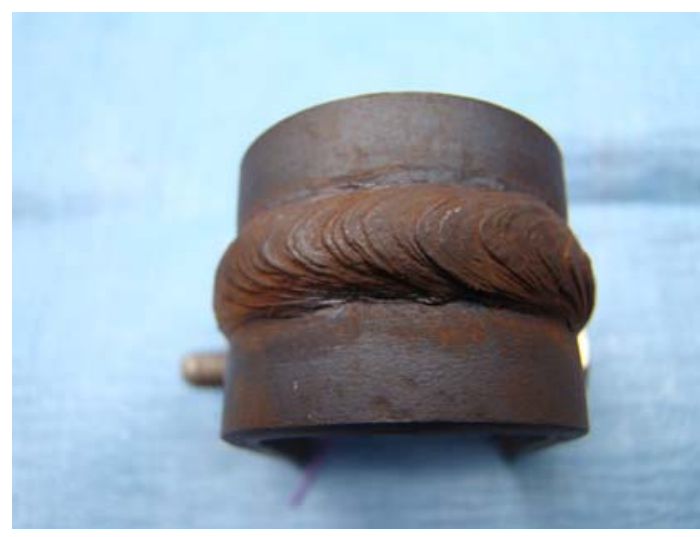

(b) Tensile side of U-bend after exposure

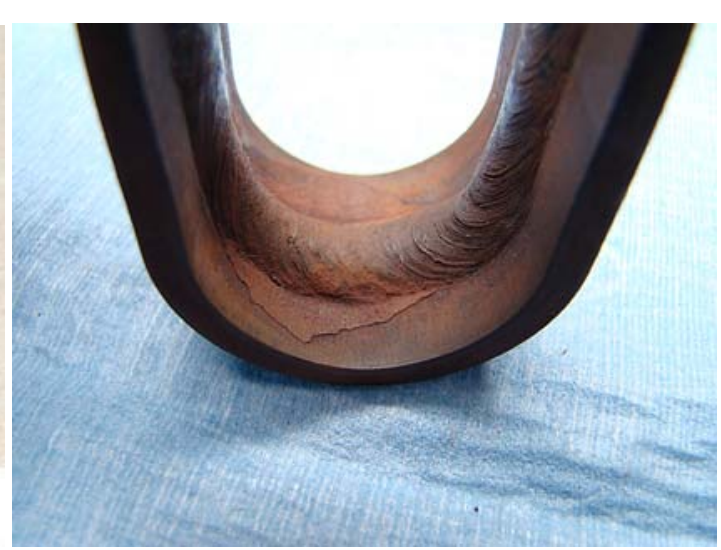

(d) Compressive side of U-bend after exposure

Figure 27 As-welded Specimen No. 248 exposed to caustic solution for 44 days. 


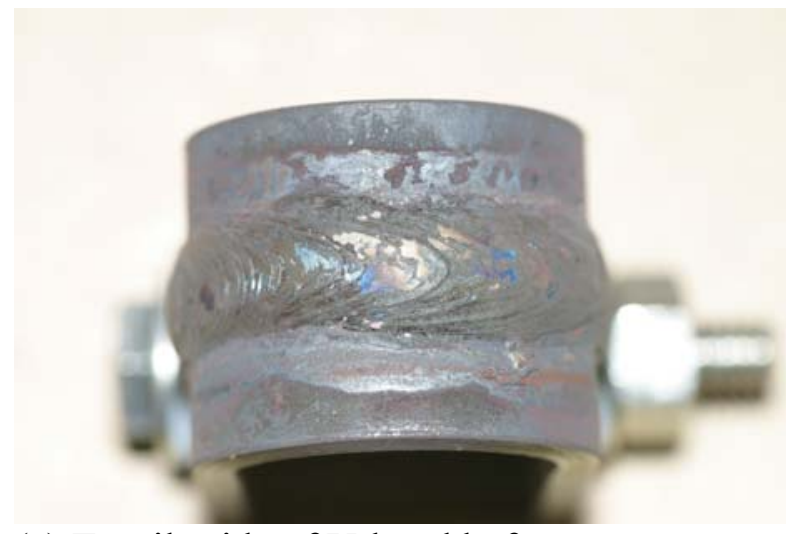

(a) Tensile side of U-bend before exposure

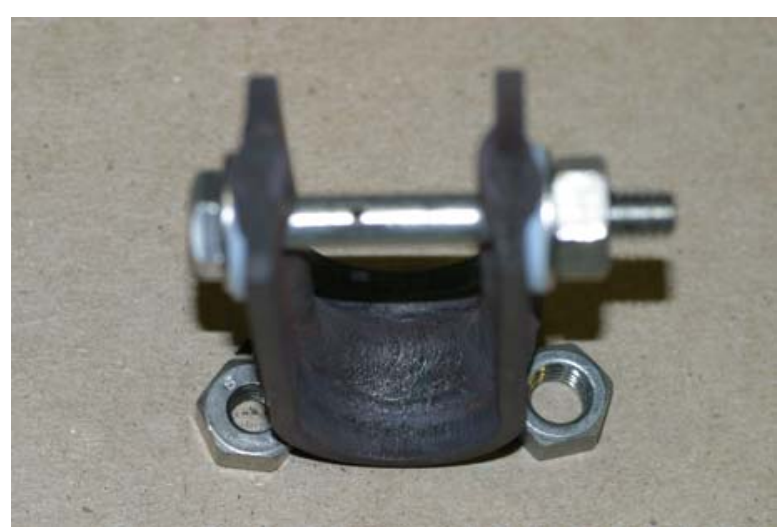

(c) Compressive side of U-bend before exposure

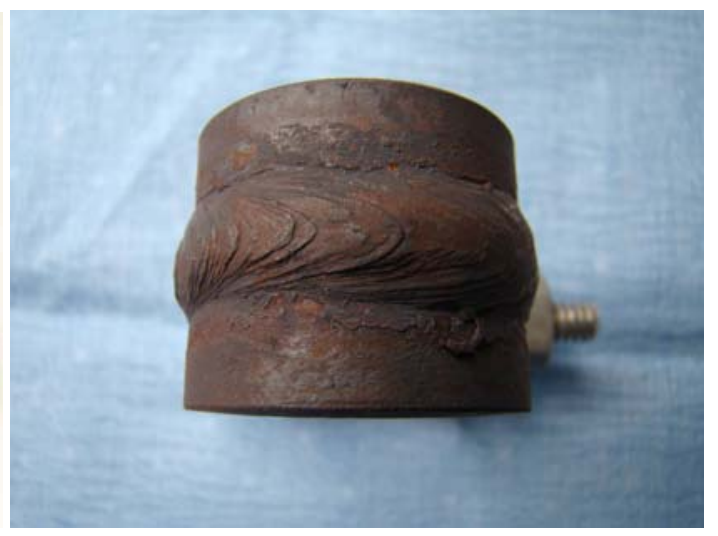

(b) Tensile side of U-bend after exposure

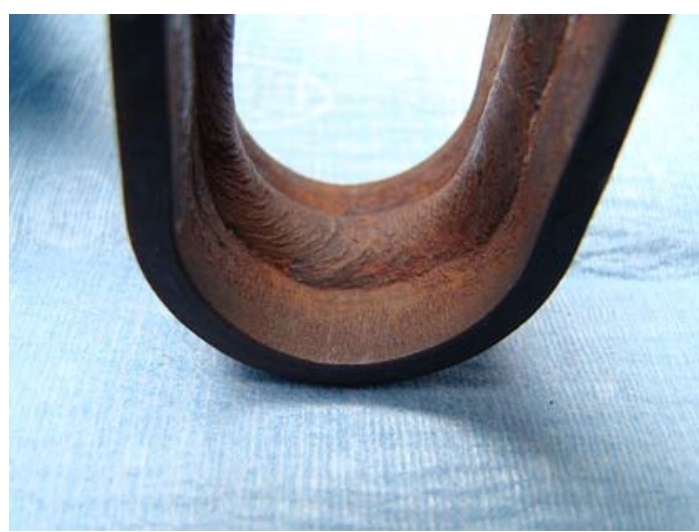

(d) Compressive side of U-bend after exposure

Figure 28 Heat-treated Specimen No. 242 exposed to caustic solution for 44 days.

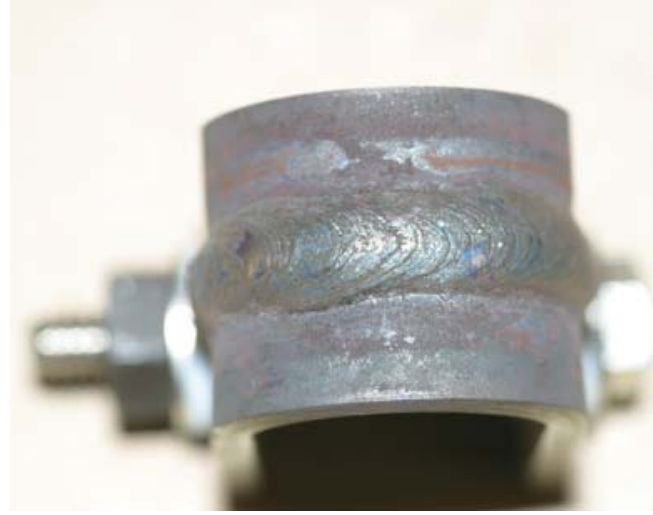

(a) Tensile side of U-bend before exposure

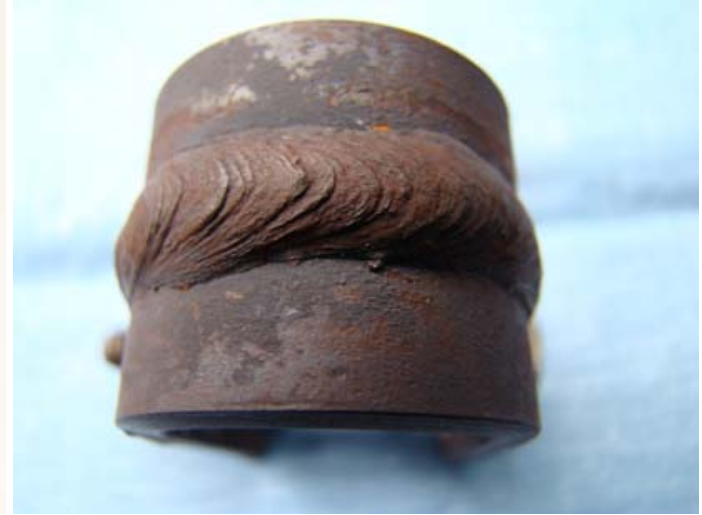

(b) Tensile side of U-bend after exposure 


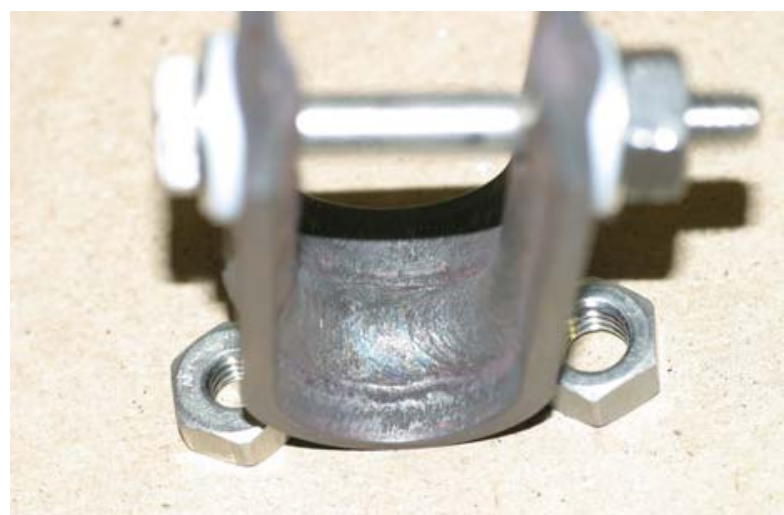

(c) Compressive side of U-bend before exposure

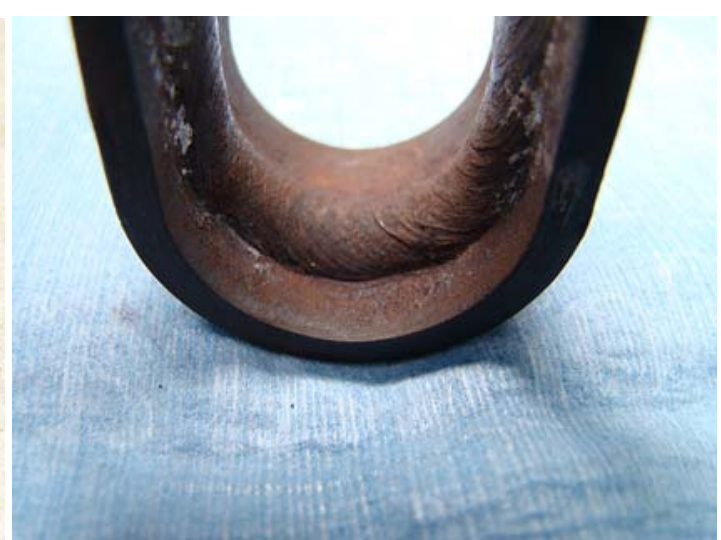

(d) Compressive side of U-bend after exposure

Figure 29 Heat-treated Specimen No. 244 exposed to caustic solution for 44 days.

\subsubsection{Exposure for 95 Days (Beaker No. 2)}

The actual exposure time for specimens in the caustic solution was 95 days, or more precisely, 2255 hours. The test temperature was at least $125{ }^{\circ} \mathrm{C}$. The pre- and postexposure photographs of these specimens are placed side-by-side for comparison (Figs. 30-32). Both the outer side of the U-bend (tensile side) and the inner side (compressive) are reported. Although cracking is unlikely on the compressive stress field; the result is included in this section for completeness.

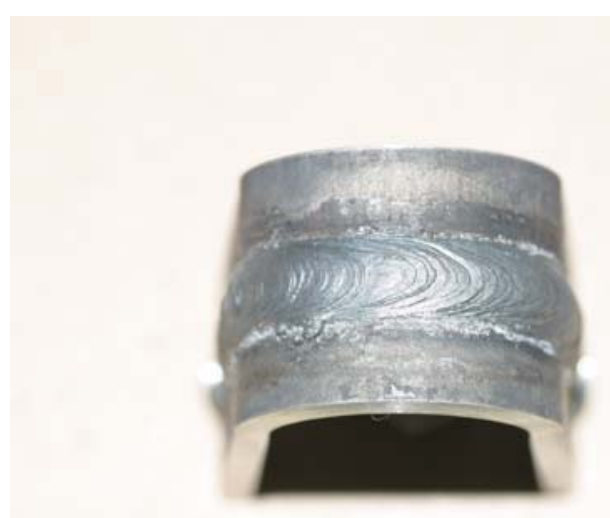

(a) Tensile side of U-bend before exposure

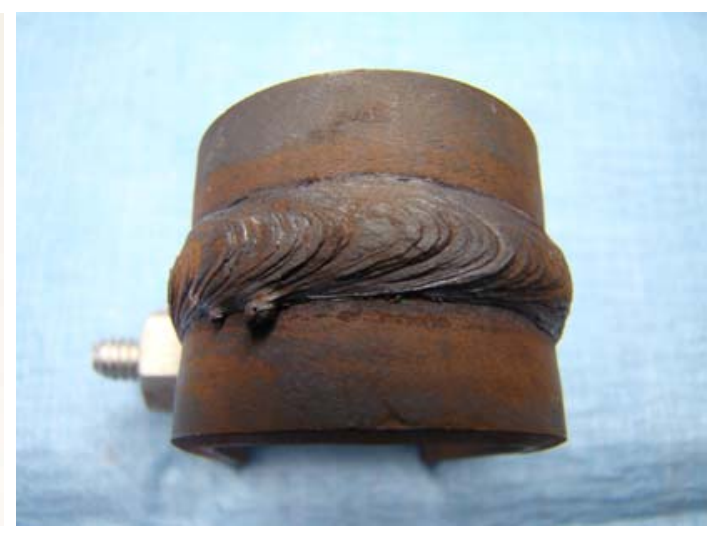

(b) Tensile side of U-bend after exposure 


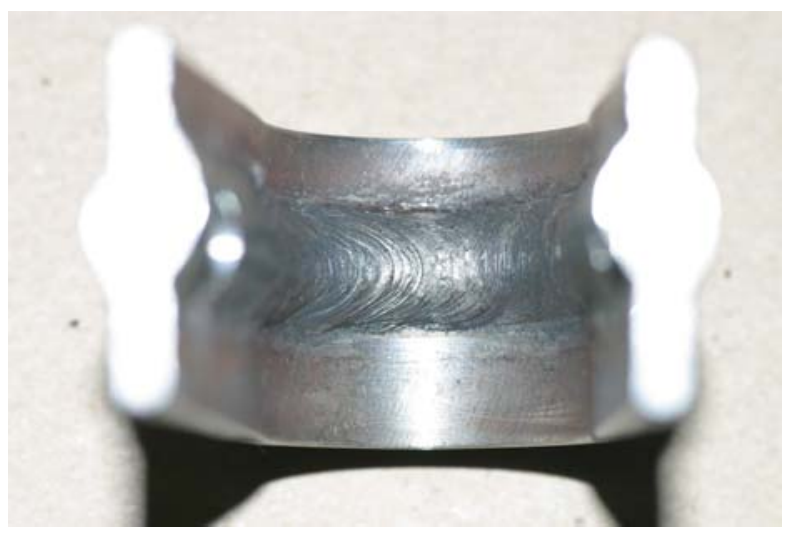

(c) Compressive side of U-bend before exposure

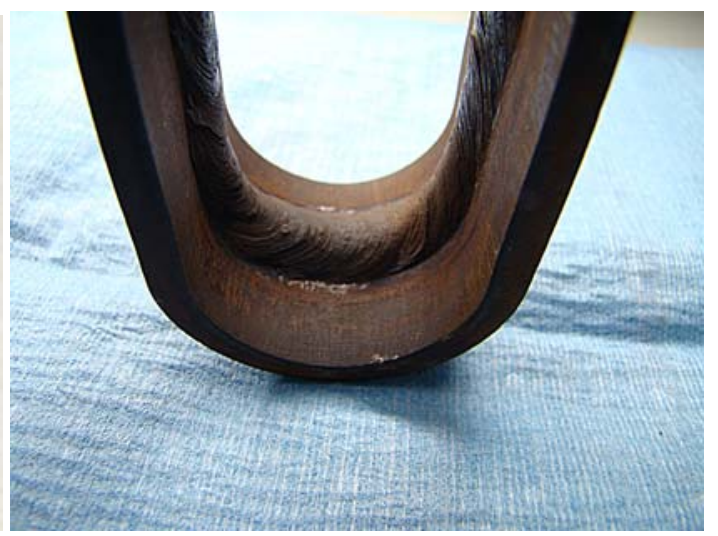

(d) Compressive side of U-bend after exposure

Figure 30 As-welded Specimen No. 245 exposed to caustic solution for 95 days.

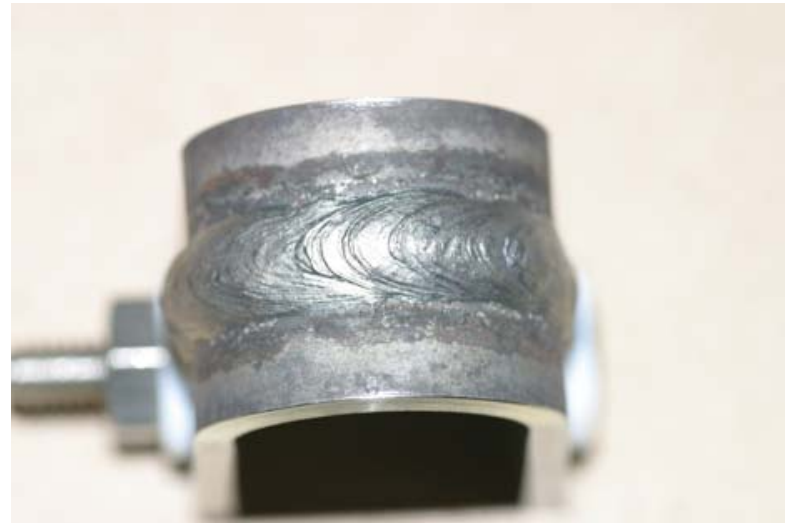

(a) Tensile side of U-bend before exposure

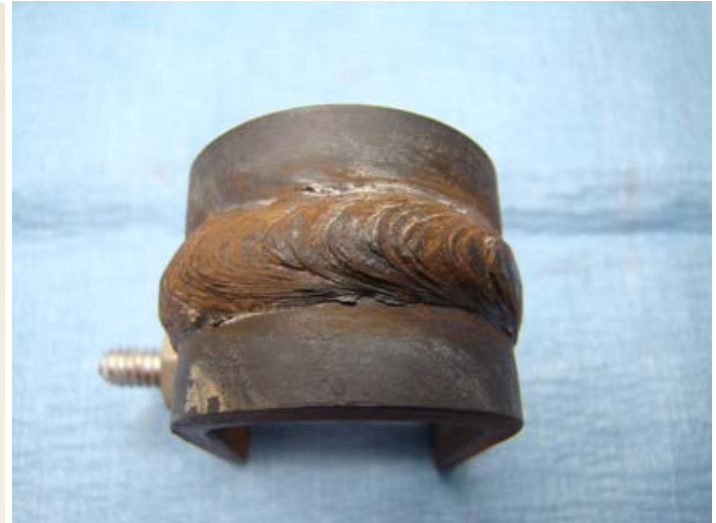

(b) Tensile side of U-bend after exposure

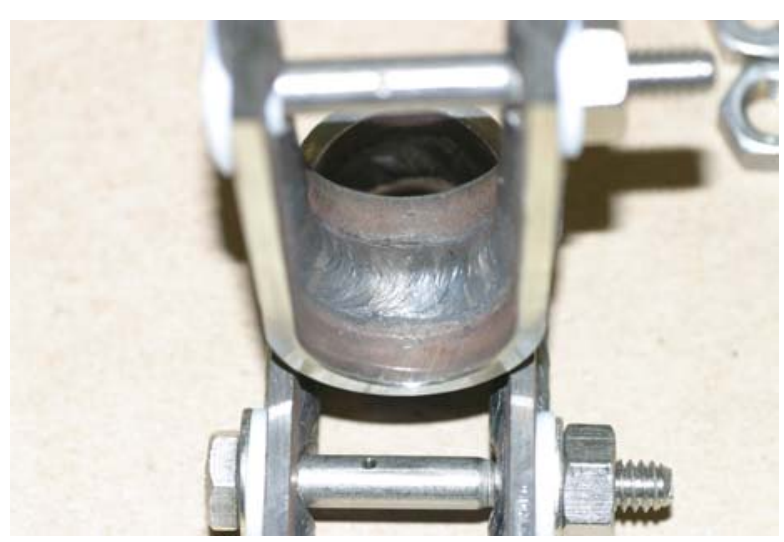

(c) Compressive side of U-bend before exposure

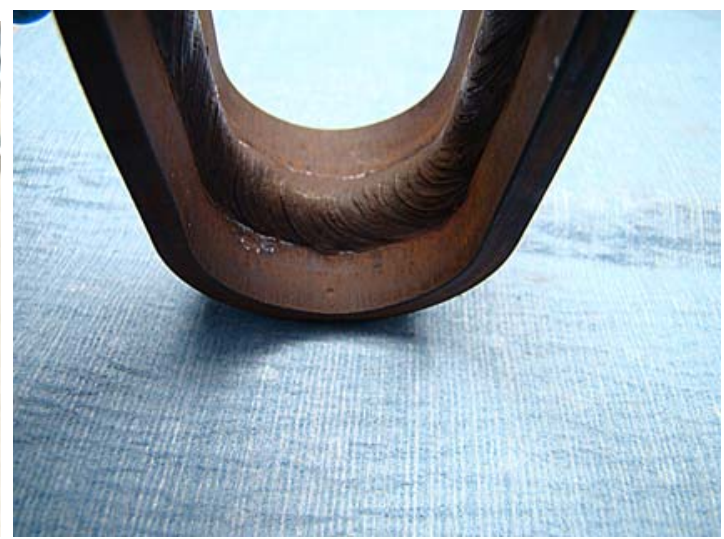

(d) Compressive side of U-bend after exposure

Figure 31 As-welded Specimen No. 247 exposed to caustic solution for 95 days. 


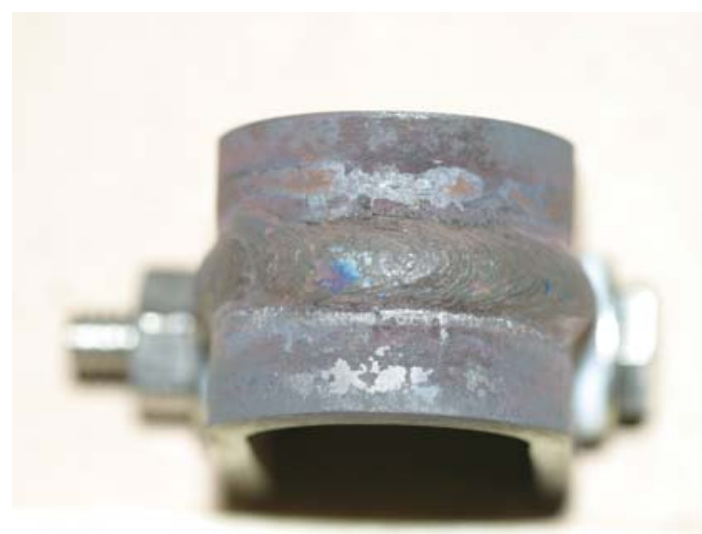

(a) Tensile side of U-bend before exposure

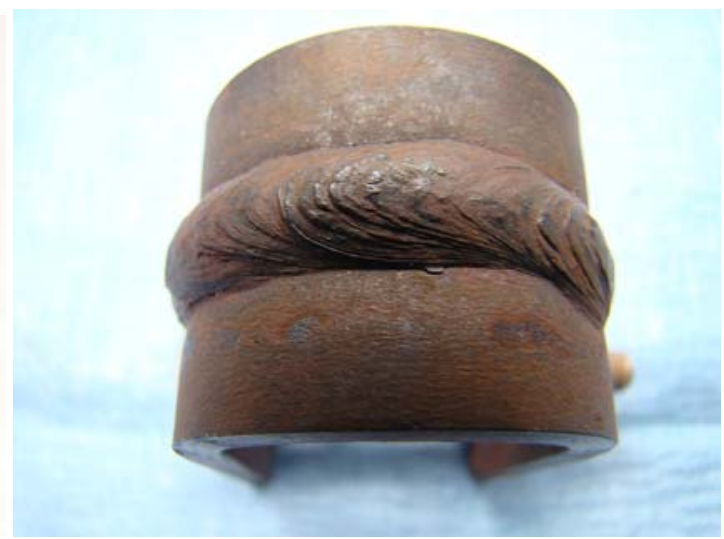

(b) Tensile side of U-bend after exposure

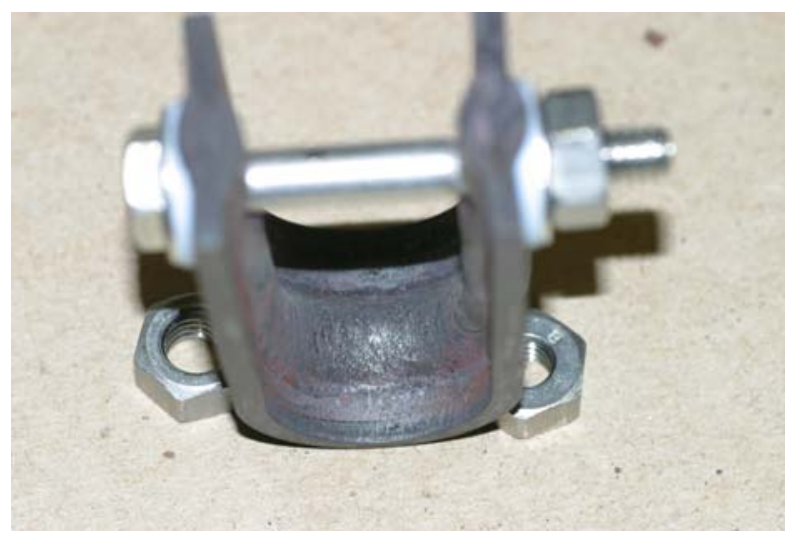

(c) Compressive side of U-bend before exposure

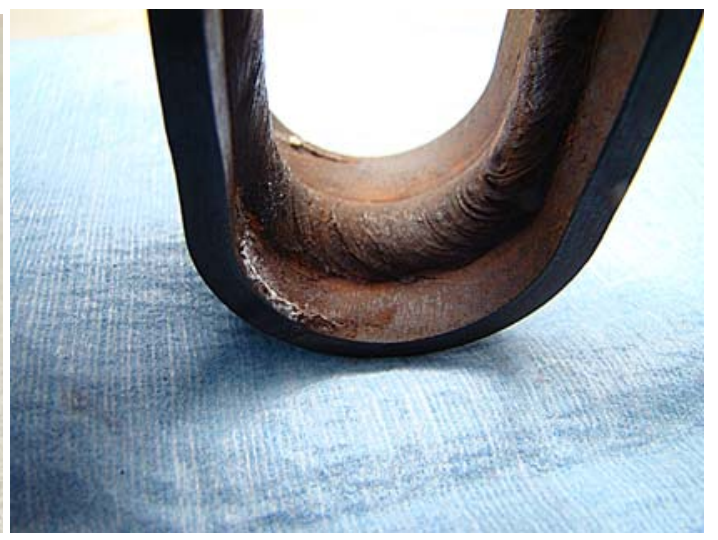

(d) Compressive side of U-bend after exposure

Figure 32 Heat-treated Specimen No. 243 exposed to caustic solution for 95 days.

\subsection{Large Plate Interim Test Results}

The large plates are to remain for 12 weeks in the caustic solution at $125{ }^{\circ} \mathrm{C}$. The experimental station has been in operation since July 14, 2009. No stress corrosion cracking has been found either in the as-welded plate or in the stress relieved/heat treated plate. The pre- and post-exposure photographs are placed side-by-side for comparison purpose. Both the front side and the back side of the plates are shown in Figures 33-34. Nine (9) machined seed cracks are visible on the front side of the plate as schematically shown earlier in Figure 14 and in the photographs on the next two pages: V1, V2, and V3 are through-the-plate cracks and are across the width of the weld (vertical cracks); V4, V5, and V6 are also vertical cracks (perpendicular to the weld) but they are partly through plate (thumbnail) cracks in the HAZ; and P1, P2, and P3 are part-through plate (thumbnail) cracks parallel to the weld and in the HAZ. On the back side of each plate, only three through-the-plate cracks are visible. 


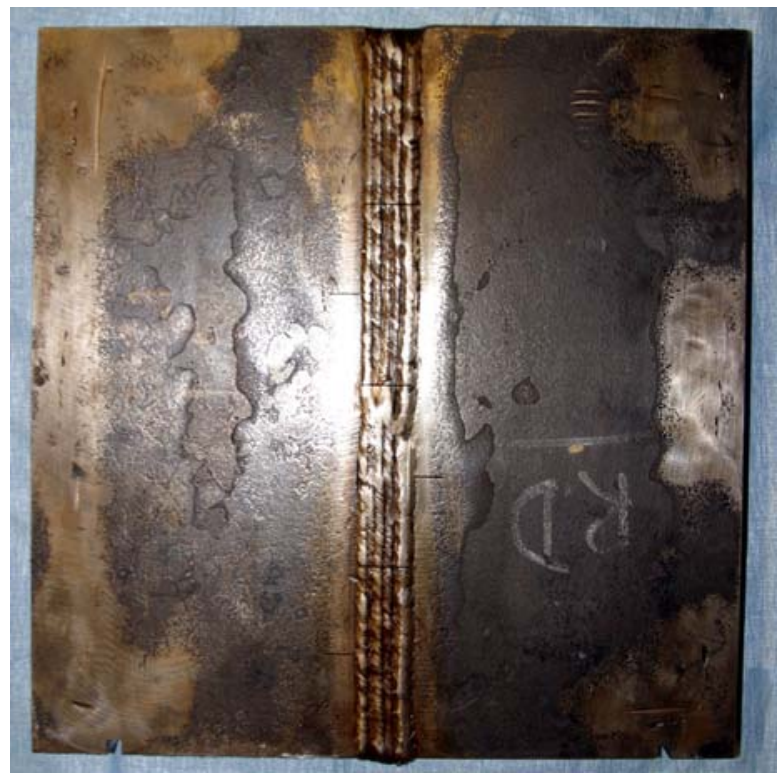

(a) Front side before exposure

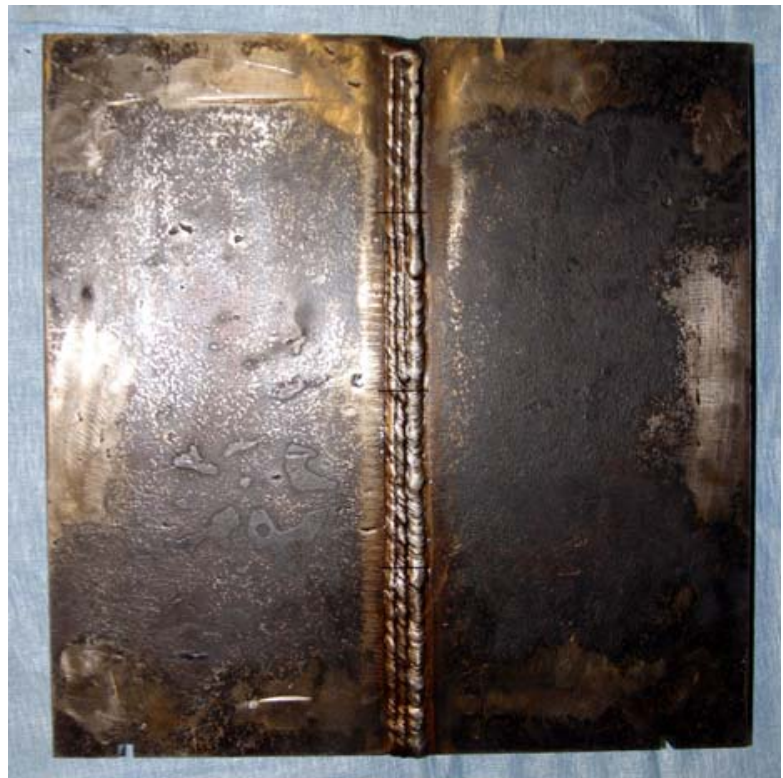

(a) Back side before exposure

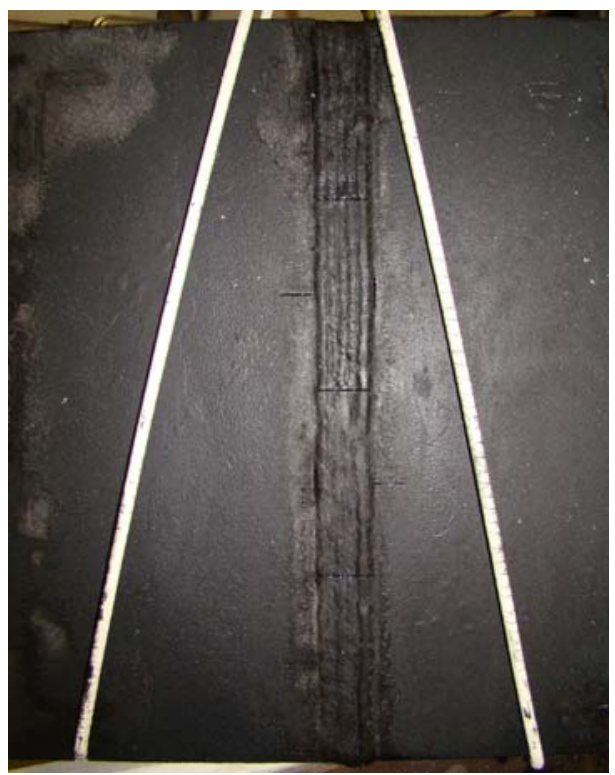

(b) Front side after exposure

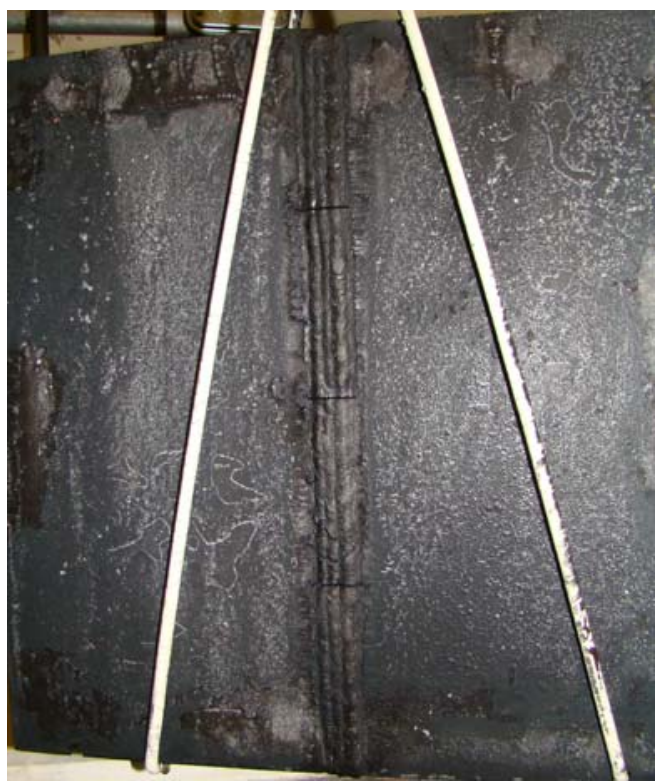

(b) Back side after exposure

Figure 33 As-welded plate before and after exposure for 9 weeks. 


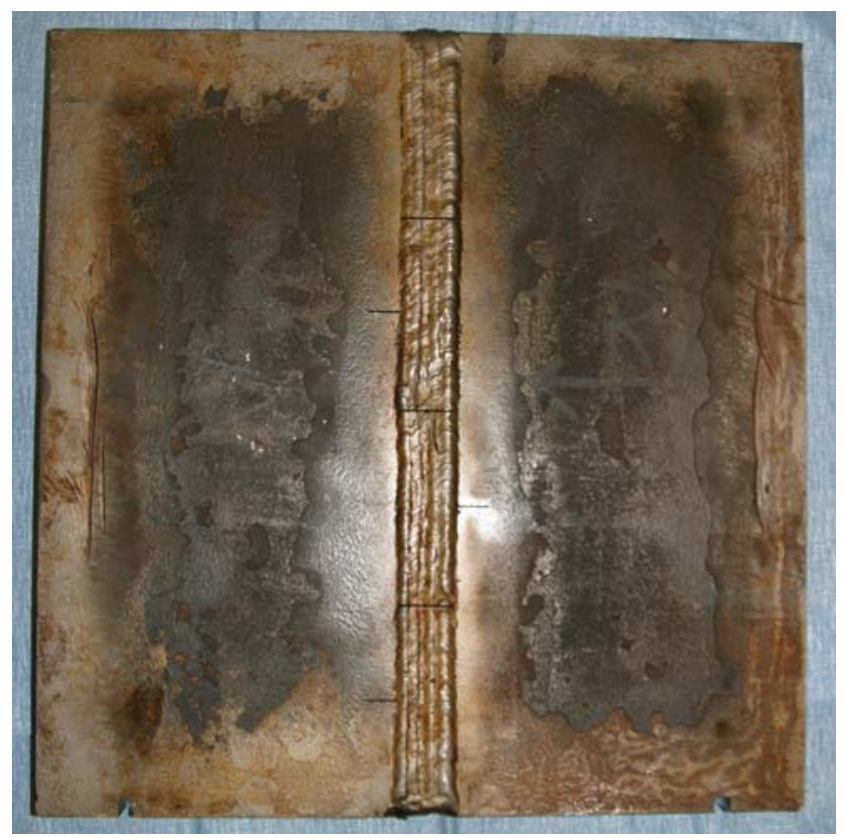

(a) Front side before exposure

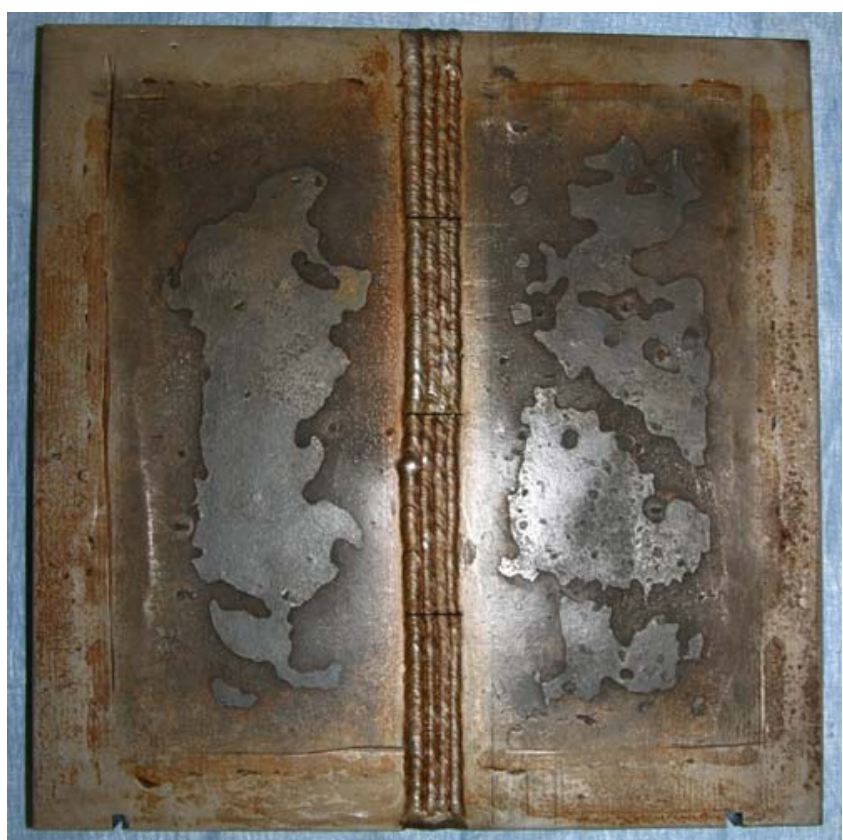

(a) Back side before exposure

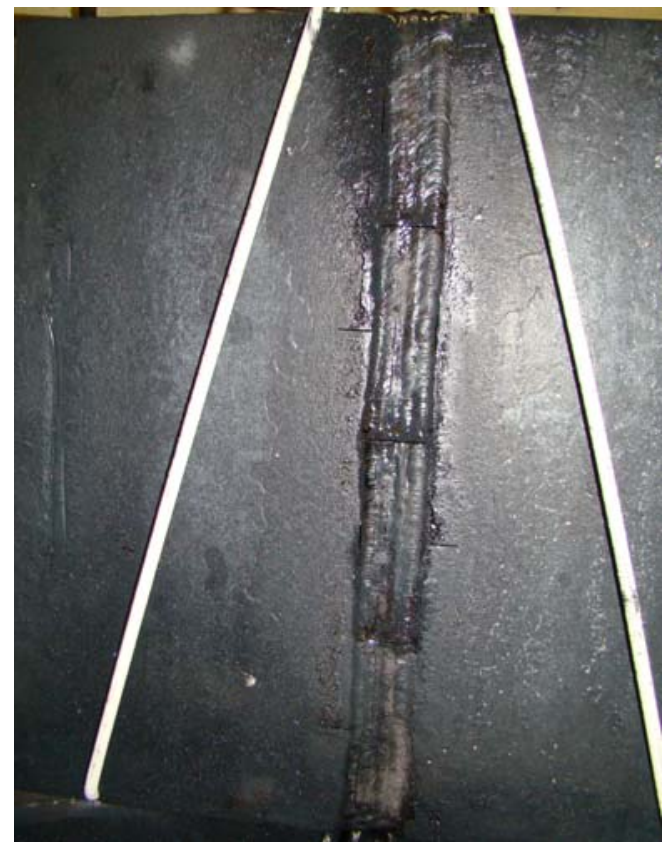

(b) Front side after exposure

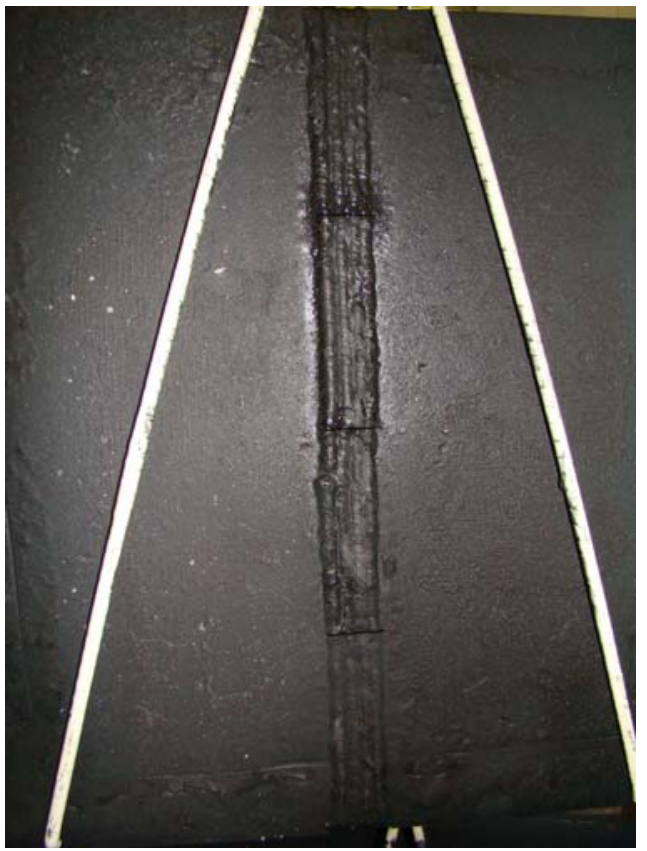

(b) Back side after exposure

Figure 34 Heat-treated plate before and after exposure for 9 weeks 


\section{CONCLUSIONS}

Based on the present observation, stress corrosion cracking of A537 carbon steel did not take place in the high temperature $\left(125^{\circ} \mathrm{C}\right)$ caustic solution, which was composed of $12 \mathrm{M}$ hydroxide, and $1 \mathrm{M}$ each of nitrate, nitride, and aluminate (in the case of large plate test, the aluminate concentration is $0.3 \mathrm{M}$ ). The actual temperature of the solution during the tests might be slightly higher than the target temperature of $125^{\circ} \mathrm{C}$ but it was below the boiling point. The lack of caustic stress corrosion cracking indicates that the inhibitors, such as $\left[\mathrm{OH}^{-}\right]$and $\left[\mathrm{NO}_{2}^{-}\right]$, maintain their adequate levels even when the solution temperatures are much higher than that specified in the waste tank corrosion control program. It is also possible that the oxygen solubility under this chemistry condition remains sufficient to form protective films on freshly exposed surfaces of A537 carbon steel, in particular, the Clarke's solution-treated crack tips on which the oxide was just removed immediately before immersion. These mechanistic details may be addressed and resolved by electrochemical testing.

\section{PATH FORWARD}

The large plate test is scheduled to be completed in early October 2009. The post-test nondestructive evaluation of the plates will be performed to detect the internal cracking with ultrasonic testing (UT), and the very fine surface cracks initiated from the seed cracks with magnetic particle testing (MT). Fracture toughness for stress corrosion cracking, $\mathrm{K}_{\mathrm{ISCC}}$, should be measured with fracture mechanics specimens if stress corrosion cracking indeed occurs. This will allow the safety margins for operating the nuclear waste tanks be assessed with structural integrity methodologies.

\section{ACKNOWLEDGMENTS}

The U-bend experimental station was designed, assembled and maintained by Mr. Craig S. Stripling. The large plate test tank assembly was designed, constructed, and maintained by Mr. Donald L. Fisher and was operated by Mr. Stripling. Their contributions are essential to the success of the CSCC experimental project. Ms. Tina M. Stefek provided her experience on the safety and controls in the large plate testing for nitrate stress corrosion cracking, which we carried out from 2002 to 2004 for A285 carbon steel nuclear waste tanks. Ms. Robbie S. Garritano's assistance in mixing the test solutions and miscellaneous laboratory tasks is greatly appreciated. Thanks also go to Drs. John I. Mickalonis and Bruce J. Wiersma for their technical advice and continuing encouragements. 


\section{REFERENCES}

[1] K. H. Subramanian and B. J. Wiersma, "Stress Corrosion Cracking Susceptibility of High Level Waste Tanks Exposed to Evaporator Recycle Waste," WSRC-TR-2008-00192, June 2008, DRAFT.

[2] B. J. Wiersma, "Determination of Temperature Limits for Radioactive Waste Tanks," WSRC-TR-98-00131, June 1999.

[3] K. H. Subramanian and J. I. Mickalonis, "Anodic Polarization Behavior of Low-Carbon Steel in Concentrated Sodium Hydroxide with Sodium Nitrate Additions," WSRC-TR-2004-00292, October 2004.

[4] K. H. Subramanian and J. I. Mickalonis, "Anodic Polarization Behavior of Low-Carbon Steel in Concentrated Sodium Hydroxide and Sodium Nitrate Solutions," Electrochimica Acta, Vol. 50, pp. 2685-2691, 2005.

[5] P.-S. Lam, C. Chang, Y. J. Chao, R. L. Sindelar, T. M. Stefek, and J. B. Elder, III, "Stress Corrosion Cracking of Carbon Steel Weldments," PVP2005-71327, Proceedings of ASME Pressure Vessels and Piping Conference, Denver, Colorado, 2005.

[6] P.-S. Lam, "Dependence of Intergranular Stress Corrosion Cracking on Weld Residual Stress," SRTC Strategic R\&D (sponsored by the WSRC High Level Waste Division), 2002.

[7] W. G. Reuter, F. A. McClintock, and P.-S. Lam, "Increasing Safety and Reducing Environmental Damage Risk from Aging High-level Radioactive Waste Tanks," U. S. Department of Energy Office of Science, Environmental Management Science Program (EMSP), 2002-2004.

[8] B. J. Wiersma, "An Assessment of the Service History and Corrosion Susceptibility of Type IV Waste Tanks," SRNS-STI-2008-00096, September 2008.

[9] W. B. DeLong to S. P. Rideout, "Properties of A516-70 Steel Used in Waste Tanks 29-32", September 10, 1974.

[10] W. B. Delong to R. G. Garvin, "FY '74 Waste Tanks Proj. 1463", August 6, 1975.

[11] B. J. Wiersma, "Re: Task Plan for the Determination of Corrosion Inhibitor Criteria for Type III/IIIA Tanks During Salt Dissolution Operations," SRNLMTS-2005-50019, August 10, 2005.

[12] J. K. Thomas, "Failure Strain and Mechanical Property Data for the Type IIIA Waste Tanks Liners", WSRC-RP-92-859, June 1992.

[13] J. A. Donovan and R. S. Ondrejcin to A. A. Kishbaugh, "Relative Resistance to Nitrate Cracking of A537 Class I and A516 Grade 70 Normalized Steels", WSRC-RP-2004-00198, March 23, 1977.

[14] B. J. Wiersma and J. I. Mickalonis, "Determination of Corrosion Inhibitor Criteria for Type III/IIIA Tanks during Salt Dissolution Operations," WSRC-STI-200600029, September 2007.

[15] B. J. Wiersma, "Waste Management Experimental Programs," WSRC-NB-9900247, Laboratory Notebook, pp. 59-77, 1997.

[16] R. J. Landrum, "Analysis of Stress Relief Heat Treatment of Waste Storage Tanks," Materials Engineering - \#950974-10, May 21, 1969. 
[17] BFF 211620 "Nooter Corporation High Level Waste Storage Tanks, Primary Knuckle Assemblies," E. I. Du Pont Nemours Co., Wilmington, DE, Job No. D4600, Sheet 17 of 18, January 10, 1968. 


\section{APPENDICES}

APPENDIX 1 Material Certificate of A537 for U-bend Specimens

APPENDIX 2 Material Certificate of A537 for Large Plate Specimens

APPENDIX 3 Certificate of Welding Electrodes for U-bend Specimens

APPENDIX 4 Welding Procedure for SRS Type III High Level Nuclear Waste Storage Tanks

APPENDIX 5 Certificate of Welding Electrodes EM 70S-2 for Large Plate Specimens

APPENDIX 6 Certificate of Welding Electrodes E-7018 for Large Plate Specimens APPENDIX 7 Welding Parameters for the As-welded Plate APPENDIX 8 Welding Parameters for the Heat-Treated Plate 
APPENDIX 1

Material Certificate of A537 for U-bend Specimens

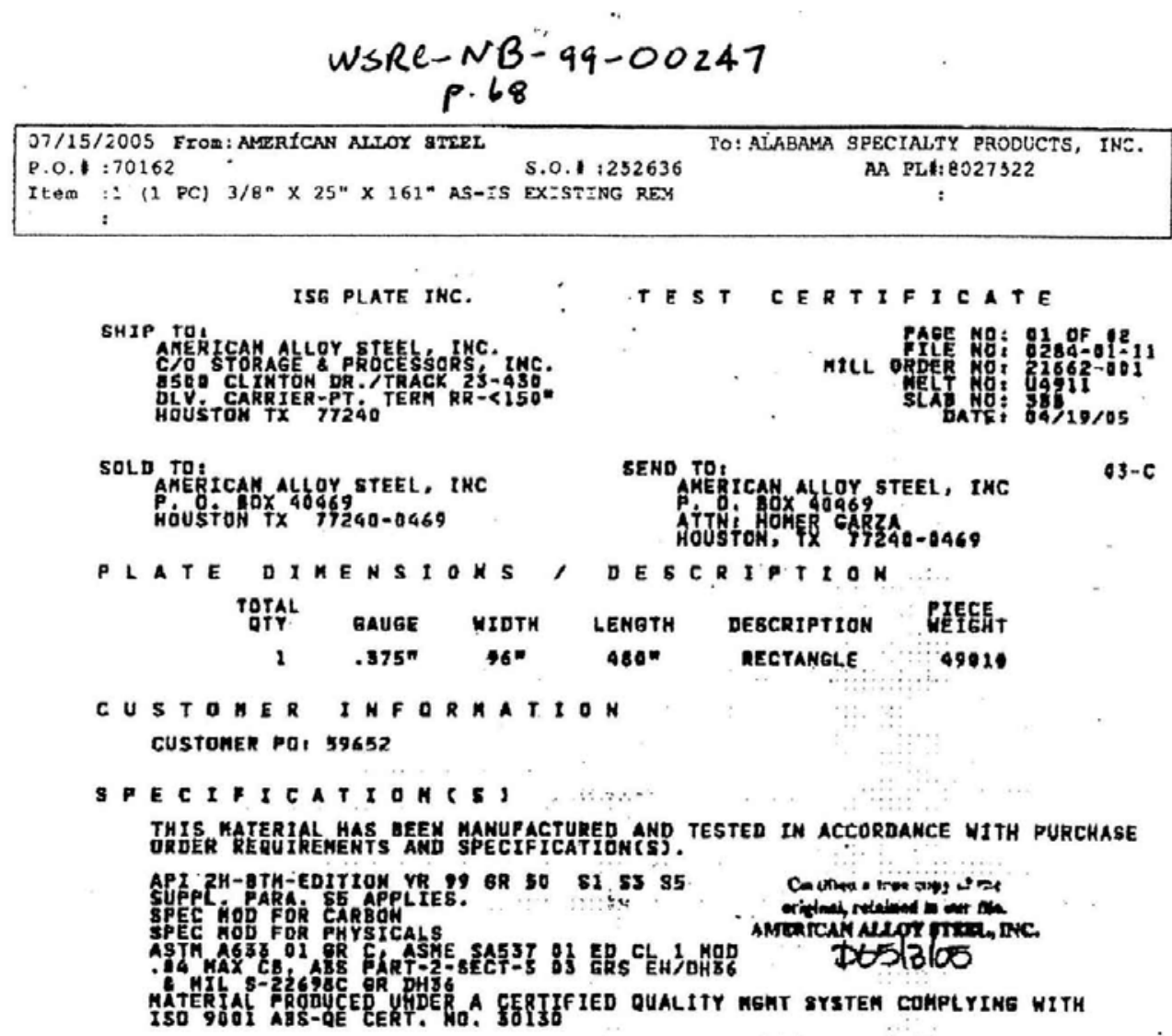

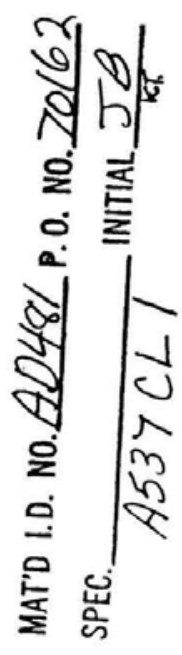

CHEMICAL CONPOSITION

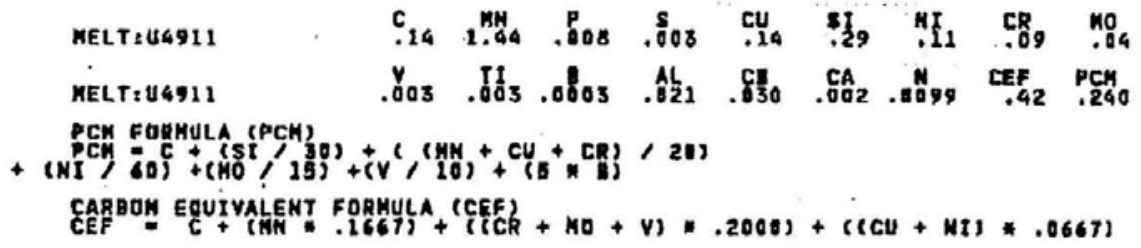




\section{Appendix 1 (continued)}

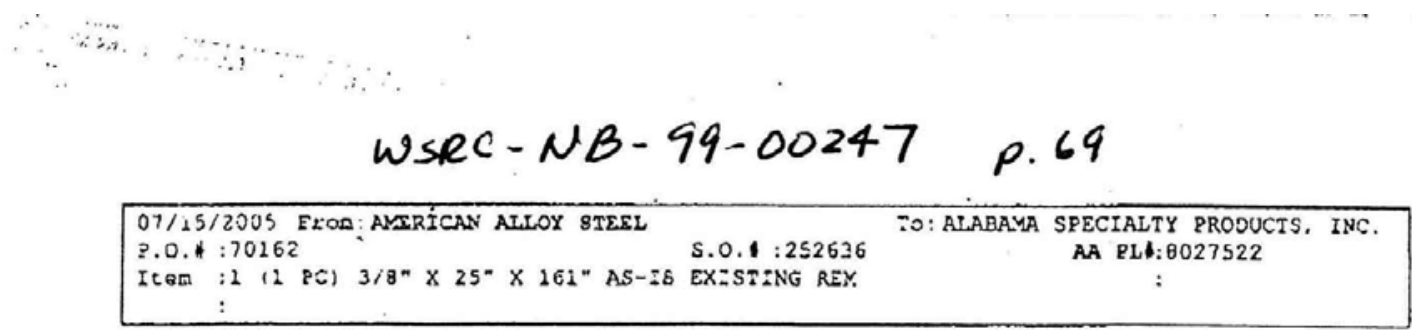

TENSILE PROPERTIES

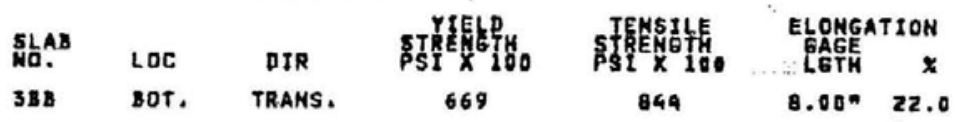

CHARPY V-NOTCH IMPACT RESULTS

$$
\begin{array}{llllllll}
\text { SLAY LOC NIR } & \text { TEMP } & \text { SIZE } & \multicolumn{2}{c}{\text { FT. LAS. }} \\
\text { 38B } & \text { BOT. TRANS. } & \text {-4OF } & 3 / 4 & 46 & 49 & 53
\end{array}
$$

GENERAL INFORNATION

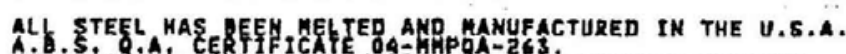

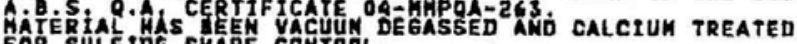

FORELINIDE SHAPE COMTRL.

TEST CEETS ARE RREPA AER IN ACCORE MITH PROCEDURES

8/L 175657 TTPX 804066

Cortitien a trew copy ot to

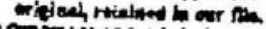

AMERICAM ALLOt intes, NiC.

\section{ME HERERY CERTIEY THE ABOVE \\ QUALETY ASSURANCE ${ }_{1}$ GBBORATORY}

$\therefore: \ldots>2.1$.

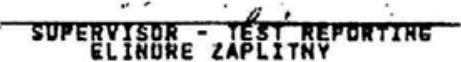




\section{APPENDIX 2}

Material Certificate of A537 for Large Plate Specimens

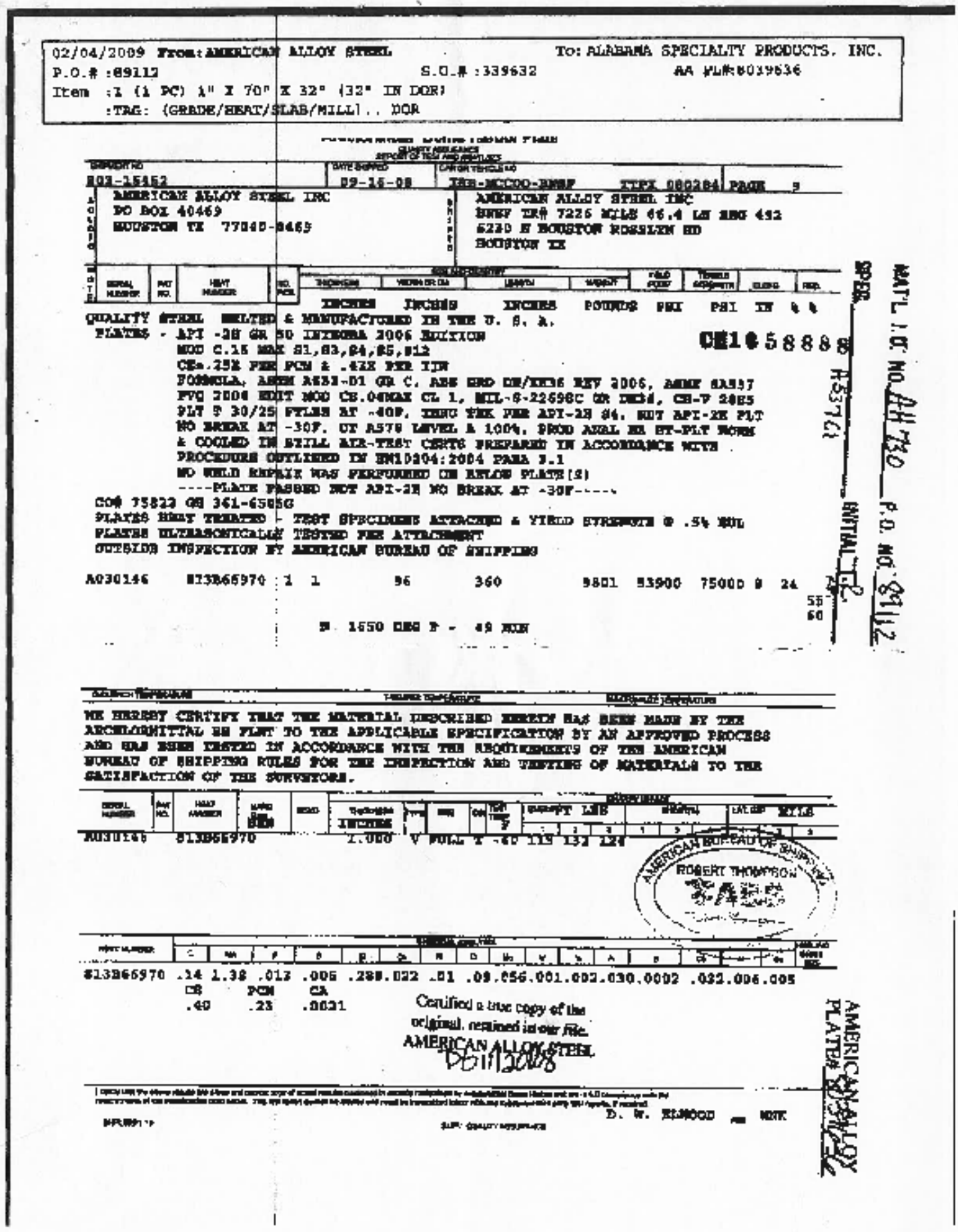




\section{APPENDIX 3 \\ Certificate of Welding Electrodes for U-bend Specimens}

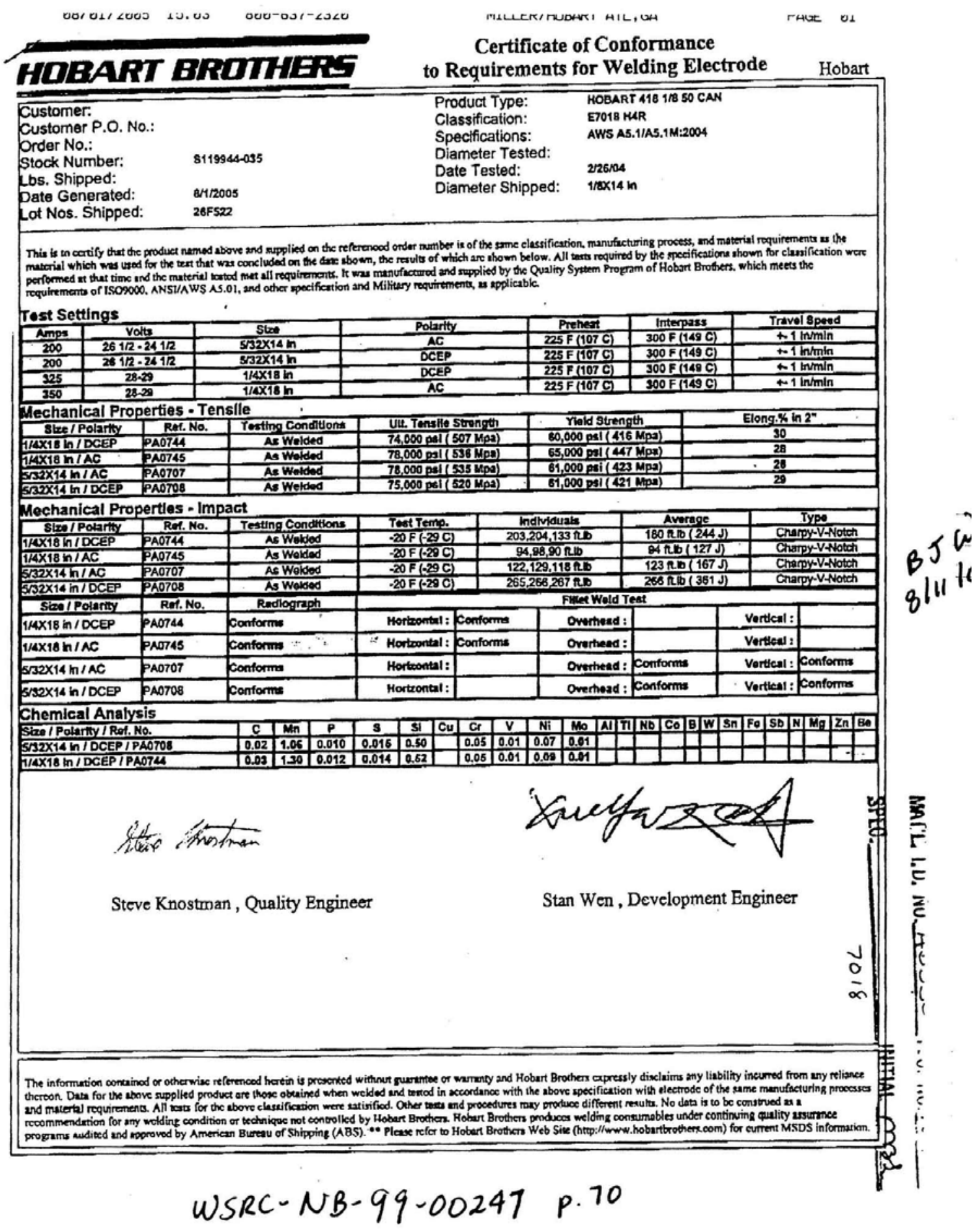




\section{APPENDIX 4}

Welding Procedure for SRS Type III High Level Nuclear Waste Storage Tanks

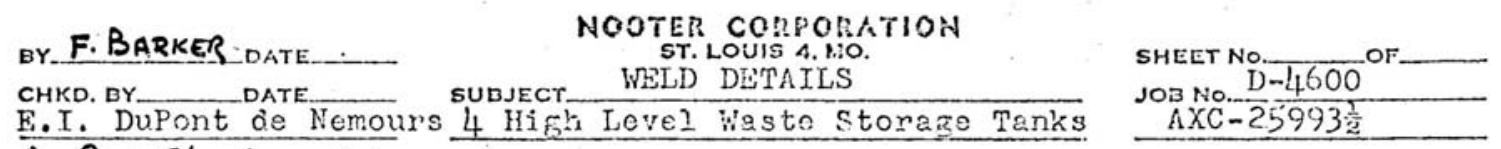

$\Delta R_{E V} .9 / 22 / 67$ G.L.

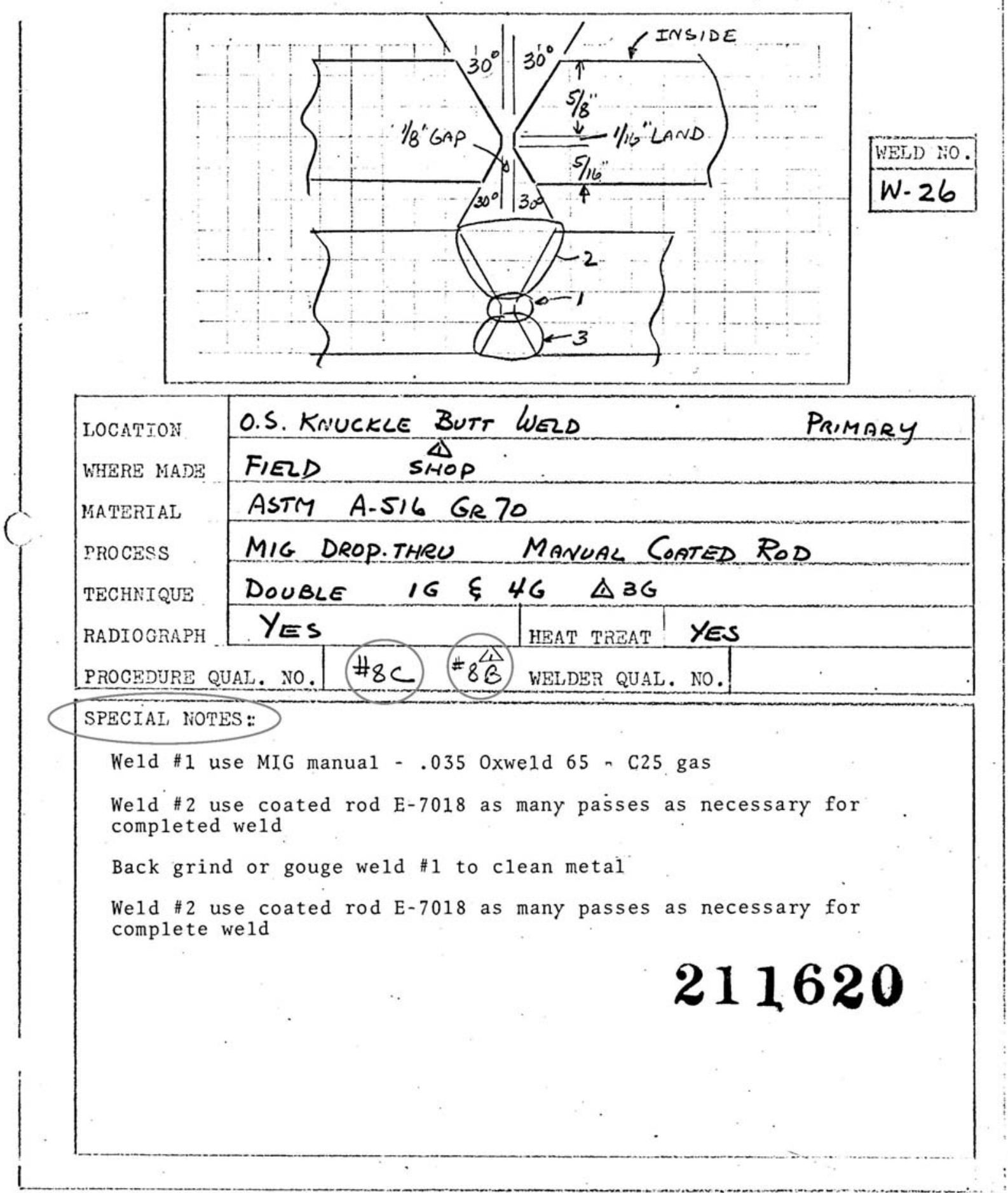




\title{
Appendix 4 (continued)
}

\author{
D-14600 - Procedure Qualification \#8B
}

HEC. NO. $1-1-41$

Re-Issue Date5/18/66

\section{NOOTER CORPORATION \\ WELDING PROCEDURE SPECIFICATION AND QUALIFICATION RECORD}

On work performed under the A.S.M.E. Code, the welding procedure to be used in fabrication and the qualification of this procedure shall be in strict conformance with the Code. The information furnished is required by Section IX of the A.S.M.E. Boiler and Pressure Vessel Code. (References to Paragraphs and Tables in any of the following statements refer to those in Section IX of the A.S.M.E. Boiler and Pressure Vessal Code.)

Procedure Specification for METAL INERT GAS AND MANUAL METALLIC ARC WELDING OF P-1 MATERIALS

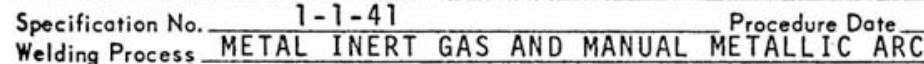
Material A-2 2 GR B to A-212 GR B of P.No. Thickness (if pipe, diameter and wall thickness) FILLER METAL Describe Filler Metal if 65 included in Table Q-11.2
or QN-11.2

Filler Metal Group No. F . Weld Metal Analysis No. A

\section{4} or QN-11.2

\section{WELDING PROCEDURE AND TECHNIQUES}

Single or Multiple Pass $\quad$ MULT I PLE $\quad$ Single or Multiple Arc Position of Groove 3-G(VERTICAL) Is Backing Strip Used? N0 Preheat Temperature Range ROOM TEMPERATURE (APPROXIMATELY $70^{\circ} \mathrm{F}$.) Postheat Treatment IIOO-1200 $\mathrm{F}$. HOLD ONE HOUR AND FURNACE COOL Joint dimensions accord with succeeding sketches

REDUCED SECTION TENSILE TEST

\begin{tabular}{|c|c|c|c|c|c|c|}
\hline \multirow{2}{*}{$\begin{array}{c}\text { SPECIMEN } \\
\text { NO. }\end{array}$} & \multicolumn{2}{|c|}{ OIMENSIONS } & \multirow{2}{*}{ AREA } & $\begin{array}{c}\text { ULTIMATE } \\
\text { TOTAL. LE. }\end{array}$ & $\begin{array}{c}\text { ULTIMATE } \\
\text { STRENGTH, PSI. }\end{array}$ & $\begin{array}{c}\text { CHARACTER } \\
\text { OFFFALURE } \\
\text { ANOLOCATION }\end{array}$ \\
\cline { 2 - 7 } & WIOTH & THICKNESS & & & PLATE \\
\hline & 1.494 & .853 & 1.274 & 96,200 & 75,600 & PLATE \\
\hline & 1.497 & .849 & 1.271 & 96,400 & 75,900 & PLATE \\
\hline
\end{tabular}

ALL WELD METAL TENSION TEST

\begin{tabular}{|l|l|l|l|l|l|}
\hline DIAMETER & AREA & YIELD, PSI & ULTIMATE STRENGTH. PSI. & FELONGATION & FRACTURE \\
\hline & & & & & \\
\hline
\end{tabular}

BEND TESTS

ADDITIONAL TESTS

\begin{tabular}{|c|c|c|c|}
\hline TYPE & RESULTS & TYPE & RESULTS \\
\hline 4 SIDE & ACCEPTABLE & & \\
\hline & & & \\
\hline
\end{tabular}

Welder's Name C. BOYER Clock No. 541 Test Conaucted by NOOTER CORPORATION Laboratory-Test No..._ B-101 We certify that the statements in this record are correct and thet the test welds were weided in accordance witi this prosedure and tested in occordance with the requirements of Section IX of the Cods.

Procedure Qualification Date MARCH 18, 1964 Signed NOOTER CORPCRATION Ih

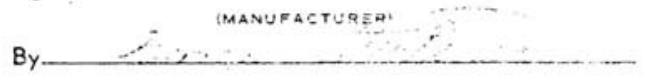




\section{Appendix 4 (continued)}

D-4600 Proct dre Qualification \#8C

Re.-Issue Date $5 / 18 / 66$

\section{NOOTER CORPORATION}

\section{WELDING PROCEDURE SPECIFICATION AND QUALIFICATION RECORD}

On work performed under the A.S.M.E. Code, the welding procedure to be used in fabrication and the qualification of this procedure shall be in strict conformance with the Code. The information furnished is required by Section IX of the A.S.M.E. Boiler and Pressure Vessel Code. (References to Paragraphs and Tables in any of the following statements refer to those in Soction IX of the A.S.M.E. Boiler and Pressure Vessel Code.)

Procedure Specification for METAL INERT GAS AND MANUAL METALLIC ARC WELOIHG OF P-1 MATERIALS Specification No. $\frac{1-1-41}{1-19}$ Procedure Date MARCH 18, 1964 Welding Process METAL INERT GAS AND MANUAL METALLIC ARC Material A-212 GR B to A-212 GR B of P-No.

Thickness (if pipo, diameter and wall thickness) FILLER METAL

Filler Metal Group No. F . 4 Wold Metal Analys is No. A $0 \times 65$

Thickness Range $3 / 16$ to FLUX or ATMOSPHERE

Flux Trade Name or Composition Inert Gos Composition $75 \%$ ARGON $25 \% \mathrm{CO}_{2}$ Trade Nome C25 Flow Rate $30-40$ CFH

\section{or QN-11.2}

.

WELDING PROCEDURE AND TECHNIQUES

Single or Multiple Pass MULTIPLE Single or Multiple Arc

4-G OVERHEAD SINGLE

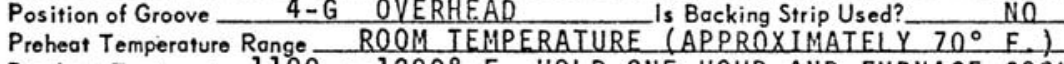

Pro

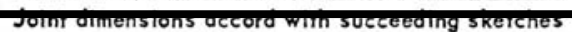

REDUCED SECTION TENSILE TEST

\begin{tabular}{|c|c|c|c|c|c|c|}
\hline \multirow{2}{*}{$\begin{array}{l}\text { SPECIMEN } \\
\text { No. }\end{array}$} & \multicolumn{2}{|c|}{ DIMENSIONS } & \multirow[t]{2}{*}{ AREA } & \multirow{2}{*}{$\begin{array}{l}\text { ULTIMATE } \\
\text { TOtALL, LE. }\end{array}$} & \multirow{2}{*}{$\begin{array}{c}\text { ULTIMATE } \\
\text { STRENGTM, PSI. }\end{array}$} & \multirow{2}{*}{$\begin{array}{l}\text { CHARACTER } \\
\text { OF FAILURE } \\
\text { AND LOCATION } \\
\end{array}$} \\
\hline & WIDTH & THICKNESS & & & & \\
\hline & 1.501 & .851 & 1.276 & 100,000 & 78,300 & PLATE \\
\hline & 1.503 & .847 & 1.272 & 98,800 & 77,700 & PLATE \\
\hline
\end{tabular}

ALL WELD METAL TENSION TEST

\begin{tabular}{|l|l|l|l|l|l|}
\hline DIAMETER & AREA & YIELD, PSI & ULTIMATE STRENGTH, PSI. & : ELONGATION & FRACTURE \\
\hline & & & & & \\
\hline
\end{tabular}

BEND TESTS

ADDITIONAL TESTS

\begin{tabular}{|c|c|c|c|}
\hline TYPE & RESULTS & TYPE & RESULTS \\
\hline 4 SIDE & ACCEPTABLE & & \\
\hline & & & \\
\hline
\end{tabular}

Welder's Nome C. BOYER Clock No. 541

Test Conducted by NOQTER COPPQRATION__ Laborotory-Test No.__ B B - 101

We certify that the statements in this record are correct and that the test welds were wolded in accordonce with this procedure and tested in accordence with the requirements of Saction IX of the Code.

Precedure Qualification Date_ MARCH 18, 1964_Signed__ NUOTER CORPORATIOIi 1.h 


\section{Appendix 4 (continued)}

- D-4600 Procedure Qualification \#8

\section{NOOTER CORPORATION}

\section{WELDING PROCEDURE SPECIFICATION AND QUALIFICATION RECORD}

The following paragraphs describe details which ate not Essential Variables. Changes in these details may be made without setting up a new Procedure Specification provided they are tecorded as revisions.

PREPARATION OF BASE MATERIAL

The edges or surfaces of the parts to be joined by welding shall be prepared by:
Grinding

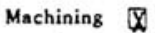
Shearing $\square$
Sawing
Burning $\square \quad$ Plasmarc Cutting $\square$
Arc Airing $\square \quad$ Chipping $\square$
Burning followed by grinding
Arc Airing followed by grinding $\square$

Plasmarc Cutcing followed by grinding $\square$ Sandblasting $\square$

The edges or surfaces of the parts to be joined by welding shall be cleaned of all oil or grease and excessive acrounts of scale or tust. ELECTRICAL CHARACTERISTICS

The curtent shall be D. C. $\mathbb{Q}$, A. C. $\square$. The polarity used shall be straight $\square$, teverse

\section{APPEARANCE OF WELDING LAYERS}

The welding curtent and manner of depositing the weld metal shall be such that there shall be practically no undercutting oo the side wall of the welding groove or the adjoining base material.

CLEANING

All slag or flux remaining on any bead of welding shall be temoved before laying down the next successive bead.

\section{DEFECTS}

Any cracks of blow holes that appeat on the surface of any bead of welding shall be removed by chipping, grinding, or gouging before depositing the next successive bead of weldiag.

TREATHENT OF UNDERSIDE OF WELDING GROOVE

THE UNDERSIDE OR SECOND SIDE OF THE WELDING GROOVE SHAIL BE BACK GOUGED LO SOUND METAL FRIOR TO WELD DEPOSIT.

\section{JOINT WELDING PROCEDURE}

The welding techoique, such as joint geomerty, sequence of operations and/or welding processes, etc., shall be substantinlly as shown on the following sketches.

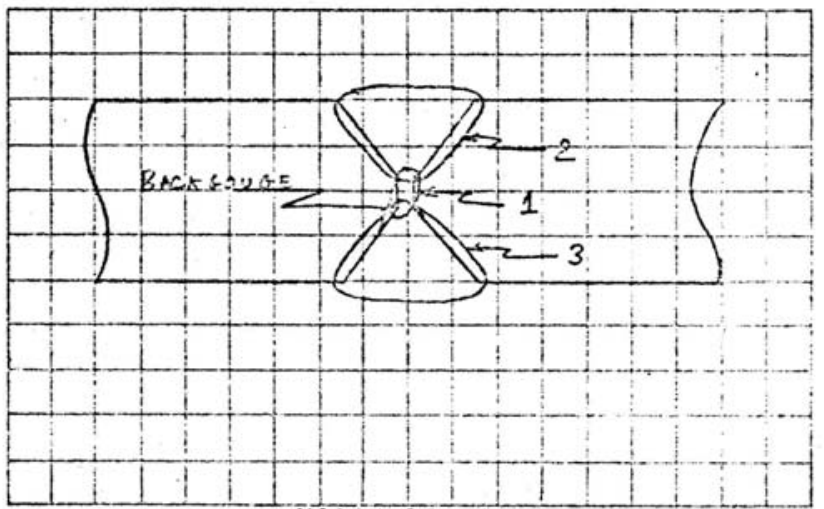

IST PASS METAL INERT GAS

2ND PASS COATED ROD

BÁCKGOUGE

$3 R D$ PASS COATED ROD

Original Procedure Date MARCH 18, 1964

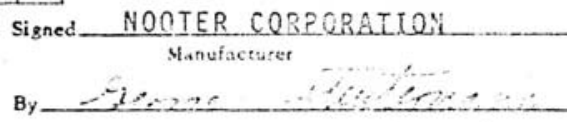

Ih

NOOTER 3Ss

By -2020 


\section{APPENDIX 5}

Certificate of Welding Electrodes EM 70S-2 for Large Plate Specimens

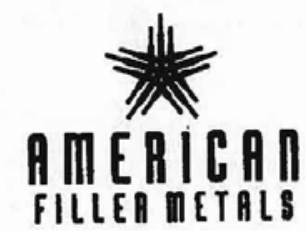

6015 Murphy - Houston, Texas 77033

Phone: 713.649.8785 - 1.800-394.4550 - Fax: 713.644.9628 • www.amfiller.com

ACTUAL MATERIAL TEST REPORT

Cüstomer: ALABÄMA WEDDING SUPPLY

1715 C PLEASANT GROVE
DOLLOMITE, AL 35061

PO: $\quad 9876$

Product: EM 70S-2 MI

Heat \#: 2712332

$\begin{array}{llllll}\mathrm{Al} & \mathrm{C} & \mathrm{Cr} & \mathrm{Cu} & \mathrm{Mn} & \mathrm{Mo} \\ .079 & .05 & .02 & .16 & 1.15 & .01 \\ \mathrm{Ni} & \mathrm{P} & \mathrm{S} & \mathrm{Si} & \mathrm{Ti} & \mathrm{V} \\ .01 & .015 & .005 & .54 & .076 & .001 \\ \mathrm{Zr} & & & & & \\ .05 & & & & & \end{array}$

\section{Dimensions: $\quad .035 \times 33$}

Specification: AWS A5.18 ER70S-2

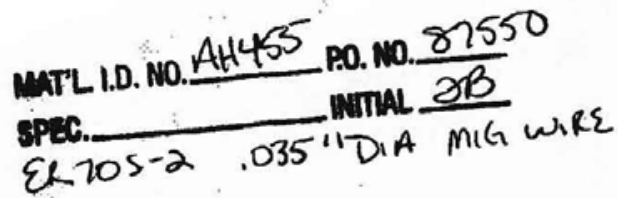

\begin{abstract}
*We certify that the chemical analys is as recorded conform to the specif ication 1 isted above as contained within the records of AFM. This material is free from mercury, radium, or alpha particle contamination. Meets EN 102043.1 .
\end{abstract}

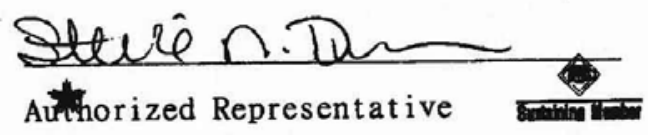




\section{APPENDIX 6}

Certificate of Welding Electrodes E-7018 for Large Plate Specimens

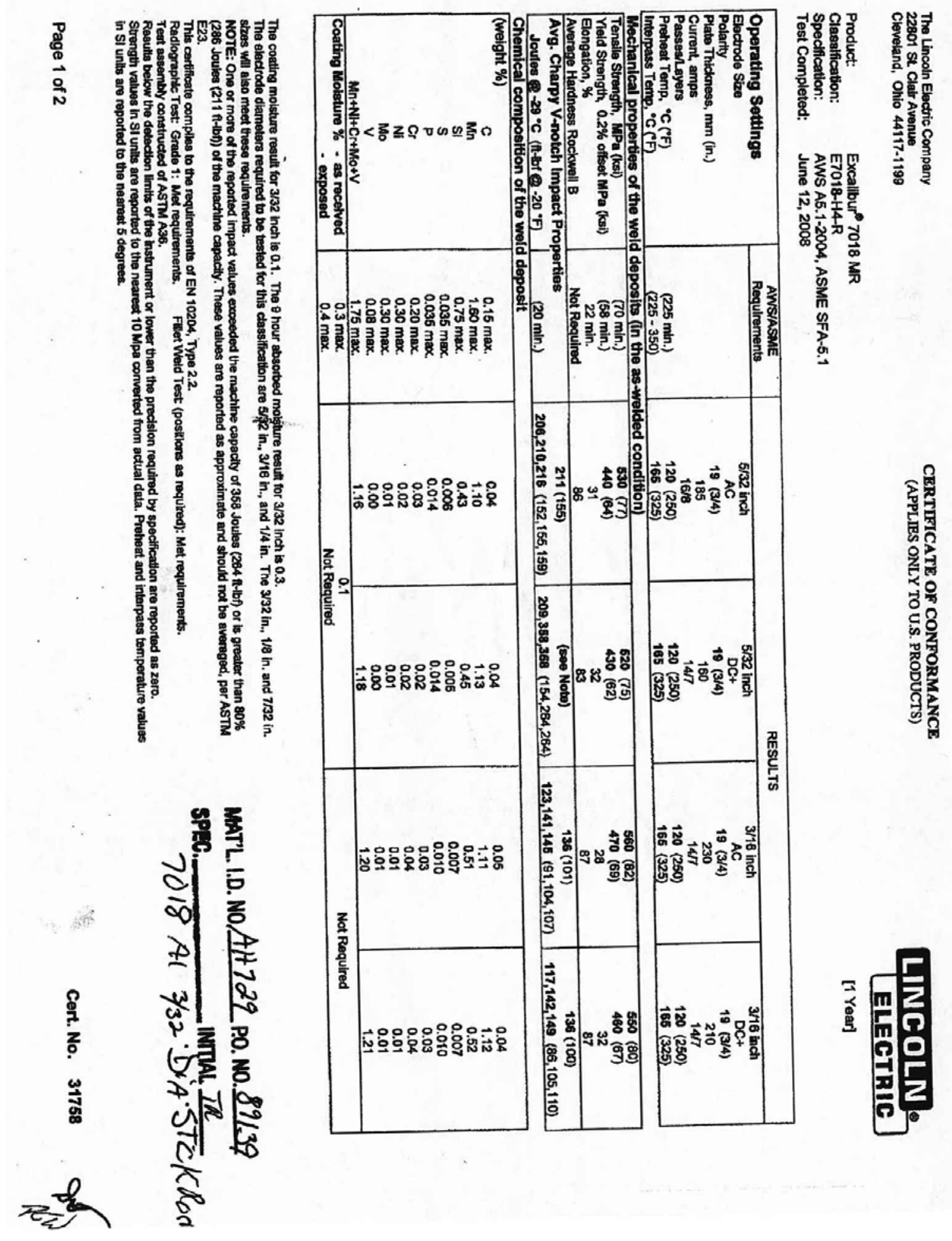




\section{APPENDIX 6 (continued)}

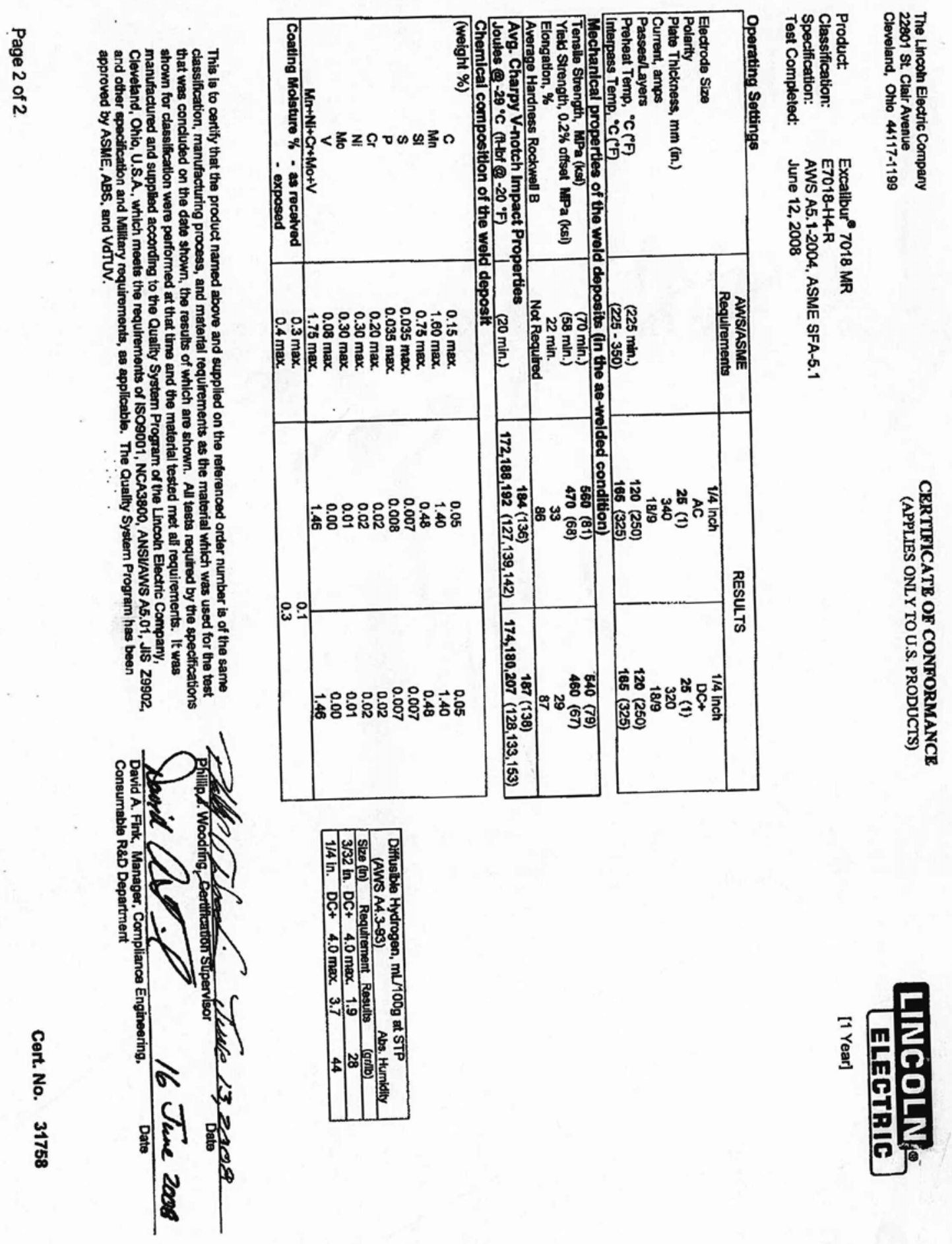




\section{APPENDIX 7}

Welding Parameters for the As-welded Plate

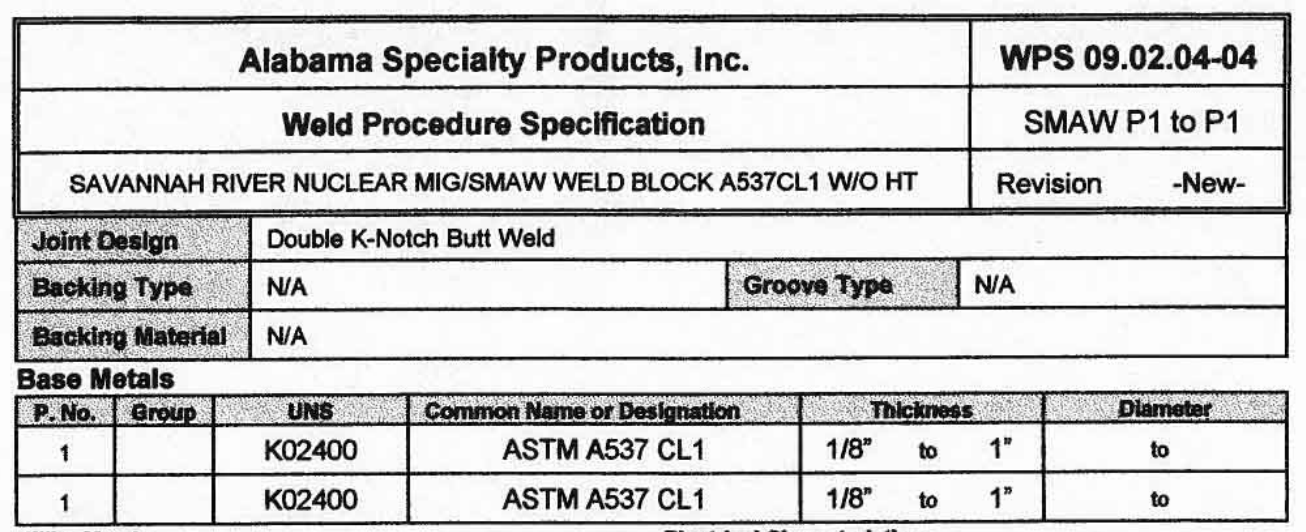

Filler Metals

\begin{tabular}{|l|c|c|}
\hline BFA Wumber & & A5.5 \\
\hline AWs Class & ER70S-2 & E7018 \\
\hline F-Nimber & & 4 \\
\hline Aflumber & & 2 \\
\hline Sire of Filler & $.035^{\prime \prime}$ & $3 / 32^{\prime \prime}$ \\
\hline Thictiness Range & $1 / 8^{\prime \prime}-1^{\prime \prime}$ & $1 / 8^{\prime \prime}-1^{\prime \prime}$ \\
\hline Consumable insert & N/A & \\
\hline
\end{tabular}

\section{Positions}

\begin{tabular}{|l|l|}
\hline Positions \\
\hline Postiton(s) of oroove & $1-G$ \\
\hline Wolatisg Progression & Flat \\
\hline Position(s) of Fillet & N/A \\
\hline
\end{tabular}

Preheat

\begin{tabular}{|l|c|}
\cline { 2 - 2 } $\begin{array}{l}\text { Preheat } \\
\text { Preheat Temperature }\end{array}$ & $250^{*} \mathrm{~F}$ \\
\hline Interpass Temperature & N/A \\
\hline Preteat Maintenance & N/A \\
\hline
\end{tabular}

Post Weld Heat Treatment

\begin{tabular}{|l|l|}
\hline Temperature Range & N/A \\
\hline Time Range & N/A \\
\hline
\end{tabular}

\begin{tabular}{|c|c|c|c|}
\hline Gas & Castust & of Mirture & Ftorthore \\
\hline shlelding & Argon/ $/ \mathrm{CO} 2$ & $95 / 5$ & $35 \mathrm{CFH}$ \\
\hline Trailing & N/A & & \\
\hline Backing & N/A & & \\
\hline
\end{tabular}

$\begin{array}{ll}\text { Author } & \text { Bart Smith } \\ \text { Approval } & \frac{\text { Larry Braden }}{\text { Name }}\end{array}$

\begin{tabular}{|c|c|c|c|}
\hline \multicolumn{4}{|c|}{ Electrical Characteristics } \\
\hline Cument type & DC & Polarity & Positive \\
\hline \multicolumn{2}{|c|}{ Current (Range) } & \multicolumn{2}{|c|}{ See attached } \\
\hline \multicolumn{2}{|l|}{ Volts (Range) } & \multicolumn{2}{|c|}{ See attached } \\
\hline \multirow{2}{*}{$\begin{array}{l}\text { Tungstan } \\
\text { Electrodes }\end{array}$} & 8600 & \multicolumn{2}{|c|}{ NAA } \\
\hline & Type & \multicolumn{2}{|c|}{ N/A } \\
\hline \multirow[b]{2}{*}{ CMAW } & Transter Mode & \multicolumn{2}{|c|}{ NA } \\
\hline & Wire Feed Speed & \multicolumn{2}{|c|}{ NA } \\
\hline
\end{tabular}

\begin{tabular}{|l|c|}
\hline Technique & String \\
\hline Bead Type & N/A \\
\hline Cas Orticel Cup Stze & See attached \\
\hline Cleaning & N/A \\
\hline Back Couging & N/A \\
\hline Oscillation & N/A \\
\hline Contact to Work Oistance & See attached \\
\hline Pesses per side & See attached \\
\hline Number of Electrodes & See attached \\
\hline Travel Speed Range & N/A \\
\hline Peenlng & \\
\hline
\end{tabular}

Other Information

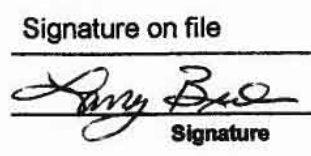

$\frac{3 / 19 / 09}{\frac{3 / 19 / 09}{D a t e}}$




\title{
APPENDIX 7 (continued)
}

\author{
WELD PROCESS \\ FOR \\ SAVANNAH RIVER \\ WELD BLOCK \#A537CL1 W/O HT
}

WELD:

Double K-Notch Butt Weld using ER70S-2 MiG wire for initial weld between closest points, followed by SMAW 7018 weld filler passes on both sides of block to fill notched area.

Base Material: A537CL1, 1" thick, material lot \#AH730

Root Filler: ER70S-2, .035" dia., material lot \#AH455

Filler: 7018, 3/32" dia., material lot \#AH729

Pre-heat: 250 degrees F.

ROOT $\left(1^{\text {st }}\right)$ PASS:

Volts: $21.5-22.5$

Amps: $115-120$

Arc Radius: 1/4" - 3/8"

Weld Pass Length: 12 1/4"

Welding Speed: 8 - 10 IPM

Weld Time: 1:20

FILLER \& CAP PASSES:

Volts: $22-24$

Amps: $95-100$

Arc Radius: 1/4" - 5/16"

Weld Pass Length: See pass info below

Welding Speed: 5-6 IPM

Weld Time: 1:00

\begin{tabular}{|c|c|c|}
\hline Pass \# & $\begin{array}{l}\text { Weld Lengths: } \\
\text { Side \#1 }\end{array}$ & \\
\hline 2 & $43 / 4 ", 5 ", 21 / 2 "$ & 3 \\
\hline 3 & $5 ", 5 ", 21 / 4 "$ & 3 \\
\hline 4 & $61 / 2 ", 53 / 4 "$ & 2 \\
\hline 5 & $7 ", 51 / 4 "$ & 2 \\
\hline 6 & 5", 5", 2 1/4" & 3 \\
\hline 7 & $7 ", 51 / 4 "$ & 2 \\
\hline 8 & $61 / 2 ", 53 / 4 "$ & 2 \\
\hline 9 & $5 ", 5 ", 21 / 4 "$ & 3 \\
\hline 10 & $61 / 2 ", 53 / 4 "$ & 2 \\
\hline 11 & $61 / 2 ", 53 / 4 "$ & 2 \\
\hline 12 & $5^{\prime \prime}, 5^{\prime \prime}, 21 / 4 "$ & 3 \\
\hline
\end{tabular}


Appendix 7 (continued)

\author{
WELD PROCESS \\ FOR \\ SAVANNAH RIVER \\ WELD BLOCK \#A537CL1 W/O HT
}

\begin{tabular}{|c|c|c|}
\hline Pass \# & Weld Lengths: & Rods \\
\hline$\frac{1 \cos \pi}{13}$ & $\frac{5^{\prime \prime}, 5^{1 / 4}}{1 / 2}, 2^{\prime \prime}$ & \\
\hline 14 & $61 / 4 ", 6 "$ & 2 \\
\hline 15 & $61 / 4 ", 6 "$ & 2 \\
\hline 16 & $61 / 4 ", 6 "$ & 2 \\
\hline 17 & $5 ", 5 ", 21 / 4 "$ & 3 \\
\hline 18 & $6^{1 / 4 ",}, 6^{\prime \prime}$ & 2 \\
\hline 19 & $51 / 2 ", 63 / 4 "$ & 2 \\
\hline
\end{tabular}

After welding $1^{\text {st }}$ side, root pass was ground, then Liquid Dye Penetrant tested for discontinuities. None found.

\title{
FILLER \& CAP PASSES:
}

Volts: $22-24$

Amps: $95-100$

Arc Radius: 1/4" - 5/16"

Weld Pass Length: See pass info below

Welding Speed: 5-6 IPM

Weld Time: 1:00

\begin{tabular}{|c|c|c|}
\hline & Weld Lengths: & \\
\hline Pass \# & $\underline{\text { Side \#2 }}$ & $\underline{\text { Rods }}$ \\
\hline 2 & $5^{1 / 2 "}, 6^{3 / 4} "$ & 2 \\
\hline 3 & $5^{\prime \prime}, 5^{\prime \prime}, 21 / 4^{\prime \prime}$ & 3 \\
\hline 4 & $4^{1 / 4 "}, 6^{1 / 2 "}, 1^{1 / 2 "}$ & 3 \\
\hline 5 & $61 / 4 ", 6 "$ & 2 \\
\hline 6 & 61/4", 6" & 2 \\
\hline 7 & $5^{1 / 2 "}, 6^{3 / 4} "$ & 2 \\
\hline 8 & $51 / 4 ", 5^{\prime \prime}, 2 "$ & 3 \\
\hline 9 & $5^{\prime \prime}, 4^{1 / 2 "}, 2^{3 / 4}$ & 3 \\
\hline 10 & $41 / 2 ", 41 / 2 ", 31 / 4 "$ & 3 \\
\hline 11 & $41 / 2 ", 41 / 2 ", 31 / 4 "$ & 3 \\
\hline 12 & $61 / 4^{\prime \prime}, 6^{\prime \prime}$ & 2 \\
\hline 13 & $6^{1 / 4 n}, 6^{n}$ & 2 \\
\hline 14 & $61 / 2 ", 53 / 4 "$ & 2 \\
\hline 15 & $3^{\prime \prime}, 5^{1 / 4 "}, 4^{\prime \prime}$ & 3 \\
\hline
\end{tabular}


APPENDIX 8

Welding Parameters for the Heat-Treated Plate

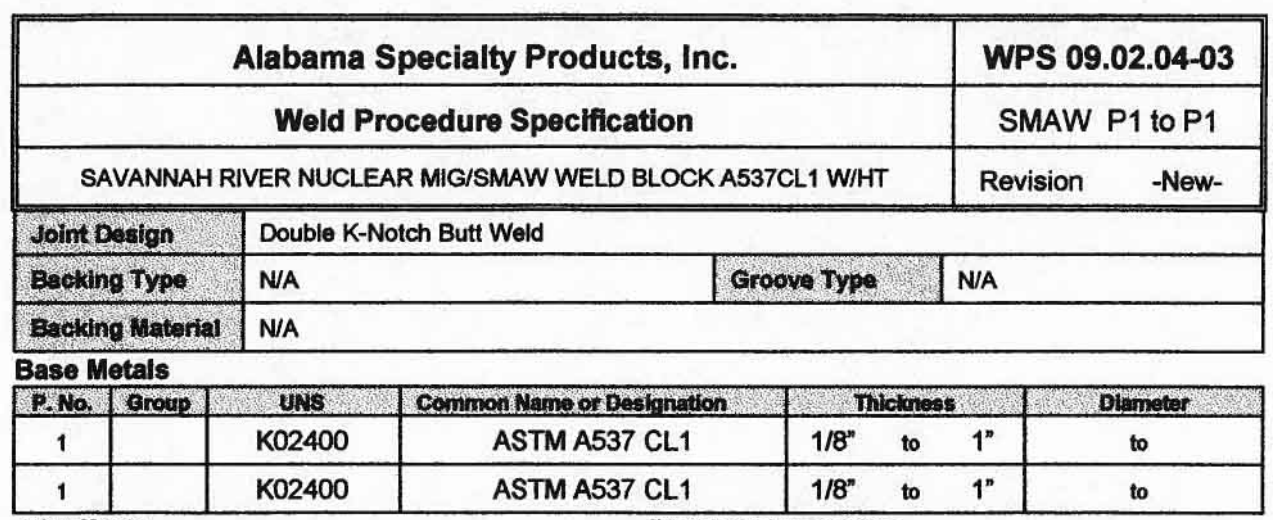

\begin{tabular}{|c|c|c|}
\hline \multicolumn{3}{|l|}{ Filler Metals } \\
\hline SFA Number & & A5.5 \\
\hline AWs Class & ER70S-2 & E7018 \\
\hline FNumber & & 4 \\
\hline Allumber & & 2 \\
\hline Bize of Finer & $.035^{\prime \prime}$ & $3 / 32^{n}$ \\
\hline Thicknoss Range & $1 / 8^{n}-1^{n}$ & $1 / 8^{\prime \prime}-1^{n}$ \\
\hline Consunuable hisent & N/A & \\
\hline
\end{tabular}

\begin{tabular}{|c|c|}
\hline \multicolumn{2}{|l|}{ Positions } \\
\hline Position's) of croove & $1-G$ \\
\hline Welding Progression & Flat \\
\hline Position(s) of fillet & N/A \\
\hline
\end{tabular}

\begin{tabular}{|l|c|}
\cline { 2 - 2 } $\begin{array}{c}\text { Preheat } \\
\text { Preheat Temperature }\end{array}$ & $250^{*} \mathrm{~F}$ \\
\hline Interpass Temperature & N/A \\
\hline Preheat Wlaintenance & N/A \\
\hline
\end{tabular}

\begin{tabular}{|l|l|}
\hline Post Weld Heat Treatment \\
\hline Temperature Range & N/A \\
\hline Time Range & N/A \\
\hline
\end{tabular}

\begin{tabular}{|l|c|c|c|}
\cline { 2 - 4 } \multicolumn{1}{c|}{ Gas } & Casles) & $\%$ Mioture & Flow Rate \\
\hline Shielaling & Argon/CO2 & $95 / 5$ & $35 \mathrm{CFH}$ \\
\hline Trailing & N/A & & \\
\hline Backing & N/A & & \\
\hline
\end{tabular}

\begin{tabular}{|c|c|c|c|}
\hline \multicolumn{4}{|c|}{ Electrical Characteristics } \\
\hline Current Type & $D C$ & Polanity & Positive \\
\hline \multicolumn{2}{|l|}{ Current (Range) } & \multicolumn{2}{|c|}{ See attached } \\
\hline \multicolumn{2}{|l|}{ Volts (Range) } & \multicolumn{2}{|c|}{ See attached } \\
\hline \multirow{2}{*}{$\begin{array}{l}\text { Tungsten } \\
\text { Electrodes }\end{array}$} & 860 & \multicolumn{2}{|c|}{ N/A } \\
\hline & Type & \multicolumn{2}{|c|}{ N/A } \\
\hline \multirow[b]{2}{*}{ cmay } & Transter Modo & \multicolumn{2}{|c|}{ N/A } \\
\hline & Wiro Feed 8peed & \multicolumn{2}{|c|}{ N/A } \\
\hline
\end{tabular}

\begin{tabular}{|l|c|}
\hline Technique & String \\
\hline Bead Type & N/A \\
\hline Cas Orifice/Cup Size & See attached \\
\hline Cleaning & N/A \\
\hline Baok Couging & N/A \\
\hline Oscillation & N/A \\
\hline Contact to Work Distance & See attached \\
\hline Passes per side & See attached \\
\hline Number of Electrodes & See attached \\
\hline Travel Speed Range & N/A \\
\hline Peening & \\
\hline
\end{tabular}

\begin{tabular}{|c|c|c|c|}
\hline Author & Bart Smith & Signature on file. & $3 / 19 / 09$ \\
\hline Approval & Larry Braden & Mnn Bere & $3 / 19 / 09$ \\
\hline
\end{tabular}




\section{Appendix 8 (continued) \\ WELD PROCESS \\ FOR \\ SAVANNAH RIVER \\ WELD BLOCK \#A537CL1 W/HT}

WELD:

Double K-Notch Butt Weld using ER70S-2 MiG wire for initial weld between closest points, followed by SMAW 7018 weld filler passes on both sides of block to fill notched area.

Base Material: A537CL1, 1" thick, material lot \#AH730

Root Filler: ER70S-2, .035" dia., material lot \#AH455

Filler: 7018, 3/32" dia., material lot \#AH729

Pre-heat: 250 degrees F.

ROOT $\left(1^{\text {st }}\right)$ PASS:

Volts: $21.5-22.5$

Amps: $115-120$

Arc Radius: 1/4" - 3/8"

Weld Pass Length: 12 1/4"

Welding Speed: 8 - 10 IPM

Weld Time: $1: 20$

FILLER \& CAP PASSES:

Volts: $22-24$

Amps: 95 - 100

Arc Radius: 1/4" - 5/16"

Weld Pass Length: See pass info below

Welding Speed: 5-6 IPM

Weld Time: 1:00

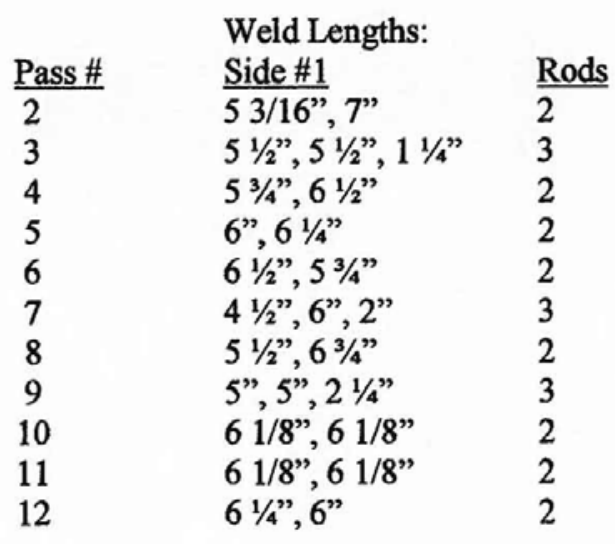


Appendix 8 (continued)

\author{
WELD PROCESS \\ FOR \\ SAVANNAH RIVER \\ WELD BLOCK \#A537CL1 W/HT
}

\begin{tabular}{|c|c|c|}
\hline Pass \# & $\begin{array}{l}\text { Weld Lengths: } \\
\text { Side \#1 }\end{array}$ & Rods \\
\hline 13 & $43 / 4 ", 53 / 4 ", 13 / 4 "$ & 3 \\
\hline 14 & $53 / 4 ", 61 / 2 "$ & 2 \\
\hline 15 & $6^{\prime \prime}, 6^{1 / 4 "}$ & 2 \\
\hline 16 & 6", $61 / 4 "$ & 2 \\
\hline 17 & $61 / 4 ", 6 "$ & 2 \\
\hline 18 & $41 / 2 ", 51 / 2 ", 2 "$ & 3 \\
\hline
\end{tabular}

After welding $1^{\text {st }}$ side, root pass was ground, then Liquid Dye Penetrant tested for discontinuities. None found.

\title{
FILLER \& CAP PASSES:
}

Volts: $22-24$

Amps: $95-100$

Arc Radius: 1/4"-5/16"

Weld Pass Length: See pass info below

Welding Speed: 5 - 6 IPM

Weld Time: 1:00

\begin{tabular}{|c|c|c|}
\hline Pass \# & $\begin{array}{l}\text { Weld Lengths: } \\
\text { Side \#2 }\end{array}$ & Rods \\
\hline 2 & $41 / 2 ", 6 ", 13 / 4 "$ & 3 \\
\hline 3 & 4", 41/2", 33/4" & 3 \\
\hline 4 & $51 / 2 ", 63 / 4 "$ & 2 \\
\hline 5 & $4^{1 / 2 "}, 5^{1 / 4 "}, 21 / 2 "$ & 3 \\
\hline 6 & $6^{\prime \prime}, 6^{1 / 4 "}$ & 2 \\
\hline 7 & $51 / 2 ", 63 / 4 "$ & 2 \\
\hline 8 & $71 / 4^{\prime \prime}, 5^{\prime \prime}$ & 2 \\
\hline 9 & $71 / 4 ", 5 "$ & 2 \\
\hline 10 & $71 / 2 ", 43 / 4 "$ & 2 \\
\hline 11 & $63 / 4 ", 51 / 2 "$ & 2 \\
\hline
\end{tabular}


SRNS-STI-2009-00564 Rev.0

\section{DISTRIBUTION}

\section{SAVANNAH RIVER SITE}

N. C. Iyer, 773-41A

M. E. Maryak, 742-5G

K. H. Subramanian, 766-H

D. C. Bumgardner, 704-56H

A. W. Wiggins, Jr., 704-60H

C. M. Cole, Sr., 704-61H

A. S. Plummer, 241-120H

K. E. Zeigler, 773-41A

B. J. Wiersma, 773-A

T. M. Adams, 773-41A

J. I. Mickalonis, 773-A

R. L. Sindelar, 773-41A

C. S. Stripling, 773-41A

D. L. Fisher, 773-A

T. M. Stefek, 773-41A

P. S. Lam, 773-41A 